\title{
Theranostics
}

Research Paper

2012; 2(9):850-870. doi: 10.7150/thno.4547

\section{Syntheses and Photodynamic Activity of Pegylated Cationic Zn(II)-Phthalocyanines in HEp2 Cells}

\author{
Benson G. Ongarora, Xiaoke Hu, Susan D. Verberne-Sutton, Jayne C. Garno and M. Graça H. Vicente ${ }^{\bowtie}$ \\ Louisiana State University, Department of Chemistry, Baton Rouge LA, 70803, USA
}

$\triangle$ Corresponding author: Maria da Graça H. Vicente, PhD, Department of Chemistry, Louisiana State University, Baton Rouge, LA, 70803; vicente@1su.edu.

(c) Ivyspring International Publisher. This is an open-access article distributed under the terms of the Creative Commons License (http://creativecommons.org/ licenses/by-nc-nd/3.0/). Reproduction is permitted for personal, noncommercial use, provided that the article is in whole, unmodified, and properly cited.

Received: 2012.05.02; Accepted: 2012.06.11; Published: 2012.09.20

\begin{abstract}
Di-cationic $\mathrm{Zn}(\mathrm{II})$-phthalocyanines (ZnPcs) are promising photosensitizers for the photodynamic therapy (PDT) of cancers and for photoinactivation of viruses and bacteria. Pegylation of photosensitizers in general enhances their water-solubility and tumor cell accumulation. A series of pegylated di-cationic $\mathrm{ZnPcs}$ were synthesized from conjugation of a low molecular weight PEG group to a pre-formed Pc macrocycle, or by mixed condensation involving a pegylated phthalonitrile. All pegylated $\mathrm{ZnPcs}$ were highly soluble in polar organic solvents but were insoluble in water; they have intense $\mathrm{Q}$ absorptions centered at $680 \mathrm{~nm}$ and fluorescence quantum yields of ca. 0.2 in DMF. The non-pegylated di-cationic $\mathrm{ZnPc} 6 \mathbf{6}$ formed large aggregates, which were visualized by atomic force microscopy. The cytotoxicity, cellular uptake and subcellular distribution of all cationic $\mathrm{ZnPcs}$ were investigated in human carcinoma HEp2 cells. The most phototoxic compounds were found to be the $\alpha$-substituted Pcs. Among these, Pcs $4 \mathrm{a}$ and 16 a were the most effective $\left(I_{50} \mathrm{ca}\right.$. $10 \mu \mathrm{M}$ at $\left.I .5 \mathrm{~J} / \mathrm{cm}^{2}\right)$, in part due to the presence of a PEG group and the two positive charges in close proximity (separated by an ethylene group) in these macrocycles. The $\beta$-substituted ZcPcs $\mathbf{6 b}$ and $\mathbf{4 b}$ accumulated the most within HEp2 cells but had low photocytoxicity $\left(\mathrm{IC}_{50}>100 \mu \mathrm{M}\right.$ at $\left.I .5 \mathrm{~J} / \mathrm{cm}^{2}\right)$, possibly as a result of their lower electron density of the ring and more extended conformations compared with the $\alpha$-substituted Pcs. The results show that the charge distribution about the Pc macrocycle and the intracellular localization of the cationic ZnPcs mainly determine their photodynamic activity.
\end{abstract}

Key words: phthalocyanine, PDT, pegylation, cationic photosensitizer

\section{Introduction}

Phthalocyanines (Pcs), also known as tetraaza-benzoporphyrins, are a class of synthetic tetrapyrrolic compounds related to the naturally occurring porphyrins; they contain an extended 18 $\pi$-electron system. Due to their strong absorptions in the near-IR, Pcs have found multiple applications in biology, medicine, and materials science, for example as colorant dyes, molecular wires, optical sensors, bioimaging agents, and as photosensitizers for the photodynamic therapy (PDT) of cancers and for inactivation of bacteria and viruses [1-4]. PDT involves light activation of a photosensitizer with subsequent in situ production of singlet oxygen, and other reactive oxygen species (ROS), which destroy photosensitizer-accumulated cells via necrosis and/or apoptosis $[5,6]$. Photofrin is a FDA-approved porphyrin, a derivative of hematoporphyrin IX, that has been used for nearly two decades in the PDT treatment of vari- 
ous cancers, including lung, skin, cervical and bladder $[7,8]$. PDT has several advantages over surgery and radiation therapy, in that it is relatively non-invasive and is a localized form of therapy, in part due to the natural tendency of porphyrin compounds for preferential accumulation in cancer tissues combined with precise light delivery, normally from a diode laser. However, Photofrin has some drawbacks because porphyrins typically absorb only weakly in the red region of the spectrum $\left(\lambda_{\max }=630 \mathrm{~nm}\right)$ where light penetrates deeper into tissue; in addition Photofrin is a complex mixture of porphyrin monomers and oligomers which tend to persist for long time periods in healthy tissues following systemic administration, causing unwanted side-effects such as patient photosensitivity for several weeks post-PDT. Pcs have emerged as promising second-generation photosensitizers due to their intense absorptions at long wavelengths $\left(\lambda_{\max }>670 \mathrm{~nm}\right)$, and their unique abilities for crossing cellular membranes and for producing ROS upon light activation. Sulfonated Al(III)Pcs, designated Photosense, and a Si(IV)Pc, designated Pc4, have been evaluated in clinical trials for PDT [9-11]. These Pcs and other potential Pc-based photosensitizers contain peripheral water-solubilizing substituents and/or axial ligands for minimizing aggregation and increasing their solubility in aqueous media, thereby improving their photodynamic activity. Of particular interest are polyethylene glycol (PEG) groups, which can be used as delivery vehicles [12-14] or may be covalently attached to Pcs [15-17] for improved delivery to target tissues. The pegylation of photosensitizers has been shown to increase their water-solubility, serum life and tumor accumulation, while reducing their uptake by the reticuloendothelial system [18-23]. On the other hand, positively charged photosensitizers are of particular interest for PDT [24-31] and for photoinactivation of virus and bacteria [32-34], because of their potential stronger interactions with negatively charged cell membranes and targeted biomolecules (e.g. DNA and RNA), which can result in effective photodamage and overall enhanced photodynamic efficacy. We have recently reported that di-cationic a-substituted ZnPcs are the most phototoxic among a series of Pcs bearing one to eight positively-charged trimethylaminophenoxy groups, and the most promising photosensitizers for PDT [35]. In our continuing investigation of photosensitizers with enhanced biological effectiveness, we report herein the synthesis of a new series of di-cationic phthalocyanines, containing a PEG group or a diglycolic spacer between the $\mathrm{ZnPc}$ and the positively charged quaternary ammonium groups. Our studies show that the pegylated di-cationic $\mathrm{ZnPcs}$ are more soluble than the non-pegylated analogues, which were observed to form large aggregates by atomic force microscopy.

\section{Methods and Materials}

\section{Syntheses}

All reagents and solvents were purchased from commercial sources and used without further purification, unless otherwise noted. Silica gel $60(230 \times 400$ mesh, Sorbent Technologies) was used for column chromatography and Sephadex G-100 and LH-20 (Amersham Biosciences) were used for purification of the water-soluble ZnPcs. Analytical thin-layer chromatography (TLC) was carried out using polyester backed TLC plates 254 (precoated, $200 \mu \mathrm{m}$ ) from Sorbent Technologies. NMR spectra were recorded on an AV-400 LIQUID Bruker spectrometer $(400 \mathrm{MHz}$ for ${ }^{1} \mathrm{H}, 100 \mathrm{MHz}$ for ${ }^{13} \mathrm{C}$ ). The chemical shifts are reported in $\delta$ ppm using the following deuterated solvents as internal references: Acetone- $d_{6} 2.05$ ppm $\left({ }^{1} \mathrm{H}\right), 29.92$ ppm $\left({ }^{13} \mathrm{C}\right)$; DMF- $d_{7} 8.03$ ppm $\left({ }^{1} \mathrm{H}\right), 163.15$ ppm $\left({ }^{13} \mathrm{C}\right)$; THF- $d_{8} 3.58 \mathrm{ppm}\left({ }^{1} \mathrm{H}\right), 67.57 \mathrm{ppm}\left({ }^{13} \mathrm{C}\right) ; \mathrm{CDCl}_{3} 7.27$ ppm $\left({ }^{1} \mathrm{H}\right), 77.23$ ppm $\left({ }^{13} \mathrm{C}\right)$; DMSO- $d_{6} 2.50 \mathrm{ppm}\left({ }^{1} \mathrm{H}\right)$, $39.51 \mathrm{ppm}\left({ }^{13} \mathrm{C}\right)$. MALDI-TOF mass spectra were recorded on a Bruker UltrafleXtreme (MALDI-TOF/TOF) using 4-chloro-a-cyanocinnamic acid as the matrix; high resolution ESI mass spectra were obtained on an Agilent Technologies 6210 TOF LC/MS. Absorption spectra were measured on a UV-vis NIR scanning spectrophotometer using $10 \mathrm{~mm}$ path length quartz cuvettes. Stock solutions $(1.0 \mathrm{mM}$, $1.0 \mathrm{~mL}$ each) of all Pcs in HPLC grade DMF solvent were prepared and dilutions obtained by spiking 20 $80 \mu \mathrm{L}$ of each stock solution into solvent $(10 \mathrm{~mL})$. Emission spectra were obtained on a Fluorolog ${ }^{\circledR}$ HORIBA JOBINVYON, Model LFI-3751 spectrofluorimeter. The optical densities of the solutions used for emission studies ranged between $0.04-0.05$ at excitation wavelengths to minimize re-absorption by the photosensitizers. All measurements were performed within $4 \mathrm{~h}$ of solution preparation and carried out at room temperature $\left(23-25^{\circ} \mathrm{C}\right)$. ZnPcs $\mathbf{1 a}, \mathbf{b}$ and $\mathbf{2 a} \mathbf{a}, \mathbf{b}$ were synthesized as we have previously described [36].

$\mathrm{ZnPc} 3 a$. To a solution of ZnPc $2 \mathbf{a}(20.0 \mathrm{mg}, 0.017$ $\mathrm{mmol})$ in DMF $(0.4 \mathrm{~mL})$ were added in the following order: $\mathrm{Et}_{3} \mathrm{~N}$ ( $\left.3.3 \mathrm{mg}, 0.032 \mathrm{mmol}\right)$, HOBt $(4.7 \mathrm{mg}, 0.035$ $\mathrm{mmol}), 1,4$-bis-Boc-triazaheptane $(7 \mathrm{mg}, 0.023 \mathrm{mmol})$, and EDCI $(4.0 \mathrm{mg}, 0.026 \mathrm{mmol})$. The reaction mixture was stirred at room temperature for 4 days, diluted with ethyl acetate $(40 \mathrm{~mL})$ and washed with water $(2 \times$ $20 \mathrm{~mL}$ ). The organic phase was dried over anhydrous $\mathrm{Na}_{2} \mathrm{SO}_{4}$ and the solvent removed under reduced pressure. The crude product was purified by column 
chromatography using $\mathrm{CH}_{2} \mathrm{Cl}_{2} /$ methanol for elution, to afford a blue solid (20.2 $\mathrm{mg}, 81.8 \%)$. ${ }^{1} \mathrm{H}$ NMR (DMSO- $\left.d_{6}\right)$ : $\delta$ 9.33-9.03 (m, 6H, Ar-H), 8.30-8.07 (m, $5 \mathrm{H}, \mathrm{Ar}-\mathrm{H})$, 7.84-7.44 (m, 5H, Ar-H), 7.20 (br, $1 \mathrm{H}, \mathrm{N}-\mathrm{H})$, 6.79 (br, $1 \mathrm{H}, \mathrm{N}-\mathrm{H}), 4.14-3.98\left(\mathrm{~m}, 4 \mathrm{H}, \mathrm{CH}_{2} \mathrm{O}\right), 3.53-3.50$ $\left(\mathrm{m}, 4 \mathrm{H}, \mathrm{CH}_{2} \mathrm{O}\right), 3.44-3.38\left(\mathrm{~m}, 12 \mathrm{H}, \mathrm{CH}_{2} \mathrm{NH}\right), 3.36-3.22$ $\left(\mathrm{m}, 2 \mathrm{H}, \mathrm{CH}_{2} \mathrm{NH}\right), 3.00\left(\mathrm{br}, 2 \mathrm{H}, \mathrm{CH}_{2} \mathrm{NH}\right), 2.31-2.20(\mathrm{~m}$, $\left.2 \mathrm{H}, \mathrm{CH}_{2} \mathrm{CO}\right), 1.80-1.76\left(\mathrm{~m}, 27 \mathrm{H}, \mathrm{C}\left(\mathrm{CH}_{3}\right)_{3}\right), 1.37-1.34$ $\left(\mathrm{m}, 18 \mathrm{H},-\mathrm{OC}\left(\mathrm{CH}_{3}\right)_{3}\right)$. ${ }^{13} \mathrm{CNMR}$ (DMSO- $\left.d_{6}\right)$ : $\delta 171.0$, $170.1,168.9,167.4,167.3(\mathrm{C}=\mathrm{O}), 155.6,155.3,154.7$, $152.9,152.6,151.5,150.8,150.4,150.2,140.2,138.1$, $137.9,137.6,135.8,135.2,133.1,132.4,130.6,128.3$, $127.4,127.0,122.5,122.0,121.8,121.5,118.9,118.6$, 117.7, 117.4, 115.8 (Ar-C), 78.5, $77.5\left(-\mathrm{OC}\left(\mathrm{CH}_{3}\right)_{3}\right), 70.6$, 70.5, 70.4, 69.6, 69.5, 68.8, $66.7\left(\mathrm{OCH}_{2}\right), 46.7,46.2,38.2$, 36.1, 35.7, $35.6\left(\mathrm{~N}-\mathrm{CH}_{2}\right), 31.8\left(\mathrm{Ar}-\mathrm{C}\left(\mathrm{CH}_{3}\right)_{3}\right), 28.2,28.0$ $\left(\mathrm{O}-\mathrm{C}\left(\mathrm{CH}_{3}\right)_{3}\right)$. MS (MALDI-TOF) $\mathrm{m} / \mathrm{z} 1455.650[\mathrm{M}]^{+}$, calcd for $\mathrm{C}_{77} \mathrm{H}_{93} \mathrm{~N}_{13} \mathrm{O}_{12} \mathrm{Zn}$ 1455.636. The blue solid (20.2 $\mathrm{mg}, 0.014 \mathrm{mmol}$ ) was dissolved in a 1:1 mixture of $\mathrm{CH}_{2} \mathrm{Cl}_{2}$ /trifluoroacetic acid (TFA) $(6 \mathrm{~mL})$ and stirred at $0{ }^{\circ} \mathrm{C}$ for $3 \mathrm{~h}$. Solvent was removed and the residue treated with $2 \mathrm{~N} \mathrm{NaOH}(10 \mathrm{~mL})$ to afford the title $\mathrm{ZnPc}$ as a blue solid (15.5 mg, $89.0 \%) .{ }^{1} \mathrm{H}$ NMR $\left(\mathrm{DMF}-d_{7}\right): \delta$ 9.59-9.07 $(\mathrm{m}, 6 \mathrm{H}, \mathrm{Ar}-\mathrm{H}), 8.41-8.32(\mathrm{~m}, 4 \mathrm{H}$, Ar-H), 8.12-8.06 (m, 1H, Ar-H), 7.92-7.85 (m, 2H, Ar-H), 7.60-7.53 (m, 2H, Ar-H), 6.96 (br, 1H, N-H), 4.23-4.10 (m, $\left.4 \mathrm{H}, \mathrm{CH}_{2} \mathrm{O}\right)$, 3.57-3.28 (m, $\left.20 \mathrm{H}, \mathrm{CH}_{2} \mathrm{O}\right)$, 2.13-2.03 (m, 2H, $\left.\mathrm{CH}_{2} \mathrm{CO}\right), 1.79-1.75(\mathrm{~m}, 27 \mathrm{H}$, $\left.\mathrm{C}\left(\mathrm{CH}_{3}\right)_{3}\right) .{ }^{13} \mathrm{CNMR}\left(\mathrm{DMF}-d_{7}\right): \delta 171.2,171.1,170.4$, 168.8, 168.7, 157.3, 156.8, 155.9, 155.7, 155.5, 155.4, $155.0,154.8,154.6,154.3,154.2,153.9,153.7,152.9$, $152.7,152.3,152.1,142.6,140.1,139.8,137.7,137.4$, $134.7,134.3,131.7,131.5,130.6,128.50,128.3,124.0$, 123.6, 123.4, 123.2, 122.6, 122.4, 120.7, 120.1, 120.0, 119.8, 119.6, 119.0118.3, 117.6, 117.1 (Ar-C), 72.4, 72.13, 72.08, 71.1, 71.0, 70.9, 70.24, 70.20, 68.3, 68.0 $\left(\mathrm{O}-\mathrm{C}\left(\mathrm{CH}_{3}\right)_{3}\right), 48.9,48.7,39.6,39.3,38.7,37.5,37.3,36.8$ $\left(\mathrm{N}-\mathrm{CH}_{2}\right), \quad 32.7, \quad 32.6 \quad\left(\mathrm{~m}, \quad 27 \mathrm{H}, \quad \mathrm{C}\left(\mathrm{CH}_{3}\right)_{3}\right) . \quad \mathrm{MS}$ (MALDI-TOF) $m / z \quad 1255.633 \quad[\mathrm{M}]^{+}$, calcd for $\mathrm{C}_{67} \mathrm{H}_{77} \mathrm{~N}_{13} \mathrm{O}_{8} \mathrm{Zn}$ 1255.531. UV-vis (DMF): $\lambda_{\max }(\log \varepsilon)$ 350 (5.00), 612 (4.77), 680 (5.52) nm.

$\mathrm{ZnPc} 3 b$. A procedure similar to the one described above for $\mathrm{ZnPc}$ 3a was used: $\mathrm{ZnPc} \mathbf{2 b}(20.0$ $\mathrm{mg}, 0.017 \mathrm{mmol}), \mathrm{DMF}(0.4 \mathrm{~mL}), \mathrm{Et}_{3} \mathrm{~N}(3.2 \mathrm{mg}, 0.032$ $\mathrm{mmol})$, HOBt $(4.7 \mathrm{mg}, \quad 0.035 \mathrm{mmol})$, 1,4-bis-Boc-triazaheptane $(7 \mathrm{mg}, 0.023 \mathrm{mmol}$ ) and EDCI $(4.0 \mathrm{mg}, 0.026 \mathrm{mmol})$. The crude product was purified as described above to afford a blue solid (19.7 $\mathrm{mg}, 79.6 \%) .{ }^{1} \mathrm{H}$ NMR (DMF- $\left.d_{7}\right): \delta$ 9.32-8.67 $(\mathrm{m}, 8 \mathrm{H}$, Ar-H), 8.35-8.30 (m, 4H, Ar-H), 8.15-8.04 (m, 2H, Ar-H), 7.94-7.82 (m, 2H, Ar-H), 7.64-7.59 (m, 2H, Ar-H), 6.90 (br, 1H, N-H), 4.39 (d, J = 13.6, 2H, $\mathrm{CH}_{2} \mathrm{O}$ ), $4.30\left(\mathrm{~d}, \mathrm{~J}=9.76,2 \mathrm{H}, \mathrm{CH}_{2} \mathrm{O}\right), 3.73-3.68\left(\mathrm{~m}, 4 \mathrm{H}, \mathrm{CH}_{2} \mathrm{O}\right)$, 3.62-3.56 (m, $\left.14 \mathrm{H}, \mathrm{CH}_{2} \mathrm{O}\right)$, 3.51-3.47 (m, $\left.2 \mathrm{H}, \mathrm{CH}_{2} \mathrm{NH}\right)$,
3.35-3.19 (m, 8H, $\left.\mathrm{CH}_{2} \mathrm{NH}\right)$, 2.47-2.42 (m, $\left.2 \mathrm{H}, \mathrm{CH}_{2} \mathrm{CO}\right)$, $1.86-1.82\left(\mathrm{~m}, 27 \mathrm{H}, \mathrm{C}\left(\mathrm{CH}_{3}\right)_{3}\right), 1.45-1.36(\mathrm{~m}, 18 \mathrm{H}$, -OC $\left.\left(\mathrm{CH}_{3}\right)_{3}\right) .{ }^{13} \mathrm{C}$ NMR $\left(\mathrm{DMF}-d_{7}\right): \delta 172.4,171.5,170.6$, 169.2, $169.1(\mathrm{C}=\mathrm{O}), 161.0,160.4,157.1,156.3,154.4$, $153.9,139.1,138.9,136.7,136.3,133.7,128.7,125.3$, $123.5,122.8,122.0,121.5,121.1,120.8,120.3,115.0$, 112.8, 111.6 (Ar-C), 79.9, $78.7\left(\mathrm{O}-\mathrm{C}\left(\mathrm{CH}_{3}\right)_{3}\right), 72.4,72.20$, 72.16, 71.3, 71.2, 71.12, 71.06, 70.4, 68.2, $67.9\left(\mathrm{OCH}_{2}\right)$, $48.6,48.3,46.139 .7,38.9,37.6,37.5,36.9,36.6\left(\mathrm{~N}^{\left.-\mathrm{CH}_{2}\right)}\right.$, $32.6\left(\mathrm{Ar}-\mathrm{C}\left(\mathrm{CH}_{3}\right)_{3}\right), \quad 29.0, \quad 28.9 \quad\left(\mathrm{O}-\mathrm{C}\left(\mathrm{CH}_{3}\right)_{3}\right) . \quad$ MS

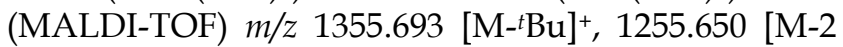
$\left.{ }^{t} \mathrm{Bu}\right]^{+}$; calcd for $\mathrm{C}_{72} \mathrm{H}_{85} \mathrm{~N}_{13} \mathrm{O}_{10} \mathrm{Zn}$ 1355.583, $\mathrm{C}_{67} \mathrm{H}_{77} \mathrm{~N}_{13} \mathrm{O}_{8} \mathrm{Zn}$ 1255.531. The blue solid $(19.0 \mathrm{mg}$, $0.013 \mathrm{mmol})$ was dissolved in 1:1 $\mathrm{CH}_{2} \mathrm{Cl}_{2}$ /TFA $(6 \mathrm{~mL})$ and stirred at $0{ }^{\circ} \mathrm{C}$ for $3 \mathrm{~h}$. The crude was treated as described for $\mathrm{ZnPc}$ 3a above to afford a blue solid $(14.9 \mathrm{mg}, 90.7 \%) .{ }^{1} \mathrm{H}$ NMR $\left(\mathrm{DMF}-d_{7}\right): \delta$ 9.56-8.89 (m, $8 \mathrm{H}, \mathrm{Ar}-\mathrm{H}), 8.39-8.31(\mathrm{~m}, 4 \mathrm{H}, \mathrm{Ar}-\mathrm{H}), 8.08-7.92(\mathrm{~m}, 2 \mathrm{H}$, Ar-H), 7.55-7.51 (m, 2H, Ar-H) $4.36(\mathrm{~d}, \mathrm{~J}=6.88,2 \mathrm{H}$, $\left.\mathrm{CH}_{2} \mathrm{O}\right), 4.26\left(\mathrm{~d}, \mathrm{~J}=6.64,2 \mathrm{H}, \mathrm{CH}_{2} \mathrm{O}\right), 3.56-3.25(\mathrm{~m}, 24 \mathrm{H}$, $\left.\mathrm{CH}_{2} \mathrm{O}\right), 2.38-2.22\left(\mathrm{~m}, 2 \mathrm{H}, \mathrm{CH}_{2} \mathrm{CO}\right), 1.80-1.76(\mathrm{~m}, 27 \mathrm{H}$, $\left.\mathrm{C}\left(\mathrm{CH}_{3}\right)_{3}\right) .{ }^{13} \mathrm{CNMR}\left(\mathrm{DMF}-d_{7}\right): \delta 171.3,170.6,169.2$, 169.1, 160.6, 160.3, 155.2, 155.1, 154.8, 154.0, 153.4, $141.5,140.0,139.8,137.7,136.5,136.2,135.1,134.9$, 134.7, 128.3, 125.1, 123.3, 122.8, 121.3, 120.7, 119.8, 115.0, 112.6, 111.5, 111.0 (Ar-C), 72.4, 72.2, 71.2, 71.1, 70.9, 70.3, $68.1\left(\mathrm{O}-\mathrm{C}\left(\mathrm{CH}_{3}\right)_{3}\right), 48.9,48.1,39.7,39.3,37.5$, $37.3\left(\mathrm{~N}-\mathrm{CH}_{2}\right), \quad 32.6\left(\mathrm{~m}, \quad 27 \mathrm{H}, \quad \mathrm{C}\left(\mathrm{CH}_{3}\right)_{3}\right)$. MS (MALDI-TOF) $m / z \quad 1255.555\left[\mathrm{M}^{+}\right.$, calcd for $\mathrm{C}_{67} \mathrm{H}_{77} \mathrm{~N}_{13} \mathrm{O}_{8} \mathrm{Zn}$ 1255.531. UV-VIS (DMF): $\lambda_{\max }(\log \varepsilon)$ 351 (4.81), 612 (4.53), 677 (5.28) nm.

$\mathrm{ZnPc} 4 a$. ZnPc 3a $(20.0 \mathrm{mg}, 0.015 \mathrm{mmol})$, DIPA $(0.015 \mathrm{~mL}, 0.107 \mathrm{mmol})$ and $\mathrm{CH}_{3} \mathrm{I}(0.2 \mathrm{~mL})$ were dissolved in dry DMF $(0.5 \mathrm{~mL})$, and the final solution stirred at room temperature for 2 days. The solvent was removed under reduced pressure and the resulting residue purified by Sephadex G-100 using $\mathrm{CH}_{2} \mathrm{Cl}_{2}$ /methanol for elution to afford a blue solid (17.2 mg, 68.3\%). ${ }^{1} \mathrm{H}$ NMR (DMF- $\left.d_{7}\right): \delta$ 9.57-9.06 (m, 7H, Ar-H), 8.38-8.18 (m, 5H, Ar-H), 7.94-7.84 (m, 3H, Ar-H), 7.61-7.54 (m, 2H, Ar-H), 4.29-4.13 (m, 8H, $\left.\mathrm{CH}_{2} \mathrm{O}\right), 3.62-3.44\left(\mathrm{~m}, 18 \mathrm{H}, \mathrm{CH}_{2} \mathrm{O} / \mathrm{N}-\mathrm{CH} 2 / \mathrm{N}-\mathrm{CH}_{3}\right)$, 3.28 (s, 9H, N-CH 3$), 2.47-2.30\left(\mathrm{~m}, 2 \mathrm{H}, \mathrm{COCH}_{2}\right), 1.78$ (s, $\left.27 \mathrm{H}, \mathrm{C}\left(\mathrm{CH}_{3}\right)_{3}\right) .{ }^{13} \mathrm{C}$ NMR $\left(\mathrm{DMF}-d_{7}\right): \delta$ 172.6, 170.5, $168.8,168.7$ (C=O), 157.1, 156.4, 155.8, 155.5, 155.3, $154.5,154.2,154.1,153.9,153.8,153.5,152.8,152.7$, $152.3,142.7,140.3,140.2,139.9,137.8,137.5,134.9$, $134.4,131.4,130.5,129.7,128.3,128.1,123.5,123.3$, $123.2,123.1,122.7,122.5,121.9,120.4,120.0,119.8$, 119.7, 118.9, 117.5 (Ar-C), 72.2, 72.0, 71.1, 71.0, 67.9 $\left(\mathrm{CH}_{2} \mathrm{O}\right), 64.6,64.4,58.6,57.1,54.3,52.4\left(\mathrm{~N}_{-} \mathrm{CH}_{3}\right), 39.6$, 37.3, $\quad 36.8 \quad\left(\mathrm{~N}-\mathrm{CH}_{2}\right) \quad 32.7, \quad 32.6 \quad\left(\mathrm{C}\left(\mathrm{CH}_{3}\right)_{3}\right) . \quad$ MS (MALDI-TOF) $m / z \quad 1493.711 \quad[\mathrm{M}-\mathrm{I}+\mathrm{K}]^{+}, 1441.654$ [M-I-CH $3+\mathrm{H}]^{+}$; calcd for $\mathrm{C}_{72} \mathrm{H}_{89} \mathrm{IKN}_{13} \mathrm{O}_{8} \mathrm{Zn}^{+}$1493.493, 
$\mathrm{C}_{71} \mathrm{H}_{88} \mathrm{IN}_{13} \mathrm{O}_{8} \mathrm{Zn}^{+}$1441.522. UV-Vis (DMF): $\lambda_{\max }(\log \varepsilon)$ 348 (4.81), 611 (4.55), 679 (5.32) nm.

$\mathrm{ZnPc} 4 b$. A procedure similar to the one described for ZnPc 4a was used: ZnPc 3b (20.0 mg, 0.015 mmol), DIPA (0.015 mL, $0.107 \mathrm{mmol}), \mathrm{CH}_{3} \mathrm{I}(0.2 \mathrm{~mL})$ and dry DMF $(0.5 \mathrm{~mL})$. The title $\mathrm{ZnPc}$ was obtained as a blue solid $(16.2 \mathrm{mg}, 64.3 \%)$. ${ }^{1} \mathrm{H}$ NMR (DMF- $\left.d_{7}\right)$ : $\delta$ 9.57-9.26 (m, 7H, Ar-H), 8.38-8.18 (m, 5H, Ar-H), 7.94-7.84 (m, 2H, Ar-H), 7.61-7.48 (m, 2H, Ar-H), 4.35-4.23 $\left(\mathrm{m}, 8 \mathrm{H}, \quad \mathrm{CH}_{2} \mathrm{O}\right), \quad 3.81-3.48(\mathrm{~m}, 18 \mathrm{H}$, $\left.\mathrm{CH}_{2} \mathrm{O} / \mathrm{N}-\mathrm{CH} 2 / \mathrm{N}_{-} \mathrm{CH}_{3}\right), 3.46\left(\mathrm{~s}, 9 \mathrm{H}, \mathrm{N}-\mathrm{CH}_{3}\right), 2.47-2.30$ $\left(\mathrm{m}, 2 \mathrm{H}, \mathrm{COCH}_{2}\right), 1.85-1.76\left(\mathrm{~m}, 27 \mathrm{H}, \mathrm{C}\left(\mathrm{CH}_{3}\right)_{3}\right) .{ }^{13} \mathrm{C}$ NMR $\left(D M F-d_{7}\right): \delta 173.0,172.6,172.4,170.6,169.2,169.1$ $(\mathrm{C}=\mathrm{O}), 160.6,160.2,155.1,154.9,154.6,154.0,153.9$, 153.2, 141.4, 140.0, 139.9, 137.6, 137.4, 136.5, 136.2, $134.9,134.6,129.5,128.7,128.4,125.0,123.3,122.8$, 121.3, 121.1, 120.7, 119.8, 115.0, 112.6, 111.5 (Ar-C), 72.4, 72.2, 71.2, 71.1, 70.3, $68.0\left(\mathrm{CH}_{2} \mathrm{O}\right), 64.6,64.4,58.6$, 57.2, 55.9, 54.4, 52.5, 49.9, $48.0\left(\mathrm{~N}-\mathrm{CH}_{3}\right), 43.2,39.7,37.5$,

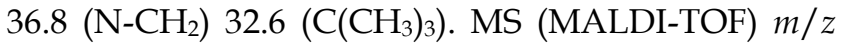
$1493.710[\mathrm{M}-\mathrm{I}+\mathrm{K}]^{+}$, calcd for $\mathrm{C}_{72} \mathrm{H}_{89} \mathrm{IKN}_{13} \mathrm{O}_{8} \mathrm{Zn}^{+}$ 1493.493. UV-Vis (DMF): $\lambda_{\max }(\log \varepsilon) 351$ (4.84), 610 (4.54), 677 (5.30) nm.

$\mathrm{ZnPc} 5 a$. A procedure similar to the one described above for ZnPc 3a was used: ZnPc 1a $(40.0 \mathrm{mg}$, $0.04 \mathrm{mmol}), \mathrm{DMF}(0.5 \mathrm{~mL}), \mathrm{Et}_{3} \mathrm{~N}(5.2 \mathrm{mg}, 0.051 \mathrm{mmol})$, HOBt (7.5 mg, $0.055 \mathrm{mmol})$, 1,4-bis-Boc-triazaheptane (15.5 mg, $0.051 \mathrm{mmol})$ and EDCI $(9.8 \mathrm{mg}, 0.051 \mathrm{mmol})$. The protected $\mathrm{ZnPc}$ was obtained as a blue solid (38.6 $\mathrm{mg}, 77.0 \%)$. ${ }^{1} \mathrm{H} \mathrm{N}$ MR (DMF- $\left.d_{7}\right): \delta 9.60-9.03(\mathrm{~m}, 6 \mathrm{H}$, Ar-H), 8.40-8.20 (m, 5H, Ar-H), 7.96-7.79 (m, 3H, Ar-H), 7.61-7.50 (m, 2H, Ar-H), 6.73 (br, 1H, N-H), 4.26-4.12 (m, $\left.4 \mathrm{H}, \mathrm{CH}_{2} \mathrm{O}\right), 3.38-3.26\left(\mathrm{~m}, 6 \mathrm{H}, \mathrm{CH}_{2} \mathrm{NH}\right)$, 3.20-3.16 (m, 2H, $\left.\mathrm{CH}_{2} \mathrm{NH}\right), 1.82-1.78(\mathrm{~m}, 27 \mathrm{H}$, $\left.\mathrm{C}\left(\mathrm{CH}_{3}\right)_{3}\right), 1.42-1.32\left(\mathrm{~m}, 18 \mathrm{H},-\mathrm{OC}\left(\mathrm{CH}_{3}\right)_{3}\right) .{ }^{13} \mathrm{C} \mathrm{NMR}$ $\left(\mathrm{DMF}-d_{7}\right): \delta 170.4,168.6(\mathrm{C}=\mathrm{O}), 157.1,156.8,156.5$, $156.2,155.5,155.4,155.3,155.2,155.0,154.6,154.4$, $154.3,154.2,154.1,153.5,152.5,152.1,142.3,140.0$, $139.9,139.6,137.6,137.5,137.2,135.0,134.5,131.7$, $130.1,129.4,128.6,128.4,123.6,123.5,122.7,122.5$, 122.0, 120.4, 120.1, 120.0, 119.8, 119.7, 119.0, 118.9, 117.5 (Ar-C), 79.9, $78.7\left(-\mathrm{OC}\left(\mathrm{CH}_{3}\right)_{3}\right), 72.3,72.0\left(\mathrm{OCH}_{2}\right)$, 48.4, 48.2, 47.6, 40.0, 39.8, 38.4, $36.8\left(\mathrm{~N}-\mathrm{CH}_{2}\right), 32.7,32.6$ $\left(\mathrm{Ar}-\mathrm{C}\left(\mathrm{CH}_{3}\right)_{3}\right), \quad 28.9, \quad 28.8 \quad\left(\mathrm{O}-\mathrm{C}\left(\mathrm{CH}_{3}\right)_{3}\right) . \quad$ MS (MALDI-TOF) $\mathrm{m} / z 1053.438[\mathrm{M}-2 \mathrm{Boc}+\mathrm{H}]^{+}$, calcd for $\mathrm{C}_{58} \mathrm{H}_{61} \mathrm{~N}_{12} \mathrm{O}_{4} \mathrm{Zn}$ 1053.423. The blue solid $(51.6 \mathrm{mg}$, $0.044 \mathrm{mmol}$ ) was dissolved in 1:1 $\mathrm{CH}_{2} \mathrm{Cl}_{2} /$ TFA $(6 \mathrm{~mL})$ and stirred at $0{ }^{\circ} \mathrm{C}$ for $3 \mathrm{~h}$. The solvent was removed and the residue treated with $2 \mathrm{~N} \mathrm{NaOH}(10 \mathrm{~mL})$ to afford a blue-greenish solid (38.2 $\mathrm{mg}, 89.2 \%)$. ${ }^{1} \mathrm{H}$ NMR (DMF- $\left.d_{7}\right): \delta$ 9.62-9.12 (m, 7H, Ar-H), 8.63-8.31 (m, 5H, Ar-H), 7.99-7.88 (m, 3H, Ar-H), 7.65-7.58 (m, $2 \mathrm{H}, \mathrm{Ar}-\mathrm{H}), 4.29-4.17\left(\mathrm{~m}, 4 \mathrm{H}, \mathrm{CH}_{2} \mathrm{O}\right), 4.01(\mathrm{br}, 4 \mathrm{H}$, $\left.\mathrm{NH}_{2}\right), 3.63-3.55\left(\mathrm{~m}, 6 \mathrm{H}, \mathrm{CH}_{2} \mathrm{NH}\right), 3.38-3.35(\mathrm{~m}, 2 \mathrm{H}$,
$\left.\mathrm{CH}_{2} \mathrm{NH}\right), 1.81\left(\mathrm{~s}, 27 \mathrm{H}, \mathrm{C}\left(\mathrm{CH}_{3}\right)_{3}\right) .{ }^{13} \mathrm{C}$ NMR $\left(\mathrm{DMF}-d_{7}\right): \delta$ 171.4, 168.6 ,168.5 (C=O), 161.2, 160.9, 160.6, 160.2, $157.1,156.4,155.9,155.8,155.6,155.5,154.9,154.8$, $154.7,154.6,154.0,153.8,153.7,153.6,153.3,152.7$, $152.3,142.8,140.5,140.3,140.0,138.0,137.9,137.6$, $134.8,134.3,131.2,130.5,129.9,128.1,127.9,123.4$, $123.2,122.9,122.7,122.5,121.9,120.3,120.0,119.8$, 119.7, 119.6, 118.7, 117.4, 116.8 (Ar-C), 72.1, 71.8 $\left(\mathrm{OCH}_{2}\right), 48.4,46.0,37.3,36.7 \quad\left(\mathrm{~N}-\mathrm{CH}_{2}\right), 32.7,32.5$ $\left(\mathrm{Ar}-\mathrm{C}\left(\mathrm{CH}_{3}\right)_{3}\right)$. MS (MALDI-TOF) $m / z 1053.433$ $[\mathrm{M}+\mathrm{H}]^{+}$, calcd for $\mathrm{C}_{58} \mathrm{H}_{61} \mathrm{~N}_{12} \mathrm{O}_{4} \mathrm{Zn}$ 1053.423. UV-vis (DMF): $\lambda_{\max }(\log \varepsilon) 350$ (4.66), 612 (4.42), 680 (5.19) nm.

$\mathrm{ZnPc} 5 \mathrm{~b}$. A procedure similar to the one described above for ZnPc 5a was used: ZnPc $\mathbf{1 b}(40.0$ $\mathrm{mg}, 0.04 \mathrm{mmol}), \mathrm{DMF}(0.5 \mathrm{~mL}), \mathrm{Et}_{3} \mathrm{~N}(5.2 \mathrm{mg}, 0.051$ mmol), HOBt $(7.5 \mathrm{mg}, \quad 0.055 \mathrm{mmol})$, 1,4-bis-Boc-triazaheptane $(15.5 \mathrm{mg}, 0.051 \mathrm{mmol})$, and EDCI $(9.8 \mathrm{mg}, 0.051 \mathrm{mmol})$. The product was obtained as a blue solid (44.4 mg, $88.6 \%) .{ }^{1} \mathrm{H}$ NMR (DMF- $\left.d_{7}\right): \delta$ 9.42-9.24 (m, 6H, Ar-H), 8.78 (br, 1H, NH), 8.40-8.20 $(\mathrm{m}, 4 \mathrm{H}, \mathrm{Ar}-\mathrm{H}), 8.10-8.04(\mathrm{~m}, 2 \mathrm{H}, \mathrm{Ar}-\mathrm{H}), 7.89-7.79(\mathrm{~m}$, $1 \mathrm{H}, \mathrm{Ar}-\mathrm{H}), 7.64-7.59(\mathrm{~m}, 2 \mathrm{H}, \mathrm{Ar}-\mathrm{H}), 6.82-6.76(\mathrm{~m}, 1 \mathrm{H}$, $\mathrm{N}-\mathrm{H}), 4.38\left(\mathrm{~d}, \mathrm{~J}=6.92 \mathrm{MHz}, 2 \mathrm{H}, \mathrm{CH}_{2} \mathrm{O}\right), 4.29(\mathrm{~d}, \mathrm{~J}=$ $9.68 \mathrm{MHz}, 2 \mathrm{H}, \mathrm{CH}_{2} \mathrm{O}$ ), 3.47 (br, $4 \mathrm{H}, \mathrm{CH}_{2} \mathrm{NH}$ ), 3.38 (br, $\left.2 \mathrm{H}, \mathrm{CH}_{2} \mathrm{NH}\right), 3.25\left(\mathrm{~m}, 2 \mathrm{H}, \mathrm{CH}_{2} \mathrm{NH}\right), 1.87-1.83(\mathrm{~m}$, $\left.27 \mathrm{H}, \mathrm{C}\left(\mathrm{CH}_{3}\right)_{3}\right), 1.48\left(\mathrm{~s}, 9 \mathrm{H},-\mathrm{OC}\left(\mathrm{CH}_{3}\right)_{3}\right), 1.41(\mathrm{~s}, 18 \mathrm{H}$, -OC $\left.\left(\mathrm{CH}_{3}\right)_{3}\right) .{ }^{13} \mathrm{CNMR}\left(\mathrm{DMF}-d_{7}\right): \delta 170.6,169.1(\mathrm{C}=\mathrm{O})$, 160.6, 160.5, 160.2, 160.1, 157.2, 156.6, 156.4, 154.8, $154.72,154.65,154.5,154.3,154.2,154.1,154.0,153.9$, $153.4,152.8,141.1,139.8,139.6,137.4,137.3,137.2$, $136.5,136.2,134.5,134.3,132.6,129.8,128.4,128.3$, $126.2,125.0,123.4,123.3,122.9,122.0,121.3,121.1$, 120.8, 120.7, 119.9, 119.7, 112.7, 111.5 (Ar-C), 80.0, 78.8 $\left(-\mathrm{OC}\left(\mathrm{CH}_{3}\right)_{3}\right), 72.4,72.1\left(\mathrm{OCH}_{2}\right), 48.5,48.3,47.7,40.1$, 39.9, 38.7, 38.5, $36.8\left(\mathrm{~N}-C H_{2}\right), 32.7\left(\mathrm{Ar}-\mathrm{C}\left(\mathrm{CH}_{3}\right)_{3}\right), 29.0$, $28.9\left(\mathrm{O}-\mathrm{C}\left(\mathrm{CH}_{3}\right)_{3}\right)$. MS (MALDI-TOF) $\mathrm{m} / \mathrm{z} 1052.447$ [M-2Boc] ${ }^{+}$, calcd for $\mathrm{C}_{58} \mathrm{H}_{60} \mathrm{~N}_{12} \mathrm{O}_{4} \mathrm{Zn} 1052.415$. The blue solid (44.4 $\mathrm{mg}, 0.035 \mathrm{mmol}$ ) was dissolved in 1:1 $\mathrm{CH}_{2} \mathrm{Cl}_{2}$ /TFA $(6 \mathrm{~mL})$ and stirred at $0{ }^{\circ} \mathrm{C}$ for $3 \mathrm{~h}$. The solvent was removed and the residue treated with $2 \mathrm{~N}$ $\mathrm{NaOH}(10 \mathrm{~mL})$ to afford a blue-greenish solid (33.5 $\mathrm{mg}, 89.9 \%) .{ }^{1} \mathrm{H}$ NMR (DMF- $\left.d_{7}\right): \delta$ 9.55-9.24 $(\mathrm{m}, 7 \mathrm{H}$, Ar-H), 8.97-8.89 (m, 1H, Ar-H), 8.40-8.11 (m, 4H, Ar-H), $8.07-8.00(\mathrm{~m}, 1 \mathrm{H}$, Ar-H), $7.92-7.90(\mathrm{~m}, 1 \mathrm{H}$, Ar-H), 7.65-7.50 (m, 2H, Ar-H), $4.37(\mathrm{~d}, \mathrm{~J}=6.88 \mathrm{MHz}$, $\left.2 \mathrm{H}, \mathrm{CH}_{2} \mathrm{O}\right), 4.26\left(\mathrm{~d}, \mathrm{~J}=4.24 \mathrm{MHz}, 2 \mathrm{H}, \mathrm{CH}_{2} \mathrm{O}\right), 3.47(\mathrm{br}$, $\left.2 \mathrm{H}, \mathrm{CH}_{2} \mathrm{NH}\right), 3.03-2.91\left(\mathrm{~m}, 2 \mathrm{H}, \mathrm{CH}_{2} \mathrm{NH}\right), 1.82-1.79(\mathrm{~m}$, $\left.27 \mathrm{H}, \mathrm{C}\left(\mathrm{CH}_{3}\right)_{3}\right)$. ${ }^{13} \mathrm{C}$ NMR $\left(\mathrm{DMF}-d_{7}\right): \delta 171.4,169.2$ ,169.1 (C=O), 160.6, 160.5, 160.2, 159.7, 155.2, 155.1, $154.8,154.7,154.3,154.1,154.0,153.4,153.2,141.4$, $140.0,139.8,137.7,137.5,134.9,134.7,128.3,128.2$, $125.0,123.3,123.2,122.8,121.2,121.1,120.7,119.9$, 119.8, 119.3, 116.4, 112.7, 111.5 (Ar-C), 72.3, 72.1, 72.0 $\left(\mathrm{OCH}_{2}\right), 49.1,48.7,47.5,47.0,39.5,38.7,36.7\left(\mathrm{~N}-\mathrm{CH}_{2}\right)$, 
$32.6\left(\mathrm{Ar}-\mathrm{C}\left(\mathrm{CH}_{3}\right)_{3}\right)$. MS (MALDI-TOF) m/z 1052.411 $[\mathrm{M}]^{+}$, calcd for $\mathrm{C}_{58} \mathrm{H}_{60} \mathrm{~N}_{12} \mathrm{O}_{4} \mathrm{Zn}$ 1052.415. UV-vis (DMF): $\lambda_{\max }(\log \varepsilon) 351$ (4.73), 609 (4.43), 676 (5.19) nm.

$\mathrm{ZnPc} 6 a$. A procedure similar to the one described above for $\mathrm{ZnPc} \mathbf{4 a}$ was used: $\mathrm{ZnPc} 5 \mathbf{5 a}(20.0 \mathrm{mg}$, $0.021 \mathrm{mmol})$, DIPA $(0.015 \mathrm{~mL}, 0.107 \mathrm{mmol}), \mathrm{CH}_{3} \mathrm{I}(0.2$ $\mathrm{mL})$ and dry THF $(0.5 \mathrm{~mL})$. The title Pc was obtained as a pale-green solid $(14.7 \mathrm{mg}, 53.3 \%) .{ }^{1} \mathrm{H}$ NMR $\left(\mathrm{DMF}-d_{7}\right): \delta$ 9.56-9.06 $(\mathrm{m}, 6 \mathrm{H}, \mathrm{Ar}-\mathrm{H}), 8.36-8.24(\mathrm{~m}, 4 \mathrm{H}$, Ar-H), 7.96-7.80 (m, 4H, Ar-H), 7.58-7.51 (m, 2H, Ar- $\mathrm{H}), 4.34-4.13\left(\mathrm{~m}, 8 \mathrm{H}, \mathrm{CH}_{2} \mathrm{O} / \mathrm{N}-\mathrm{CH}_{2}\right), 3.80-3.67(\mathrm{~m}$, $\left.4 \mathrm{H}, \mathrm{N}-\mathrm{CH}_{2}\right), 3.62-3.47\left(\mathrm{~m}, 6 \mathrm{H}, \mathrm{N}-\mathrm{CH}_{3}\right), 3.41-3.27(\mathrm{~m}$, $\left.9 \mathrm{H}, \mathrm{N}-\mathrm{CH}_{3}\right), 1.79-1.71\left(\mathrm{~m}, 27 \mathrm{H}, \mathrm{C}\left(\mathrm{CH}_{3}\right)_{3}\right) .{ }^{13} \mathrm{C} \mathrm{NMR}$ $\left(\mathrm{DMF}-d_{7}\right): \delta$ 171.3, 168.7, 168.6, 168.4, 157.2, 156.7, $155.9,155.8,155.7,155.6,155.5,155.43,155.36,155.1$, 155.0, 154.9, 154.8, 154.7, 154.6, 154.5, 154.1, 154.0, 153.8, 153.7, 153.6, 153.5, 153.2, 152.7, 152.63, 152.55, 152.33, 152.27, 152.2, 142.8, 140.4, 140.3, 140.0, 137.9, 137.6, 134.7, 134.3, 133.4, 132.5, 131.8, 131.4, 130.6, $129.9,128.3,128.0,123.4,123.3,123.2,123.0,122.6$, $122.4,120.5,120.0,119.9,119.8,119.7,119.6,119.5$, 118.6, 117.3 (Ar-C), 72.0, 71.9, 71.8, $71.4\left(\mathrm{CH}_{2} \mathrm{O}\right), 66.9$, 66.6, 64.9, 64.5, 58.6, 58.5, 57.1, 54.3, 52.40, 52.35 $\left(\mathrm{N}-\mathrm{CH}_{3}\right), 36.8,36.7\left(\mathrm{~N}-\mathrm{CH}_{2}\right) 32.7,32.6\left(\mathrm{C}\left(\mathrm{CH}_{3}\right)_{3}\right) . \mathrm{MS}$ (MALDI-TOF) $m / z$ 1238.544 [M-I-CH $\left.{ }_{3}+2 \mathrm{H}\right]^{+}$, calcd for $\mathrm{C}_{62} \mathrm{H}_{71} \mathrm{IN}_{12} \mathrm{O}_{4} \mathrm{Zn}$ 1238.406. UV-Vis (DMF): $\lambda_{\max }(\log \varepsilon)$ 357 (4.72), 611 (4.46), 679 (5.23) nm

$\mathrm{ZnPc} 6 b$. A procedure similar to the one described above for $\mathrm{ZnPc}$ 4a was used: $\mathrm{ZnPc} 5 \mathbf{b}$ (20.0 $\mathrm{mg}, 0.021 \mathrm{mmol})$, DIPA (0.015 mL, $0.107 \mathrm{mmol}), \mathrm{CH}_{3} \mathrm{I}$ $(0.2 \mathrm{~mL})$ and dry THF $(0.5 \mathrm{~mL})$. The title $\mathrm{ZnPc}$ was obtained as a blue-green solid (16.1 mg, 58.3\%). ${ }^{1} \mathrm{H}$ NMR (DMF- $\left.d_{7}\right): \delta$ 9.56-9.19 (m, 6H, Ar-H), 9.03-8.77 $(\mathrm{m}, 2 \mathrm{H}, \mathrm{Ar}-\mathrm{H}), 8.39-8.27(\mathrm{~m}, 3 \mathrm{H}, \mathrm{Ar}-\mathrm{H}), 8.01-8.86(\mathrm{~m}$, $3 \mathrm{H}, \mathrm{Ar}-\mathrm{H}), 7.58-7.45(\mathrm{~m}, 4 \mathrm{H}, \mathrm{Ar}-\mathrm{H}), 4.41-4.27(\mathrm{~m}, 8 \mathrm{H}$, $\left.\mathrm{CH}_{2} \mathrm{O} / \mathrm{N}-\mathrm{CH}_{2}\right), 3.92-3.82\left(\mathrm{~m}, 4 \mathrm{H}, \mathrm{N}-\mathrm{CH}_{2}\right), 3.53(\mathrm{~s}, 6 \mathrm{H}$, $\left.\mathrm{N}-\mathrm{CH}_{3}\right), 3.49$ (s, 9H, N-CH $), 1.86-1.72(\mathrm{~m}, 27 \mathrm{H}$, $\left.\mathrm{C}\left(\mathrm{CH}_{3}\right)_{3}\right) .{ }^{13} \mathrm{C}$ NMR $\left(\mathrm{DMF}-d_{7}\right): \delta 171.4,169.0,168.6$, $168.9,160.5,160.4,160.1,160.0,155.9,155.5,155.3$, $155.2,155.1,154.9,154.8,154.3,154.0,153.9,153.8$, $141.6,140.2,140.0,137.8,137.7,137.6,136.3,136.0$, 135.2, 135.0, 128.3, 128.12, 128.07, 125.1, 123.24, 123.15, 123.0, 122.8, 122.7, 121.3, 121.1, 120.6, 119.9, 119.8, 119.7, 112.8, 111.7 (Ar-C), 72.1, $71.9\left(\mathrm{CH}_{2} \mathrm{O}\right), 64.5$, 58.7, 57.3, 54.5, $52.5\left(\mathrm{~N}-\mathrm{CH}_{3}\right), 36.7\left(\mathrm{~N}-\mathrm{CH}_{2}\right) 32.6\left(\mathrm{C}\left(\mathrm{CH}_{3}\right)_{3}\right)$. MS (MALDI-TOF) $m / z 1252.575$ [M-I+2H] $]^{+}$, calcd for $\mathrm{C}_{63} \mathrm{H}_{73} \mathrm{IN}_{12} \mathrm{O}_{4} \mathrm{Zn}$ 1252.421. UV-Vis (DMF): $\lambda_{\max }(\log \varepsilon)$ 351 (4.83), 610 (4.55), 676 (5.31) nm.

$\mathrm{ZnPc} 7 a$. A procedure similar to the one described above for ZnPc 3a was used: ZnPc 1a (50.0 mg, $0.05 \mathrm{mmol}), \mathrm{DMF}(0.8 \mathrm{~mL}), \mathrm{Et}_{3} \mathrm{~N}(6.2 \mathrm{mg}, 0.061 \mathrm{mmol})$, HOBt $(9.3 \mathrm{mg}, 0.069 \mathrm{mmol})$, aspartic acid di-tert-butyl ester hydrochloride $(18 \mathrm{mg}, 0.064 \mathrm{mmol})$ and EDCI (12.3 $\mathrm{mg}, 0.064 \mathrm{mmol})$. The crude product was puri- fied by column chromatography using $\mathrm{CH}_{2} \mathrm{Cl}_{2}$ /methanol (98/2) for elution, giving the di-ester $\mathrm{ZnPc}$ as a blue solid (0.052 g, 87.1\%). ${ }^{1} \mathrm{H}$ NMR $\left(\mathrm{DMF}-d_{7}\right): \delta 10.09,10.05(\mathrm{~s}, 1 \mathrm{H}, \mathrm{N}-\mathrm{H}), 9.63-9.28(\mathrm{~m}, 6 \mathrm{H}$, Ar-H), 9.19-9.01 (m, 1H, Ar-H), 8.47-8.20 (m, 5H, Ar-H), 7.97-7.79 (m, 3H, N-H), 7.62-7.47 (m, 2H, N-H), 4.55-4.45 (m, $1 \mathrm{H}, \mathrm{N}-\mathrm{H}), 4.28-4.19\left(\mathrm{~m}, 4 \mathrm{H}, \mathrm{CH}_{2} \mathrm{O}\right)$, 2.96-2.67 (m, 3H, $\left.\mathrm{CH}_{2}\right), 1.81-1.77\left(\mathrm{~m}, 27 \mathrm{H}, \mathrm{C}\left(\mathrm{CH}_{3}\right)_{3}\right)$, 1.45-1.36 (m, 18H, -OC $\left.\left(\mathrm{CH}_{3}\right)_{3}\right) .{ }^{13} \mathrm{C}$ NMR $\left(\mathrm{DMF}-d_{7}\right): \delta$ $170.9,170.7,170.4,170.0,168.7(\mathrm{C}=\mathrm{O}), 156.8,156.2$, $155.6,155.4,154.5,154.3,154.1,153.6,152.5,152.2$, $142.3,140.0,139.9,139.6,1137.5,137.5,137.2,135.2$, $134.6,131.8,130.2,129.5,128.8,128.5,123.7,123.5$, $123.3,122.5,122.3,120.4,120.1,119.9,119.7,119.0$, $117.6(\mathrm{Ar}-\mathrm{C}), 82.4,81.7\left(-\mathrm{OC}\left(\mathrm{CH}_{3}\right)_{3}\right), 72.3,71.9\left(\mathrm{OCH}_{2}\right)$, 50.4, 38.4, $36.8\left(\mathrm{~N}^{\left.-\mathrm{CH}_{2}\right)}, 32.7,32.6\left(\mathrm{Ar}-\mathrm{C}\left(\mathrm{CH}_{3}\right)_{3}\right), 28.4\right.$, $28.3\left(\mathrm{O}-\mathrm{C}\left(\mathrm{CH}_{3}\right)_{3}\right)$. MS (MALDI-TOF) $\mathrm{m} / \mathrm{z} 1083.625$ $\left[\mathrm{M}-2 \mathrm{C}_{4} \mathrm{H}_{9}+\mathrm{H}\right]^{+}$, calcd for $\mathrm{C}_{58} \mathrm{H}_{55} \mathrm{~N}_{10} \mathrm{O}_{8} \mathrm{Zn}$ 1083.350. The product $(0.052 \mathrm{~g}, 0.044 \mathrm{mmol})$ was dissolved in 1:1 $\mathrm{CH}_{2} \mathrm{Cl}_{2}$ /TFA $(8 \mathrm{~mL})$ and stirred for $4 \mathrm{~h}$ at $0^{\circ} \mathrm{C}$. The tert-butyl group was removed as described for $\mathrm{ZnPc}$ $5 \mathrm{a}$ to give the title compound as a blue solid $(34.3 \mathrm{mg}$, $82.3 \%$ ). (MALDI-TOF) $\mathrm{m} / z 1195.180[\mathrm{M}+\mathrm{Na}]^{+}$, calcd for $\mathrm{C}_{58} \mathrm{H}_{54} \mathrm{~N}_{10} \mathrm{NaO}_{8} \mathrm{Zn}$ 1105.332. UV-vis (DMF): $\lambda_{\max }$ $(\log \varepsilon) 349$ (4.68), 612 (4.41), 679 (5.17) nm.

$\mathrm{ZnPc} 7 b$. A procedure similar to the one described above for $\mathrm{ZnPc}$ 3a was used: $\mathrm{ZnPc} \mathbf{1 b}$ (50.0 $\mathrm{mg}, 0.05 \mathrm{mmol}), \mathrm{DMF}(0.8 \mathrm{~mL}), \mathrm{Et}_{3} \mathrm{~N}(6.2 \mathrm{mg}, 0.061$ mmol), HOBt $(9.3 \mathrm{mg}, 0.069 \mathrm{mmol})$, aspartic acid di-tert-butyl ester hydrochloride $(18 \mathrm{mg}, 0.064 \mathrm{mmol}$ ) and EDCI $(12.3 \mathrm{mg}, 0.064 \mathrm{mmol})$. The protected $\mathrm{ZnPc}$ was obtained as a blue solid $(0.056 \mathrm{~g}, 89 \%) .{ }^{1} \mathrm{H}$ NMR (Acetone- $\left.d_{6}\right): \delta$ 9.86-9.68 (m, $\left.1 \mathrm{H}, \mathrm{N}-\mathrm{H}\right), 9.37-8.57(\mathrm{~m}$, $6 \mathrm{H}, \mathrm{Ar}-\mathrm{H}), 8.38-7.96(\mathrm{~m}, 6 \mathrm{H}, \mathrm{Ar}-\mathrm{H}), 7.92-7.56(\mathrm{~m}, 4 \mathrm{H}$, Ar-H), 4.74 (br, 1H, N-H), 4.25 (s, 4H, $\mathrm{CH}_{2} \mathrm{O}$ ), 2.82 (s, $1 \mathrm{H}, \mathrm{CH}), 2.66(\mathrm{~s}, 2 \mathrm{H}, \mathrm{CH}), 1.94-1.87\left(\mathrm{~m}, 27 \mathrm{H}, \mathrm{C}\left(\mathrm{CH}_{3}\right)_{3}\right)$, $1.45\left(\mathrm{~s}, 18 \mathrm{H},-\mathrm{OC}\left(\mathrm{CH}_{3}\right)_{3}\right) .{ }^{13} \mathrm{C}$ NMR (Acetone- $\left.d_{6}\right): \delta$ $170.6,170.4,169.99,169.95,168.3,168.23,168.17$ (C=O), $160.0,159.9,159.8,159.4,159.3,159.2,155.3,155.1$, 154.6, 154.4, 153.2, 1153.1, 153.03, 152.97, 139.4, 139.1, $139.0,136.8,135.9,135.8,135.4,127.7,124.3,122.8$, $122.4,121.8,121.1,121.0,120.5,120.4,119.5,112.8$, 112.6, 111.5 (Ar-C), 82.4, $81.7\left(-\mathrm{OC}\left(\mathrm{CH}_{3}\right)_{3}\right), 72.4,71.9$ $\left(\mathrm{OCH}_{2}\right), \quad 50.1, \quad 50.0, \quad 38.4, \quad 36.6 \quad\left(\mathrm{~N}-\mathrm{CH}_{2}\right), \quad 32.6$ $\left(\mathrm{Ar}-\mathrm{C}\left(\mathrm{CH}_{3}\right)_{3}\right), \quad 28.4, \quad 28.2 \quad\left(\mathrm{O}-\mathrm{C}\left(\mathrm{CH}_{3}\right)_{3}\right) . \quad$ MS $\begin{array}{llll}(\text { MALDI-TOF) } & m / z & 1194.433 \quad[\mathrm{M}+\mathrm{H}]^{+}, & 1138.332\end{array}$ $\left[\mathrm{M}-\mathrm{C}_{4} \mathrm{H}_{9}\right]^{+}, \quad 1083.257 \quad\left[\mathrm{M}-2 \mathrm{C}_{4} \mathrm{H}_{9}+\mathrm{H}\right]^{+}$, calcd for $\mathrm{C}_{66} \mathrm{H}_{70} \mathrm{~N}_{10} \mathrm{O}_{8} \mathrm{Zn}$ 1194.467, $\mathrm{C}_{62} \mathrm{H}_{62} \mathrm{~N}_{10} \mathrm{O}_{8} \mathrm{Zn}$ 1138.404, $\mathrm{C}_{58} \mathrm{H}_{55} \mathrm{~N}_{10} \mathrm{O}_{8} \mathrm{Zn} 1083.350$. The product $(0.056 \mathrm{~g}$, 0.047 $\mathrm{mmol})$ was dissolved in 1:1 $\mathrm{CH}_{2} \mathrm{Cl}_{2} / \mathrm{TFA}(8 \mathrm{~mL})$ and stirred for $4 \mathrm{~h}$ at $0^{\circ} \mathrm{C}$. The solvent was removed and the residue treated with $2 \mathrm{~N} \mathrm{NaOH}(10 \mathrm{~mL})$ to afford a blue solid (42.1 mg, $83.0 \%$ ). MS (MALDI-TOF) $\mathrm{m} / \mathrm{z}$ $1082.7[\mathrm{M}]^{+}, \quad 1105.3315[\mathrm{M}+\mathrm{Na}]^{+}, \quad$ calcd for 
$\mathrm{C}_{58} \mathrm{H}_{54} \mathrm{~N}_{10} \mathrm{O}_{8} \mathrm{Zn} \quad 1082.34, \quad \mathrm{C}_{58} \mathrm{H}_{54} \mathrm{~N}_{10} \mathrm{NaO}_{8} \mathrm{Zn} \quad 1105.7$. UV-vis (DMF): $\lambda_{\max }(\log \varepsilon) 351$ (4.83), 610 (4.51), 677 (5.28) $\mathrm{nm}$.

$\mathrm{ZnPc} 8 a$. A procedure similar to the one described above for ZnPc 3a was used: $\mathrm{ZnPc} 7 \mathrm{a}(18.4 \mathrm{mg}$, $0.017 \mathrm{mmol}), \mathrm{DMF}(0.5 \mathrm{~mL}), \mathrm{Et}_{3} \mathrm{~N}(6.2 \mathrm{mg}, 0.061$ $\mathrm{mmol})$, HOBt $(5.7 \mathrm{mg}, \quad 0.042 \mathrm{mmol})$, $\mathrm{N}$-Boc-2,2'-(ethylenedioxy)diethylamine $(9.4 \mathrm{mg}, 0.038$ $\mathrm{mmol})$ and EDCI $(6.5 \mathrm{mg}, 0.042 \mathrm{mmol})$. The crude product was purified by column chromatography using $\mathrm{CH}_{2} \mathrm{Cl}_{2} /$ methanol (95:5) for elution to give a blue solid $(13.6 \mathrm{mg}, 51.9 \%)$. ${ }^{1} \mathrm{H}$ NMR $\left(\mathrm{DMF}-d_{7}\right)$ : $\delta$ 9.59-9.08 (m, 6H, Ar-H), 8.50-8.27 (m, 5H, Ar-H), 7.99-7.74 (m, 5H, Ar-H), 7.61-7.53 (m, 2H, Ar-H), 6.65 (br, $1 \mathrm{H}, \mathrm{Ar}-\mathrm{H}), 4.77-4.71\left(\mathrm{~m}, 1 \mathrm{H}, \mathrm{NHCH}\left(\mathrm{CH}_{2}\right) \mathrm{CO}\right)$, 4.28-4.16 (m, $\left.4 \mathrm{H}, \mathrm{CH}_{2} \mathrm{O}\right), 3.48-3.36\left(\mathrm{~m}, 14 \mathrm{H}, \mathrm{CH}_{2} \mathrm{O}\right)$, 3.31-3.16 (m, 8H, $\left.\mathrm{CH}_{2} \mathrm{O}\right), 2.75-2.67(\mathrm{~m}, 2 \mathrm{H}$, $\left.\mathrm{CHCH}_{2} \mathrm{CO}\right), 1.81-1.76\left(\mathrm{~m}, 27 \mathrm{H}, \mathrm{C}\left(\mathrm{CH}_{3}\right)_{3}\right), 1.37$ (s, $18 \mathrm{H}$, $\left.\mathrm{OC}\left(\mathrm{CH}_{3}\right)_{3}\right) .{ }^{13} \mathrm{C}$ NMR $\left(\mathrm{DMF}-d_{7}\right): \delta$ 171.90, 171.86, 171.35, 171.28, 170.3, 168.7, 168.6 (C=O), 157.1, 155.4, $155.3,154.5,153.6,152.6,142.4,140.0,137.6,135.1$, 134.6, 132.5, 131.8, 129.9, 128.7, 123.4, 122.6, 122.4, 120.1, 119.0, 117.6 (Ar-C), $78.7\left(\mathrm{OC}\left(\mathrm{CH}_{3}\right)_{3}\right), 72.1,71.9$, 71.0, 70.95, 70.7, 70.4, $70.3 \quad\left(\mathrm{CH}_{2} \mathrm{O}\right), \quad 51.1$ $\left(\mathrm{NHCH}\left(\mathrm{CH}_{2}\right) \mathrm{CO}\right), 41.2,40.1,38.4,36.8\left(\mathrm{CH}_{2}\right), 32.7$, $32.6\left(\mathrm{C}\left(\mathrm{CH}_{3}\right)_{3}\right), 28.9\left(\mathrm{OC}\left(\mathrm{CH}_{3}\right)_{3}\right)$. MS (MALDI-TOF) $\mathrm{m} / \mathrm{z} 1542.669[\mathrm{M}]^{+}$, calcd for $\mathrm{C}_{80} \mathrm{H}_{98} \mathrm{~N}_{14} \mathrm{O}_{14} \mathrm{Zn} 1542.668$. The protected $\mathrm{ZnPc}(13.1 \mathrm{mg}, 8.5 \mathrm{mmol})$ was dissolved in a 1:1 mixture of $\mathrm{CH}_{2} \mathrm{Cl}_{2} / \mathrm{TFA}(4 \mathrm{~mL})$ and stirred at $0^{\circ} \mathrm{C}$ for $3 \mathrm{~h}$. The solvent was removed under reduced pressure and the residue treated with $2 \mathrm{~N}$ $\mathrm{NaOH}(10 \mathrm{~mL})$ to afford a blue solid $(10.5 \mathrm{mg}, 92.3 \%)$. ${ }^{1} \mathrm{H}$ NMR (DMF- $\left.d_{7}\right): \delta$ 9.60-9.10 $(\mathrm{m}, 7 \mathrm{H}, \quad$ Ar-H), 8.60-8.29 (m, 5H, Ar-H), 7.95-7.87 (m, 2H, Ar-H), 7.56-7.51 (m, 2H, Ar-H), $4.56(\mathrm{br}, 1 \mathrm{H}, \mathrm{NH}), 4.21$ (d, $\left.9.48 \mathrm{~Hz}, 2 \mathrm{H}, \mathrm{CH}_{2} \mathrm{O}\right), 4.16\left(\mathrm{~d}, 8.92 \mathrm{~Hz}, 2 \mathrm{H}, \mathrm{CH}_{2} \mathrm{O}\right)$, 3.75-3.35 (m, $\left.10 \mathrm{H}, \mathrm{CH}_{2} \mathrm{O}\right), 3.16-2.95\left(\mathrm{~m}, 9 \mathrm{H}, \mathrm{CH}_{2} \mathrm{O}\right)$, 2.90-2.80 (m, 3H, $\left.\mathrm{CH}_{2} \mathrm{O}\right), 2.90-2.80\left(\mathrm{~m}, 3 \mathrm{H}, \mathrm{CH}_{2} \mathrm{O}\right)$, 2.62-2.47 (m, 2H, $\left.\mathrm{CH}_{2}\right), 2.19$ (br, $\left.2 \mathrm{H}, \mathrm{NH}_{2}\right), 1.80-1.74$ $\left(\mathrm{m}, 27 \mathrm{H}, \mathrm{C}\left(\mathrm{CH}_{3}\right)_{3}\right) .{ }^{13} \mathrm{C}$ NMR $\left(\mathrm{DMF}-d_{7}\right): \delta 171.8,171.3$, $171.2,170.2,168.6,168.5,157.7,157.4,155.9,155.6$, 155.5, 155.0, 154.3, 154.2, 154.1, 154.0, 153.7, 152.4, $151.7,142.4,140.1,139.8,137.7,137.3,134.4,134.1$, 131.7, 130.8, 128.5, 123.7, 123.4, 123.1, 122.5, 122.3, 120.1, 120.0, 119.8, 117.6, 116.7 (Ar-C), 72.0, 71.8, 71.5, 71.0, 70.5, 70.4, $70.0(\mathrm{~N}-\mathrm{CH}), 51.2\left(\mathrm{NHCH}\left(\mathrm{CH}_{2}\right) \mathrm{CO}\right)$, 40.9 , 39.9, 39.8, 38.1, $36.8\left(\mathrm{CH}_{2}\right), 32.7,32.6\left(\mathrm{C}_{\left.\left(\mathrm{CH}_{3}\right)_{3}\right)}\right.$. MS (MALDI-TOF) m/z $1343.610[\mathrm{M}+\mathrm{H}]^{+}$, calcd for $\mathrm{C}_{70} \mathrm{H}_{83} \mathrm{~N}_{14} \mathrm{O}_{10} \mathrm{Zn} 1343.571$. UV-vis (DMF): $\lambda_{\max }(\log \varepsilon)$ 349 (4.70), 612 (4.45), $680(5.20) \mathrm{nm}$.

$\mathrm{ZnPc} 8 b$. A procedure similar to the one described above for $\mathrm{ZnPc} 3 \mathbf{a}$ was used: $\mathrm{ZnPc} 7 \mathbf{b}$ (18.4 $\mathrm{mg}, 0.017 \mathrm{mmol}), \mathrm{DMF}(0.5 \mathrm{~mL}), \mathrm{Et}_{3} \mathrm{~N}(6.2 \mathrm{mg}, 0.061$ $\mathrm{mmol})$ HOBt $(5.7 \mathrm{mg}, 0.042 \mathrm{mmol})$,
$\mathrm{N}$-Boc-2,2'-(ethylenedioxy)diethylamine $(9.4 \mathrm{mg}, 0.038$ $\mathrm{mmol})$ and EDCI $(6.5 \mathrm{mg}, 0.042 \mathrm{mmol})$. The ZnPc was obtained as a blue solid (13.3 mg, $50.8 \%) .{ }^{1} \mathrm{H}$ NMR (DMF- $\left.d_{7}\right)$ : $\delta$ 9.52-9.15 (m, 6H, Ar-H), 8.81-8.54 (m, 2H, Ar-H) , 8.42-8.34 (m, 3H, Ar-H), 8.17-8.05 (m, $4 \mathrm{H}$, Ar-H), 7.97-7.88 (m, 1H, Ar-H), 7.65-7.59 (m, 2H, Ar-H), 6.70 (br, 2H, Ar-H), $4.87-4.85$ (m, 1H, N-H), $4.42\left(\mathrm{~d}, 8.0 \mathrm{~Hz}, 2 \mathrm{H}, \mathrm{CH}_{2} \mathrm{O}\right), 4.33(\mathrm{~d}, 5.96 \mathrm{~Hz}, 2 \mathrm{H}$, $\left.\mathrm{CH}_{2} \mathrm{O}\right), 3.58-3.46\left(\mathrm{~m}, 16 \mathrm{H}, \mathrm{CH}_{2} \mathrm{O}\right), 3.42-3.37(\mathrm{~m}, 4 \mathrm{H}$, $\left.\mathrm{CH}_{2} \mathrm{NH}\right), 3.25-3.19\left(\mathrm{~m}, 4 \mathrm{H}, \mathrm{CH}_{2} \mathrm{NH}\right), 2.83-2.78(\mathrm{~m}, 2 \mathrm{H}$, $\left.\mathrm{CH}_{2} \mathrm{CO}\right), 1.86-1.83\left(\mathrm{~m}, 27 \mathrm{H}, \mathrm{C}\left(\mathrm{CH}_{3}\right)_{3}\right), 1.40-1.36(\mathrm{~m}$, $\left.18 \mathrm{H}, \mathrm{OC}\left(\mathrm{CH}_{3}\right)_{3}\right) .{ }^{13} \mathrm{C}$ NMR $\left(\mathrm{DMF}-d_{7}\right): \delta 172.0,171.4$, 170.42, 170,40, 169.1, 169.0, 160.6, 160.5, 160.2, 160.1, 157.1, 154,73, 154.67, 154.4, 154.2, 154.0, 153.9, 153.4, 152.9, 141.2, 139.8, 139.6, 137.5, 137.3, 136.,5, 136.2, 134.6, 128.4, 125.1, 123.35, 123.25, 122.83, 122.79, 122.0, 121.3, 121.2, 121,1, 120.73, 120.67, 119.9, 1119.8, 112.8, 111.6 (Ar-C), $78.8\left(\mathrm{OC}\left(\mathrm{CH}_{3}\right)_{3}\right), 72.2,72.0,71.1,70.04$, 70.01， 71.0, 70.8, 70.5, $70.4 \quad\left(\mathrm{CH}_{2} \mathrm{O}\right), \quad 51.2$ $\left(\mathrm{NHCH}\left(\mathrm{CH}_{2}\right) \mathrm{CO}\right), 42.5,41.2,40.2,38.5\left(\mathrm{CH}_{2}\right), 32.6$ $\left(\mathrm{C}\left(\mathrm{CH}_{3}\right)_{3}\right), 28.9\left(\mathrm{OC}\left(\mathrm{CH}_{3}\right)_{3}\right)$. MS (MALDI-TOF) $\mathrm{m} / \mathrm{z}$ $1544.802[\mathrm{M}]^{+}$, calcd for $\mathrm{C}_{80} \mathrm{H}_{98} \mathrm{~N}_{14} \mathrm{O}_{14} \mathrm{Zn} 1544.669$. The protected $\mathrm{ZnPc}(13.1 \mathrm{mg}, 8.5 \mathrm{mmol})$ was dissolved in a 1:1 a mixture of $\mathrm{CH}_{2} \mathrm{Cl}_{2} / \mathrm{TFA}(8 \mathrm{~mL})$ and stirred at $0^{\circ} \mathrm{C}$ for $3 \mathrm{~h}$. The solvent was removed under reduced pressure and the residue treated with $2 \mathrm{~N} \mathrm{NaOH}(10$ $\mathrm{mL})$ to give the title product $(10.2 \mathrm{mg}, 89.7 \%) .{ }^{1} \mathrm{H}$ NMR (DMF- $\left.d_{7}\right): \delta$ 9.54-9.23 (m, 7H, Ar-H), 9.00-8.77 $(\mathrm{m}, 1 \mathrm{H}, \mathrm{Ar}-\mathrm{H}), 8.39-8.29(\mathrm{~m}, 3 \mathrm{H}, \mathrm{Ar}-\mathrm{H}), 8.09-7.94(\mathrm{~m}$, $3 \mathrm{H}, \mathrm{Ar}-\mathrm{H}), 7.47-7.42$ (m, 2H, Ar-H), 4.66 (br, 1H, $\mathrm{NH}), 4.33\left(\mathrm{~d}, 7.36 \mathrm{~Hz}, 2 \mathrm{H}, \mathrm{CH}_{2} \mathrm{O}\right), 4.33(\mathrm{~d}, 5.16 \mathrm{~Hz}, 2 \mathrm{H}$, $\left.\mathrm{CH}_{2} \mathrm{O}\right), 3.65-3.45\left(\mathrm{~m}, 8 \mathrm{H}, \mathrm{CH}_{2} \mathrm{O}\right), 3.25-3.14(\mathrm{~m}, 8 \mathrm{H}$, $\left.\mathrm{CH}_{2} \mathrm{O}\right)$, 3.08-3.02 (m, $\left.2 \mathrm{H}, \mathrm{CH}_{2} \mathrm{NH}\right), 2.98-2.91(\mathrm{~m}, 2 \mathrm{H}$, $\left.\mathrm{CH}_{2} \mathrm{NH}\right), 2.87-2.80\left(\mathrm{~m}, 2 \mathrm{H}, \mathrm{CH}_{2} \mathrm{NH}\right), 2.72-2.58(\mathrm{~m}, 2 \mathrm{H}$, $\mathrm{CH}_{2} \mathrm{CO}$ ), 2.34 (br, 2H, $\left.\mathrm{NH}_{2}\right), 2.13$ (br, $2 \mathrm{H}, \mathrm{NH}_{2}$ ), 1.80-1.73 (m, 27H, C $\left.\left(\mathrm{CH}_{3}\right)_{3}\right) .{ }^{13} \mathrm{C}$ NMR $\left(\mathrm{DMF}-d_{7}\right): \delta$ $171.9,171.5,170.2,170.17,168.95,168.87,160.5,160.0$, 155.5, 155.4, 155.2, 155.1, 155.0, 154.8, 154.4, 154.1, $153.9,153.3,141.5,140.0,139.9,137.7,136.2,135.2$, $134.9,132.5,129.9,128.5,125.2,123.3,122.8,122.7$, 122.3, 122.0, 120.8, 120.1, 119.8, 113.3, 112.1 (Ar-C), 72.1, 72.0, 71.4, 71.1, 70.7, 70.52, 70.46, 70.3, 70.2, 70.1 $(\mathrm{N}-\mathrm{CH}), 51.2\left(\mathrm{NHCH}\left(\mathrm{CH}_{2}\right) \mathrm{CO}\right), 40.6,40.2,40.0,39.9$,

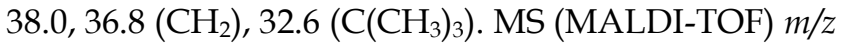
$1343.588[\mathrm{M}+\mathrm{H}]^{+}, 1365.575[\mathrm{M}+\mathrm{Na}]^{+}, 1381.546[\mathrm{M}+\mathrm{K}]^{+}$ calcd for $\mathrm{C}_{70} \mathrm{H}_{83} \mathrm{~N}_{14} \mathrm{O}_{10} \mathrm{Zn}$ 1343.5708, $\mathrm{C}_{70} \mathrm{H}_{82} \mathrm{NaN}_{14} \mathrm{O}_{10} \mathrm{Zn} \quad 1365.5528, \quad \mathrm{C}_{70} \mathrm{H}_{82} \mathrm{KN}_{14} \mathrm{O}_{10} \mathrm{Zn}$ 1381.5267. UV-vis (DMF): $\lambda_{\max }(\log \varepsilon) 352$ (4.77), 611 (4.50), 677 (5.27) $\mathrm{nm}$.

$\mathrm{ZnPc} 9 a$. A procedure similar to the one described above for $\mathrm{ZnPc} 4 \mathbf{a}$ was used: $\mathrm{ZnPc} 8 \mathbf{8}(20.0 \mathrm{mg}$, $0.015 \mathrm{mmol})$, DIPA $(0.015 \mathrm{~mL}, 0.107 \mathrm{mmol}), \mathrm{CH}_{3} \mathrm{I}(0.2$ $\mathrm{mL})$ and dry DMF $(0.5 \mathrm{~mL})$. The title compound was obtained as a blue solid (17.2 $\mathrm{mg}, 68.3 \%) .{ }^{1} \mathrm{H}$ NMR 
$\left(\mathrm{DMF}-d_{7}\right): \delta$ 9.57-9.33 (m, 5H, Ar-H), 9.20-9.05 (m, $1 \mathrm{H}$, Ar-H), 8.52-8.28 (m, 4H, Ar-H), 7.95-7.84 (m, $4 \mathrm{H}$, Ar-H), 7.61-7.52 (m, 2H, Ar-H), 4.31-4.11 (m, 4H, $\left.\mathrm{OCH}_{2}\right), 3.93(\mathrm{br}, 2 \mathrm{H}, \mathrm{NH}), 3.71-3.40(\mathrm{~m}, 27 \mathrm{H}$, $\left.\mathrm{OCH}_{2} / \mathrm{N}-\mathrm{CH}_{3}\right), 3.33-3.29\left(\mathrm{~m}, 10 \mathrm{H}, \mathrm{N}-\mathrm{CH}_{3}\right), 1.80-1.76$ $\left(\mathrm{m}, 27 \mathrm{H}, \mathrm{C}\left(\mathrm{CH}_{3}\right)_{3}\right)$. MS (MALDI-TOF) $\mathrm{m} / z 1427.749$ $[\mathrm{M}-2 \mathrm{I}-\mathrm{H}]^{+}$, calcd for $\mathrm{C}_{76} \mathrm{H}_{95} \mathrm{~N}_{14} \mathrm{O}_{10} \mathrm{Zn}^{+}$1427.665. UV-Vis (DMF): $\lambda_{\max }(\log \varepsilon) 348$ (4.48), 612 (4.23), 680 (5.01) $\mathrm{nm}$.

$\mathrm{ZnPc} 96$. A procedure similar to the one described above for $\mathrm{ZnPc}$ 4a was used: $\mathrm{ZnPc} \mathbf{8 b}(20.0$ $\mathrm{mg}, 0.015 \mathrm{mmol})$, DIPA (0.015 mL, $0.107 \mathrm{mmol}), \mathrm{CH}_{3} \mathrm{I}$ $(0.2 \mathrm{~mL})$ and dry DMF $(0.5 \mathrm{~mL})$. The title compound was obtained as a blue solid $(16.2 \mathrm{mg}, 64.3 \%) .{ }^{1} \mathrm{H}$ NMR (DMF- $\left.d_{7}\right): \delta$ 9.56-9.27 (m, 7H, Ar-H), 9.06-8.83 $(\mathrm{m}, 2 \mathrm{H}, \mathrm{Ar}-\mathrm{H}), 8.36-8.26(\mathrm{~m}, 4 \mathrm{H}, \mathrm{Ar}-\mathrm{H}), 8.13-8.06(\mathrm{~m}$, $2 \mathrm{H}, \mathrm{Ar}-\mathrm{H}), 7.92-7.81(\mathrm{~m}, 1 \mathrm{H}, \mathrm{Ar}-\mathrm{H}), 7.52-7.44(\mathrm{~m}, 2 \mathrm{H}$, Ar-H), $4.38(\mathrm{~d}, 8.0 \mathrm{~Hz}, 2 \mathrm{H}), 4.28(\mathrm{~d}, 6.0 \mathrm{~Hz}, 2 \mathrm{H})$, 3.94-3.90 (m, 5H, NH), 3.73-3.49 (m, $\left.24 \mathrm{H}, \mathrm{OCH}_{2}\right)$, 3.34-3.23 (m, $\left.18 \mathrm{H}, \mathrm{N}-\mathrm{CH}_{3}\right), 1.78-1.64(\mathrm{~m}, 27 \mathrm{H}$, $\left.\mathrm{C}\left(\mathrm{CH}_{3}\right)_{3}\right) .{ }^{13} \mathrm{C}$ NMR $\left(\mathrm{DMF}-d_{7}\right): \delta 172.2,171.5,170.5$, $169.2(\mathrm{C}=\mathrm{O}), 159.9,159.1,155.6,155.1,153.8,141.8$, $140.4,140.2$, 137.9, 136.3, 135.9, 135.2, 128.1, 124.9, 123.1, 122.9, 122.8, 121.0, 120.4, 119.7, 112.7, 111.6 (Ar-C), 72.2, 72.0, 71.0, 70.9, 70.8, 70.7, $70.4\left(\mathrm{OCH}_{2}\right)$, 66.2, 65.65, $65.60\left(\mathrm{NHCH}_{2}\right), \quad 54.4 \quad\left(\mathrm{~N}^{\left.-\mathrm{CH}_{3}\right),} 32.6\right.$

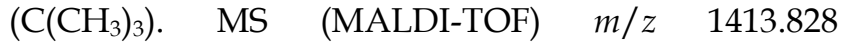
[M-2I-CH $\left.]_{3}\right]^{+}$, calcd for $\mathrm{C}_{75} \mathrm{H}_{93} \mathrm{~N}_{14} \mathrm{O}_{10} \mathrm{Zn}^{+} 1413.649$. $\mathrm{UV}-\mathrm{Vis}$ (DMF): $\lambda_{\max }(\log \varepsilon) 350$ (4.51), 610 (4.26), 677 (5.01) $\mathrm{nm}$.

$\mathrm{ZnPc} 10 a$. A procedure similar to the one described above for $\mathrm{ZnPc} 3 \mathrm{a}$ was used: $\mathrm{ZnPc} 7 \mathrm{a}(18.4 \mathrm{mg}$, $0.017 \mathrm{mmol}), \mathrm{DMF}(0.5 \mathrm{~mL}), \mathrm{Et}_{3} \mathrm{~N}(6.2 \mathrm{mg}, 0.061$ mmol), HOBt (5.7 mg, $0.042 \mathrm{mmol})$, $\mathrm{N}$-Boc-ethylenediamine $(6.1 \mathrm{mg}, 0.038 \mathrm{mmol})$ and EDCI $(6.5 \mathrm{mg}, 0.042 \mathrm{mmol})$. The final reaction mixture was stirred for 4 days at room temperature. The solvent was removed under reduced pressure and the residue treated with $2 \mathrm{~N} \mathrm{NaOH}(10 \mathrm{~mL})$ to give a blue solid (13.4 mg, $57.8 \%$ ). ${ }^{1} \mathrm{H}$ NMR (DMF- $\left.d_{7}\right): \delta$ 9.59-9.21 $(\mathrm{m}, 6 \mathrm{H}, \mathrm{Ar}-\mathrm{H}), 8.45-8.23(\mathrm{~m}, 4 \mathrm{H}, \mathrm{Ar}-\mathrm{H}), 8.12-7.82(\mathrm{~m}$, $3 \mathrm{H}, \mathrm{Ar}-\mathrm{H}), 7.62-7.52(\mathrm{~m}, 2 \mathrm{H}, \mathrm{Ar}-\mathrm{H}), 6.73-6.66(\mathrm{~m}, 2 \mathrm{H}$, Ar-H), $4.75-4.71(\mathrm{~m}, 1 \mathrm{H}, \mathrm{NH}), 4.28-4.18(\mathrm{~m}, 4 \mathrm{H}$, $\left.\mathrm{CH}_{2} \mathrm{O}\right), 3.29-3.11\left(\mathrm{~m}, 8 \mathrm{H}, \mathrm{CH}_{2} \mathrm{NH}\right), 2.70-2.65(\mathrm{~m}, 2 \mathrm{H}$, $\left.\mathrm{CH}_{2} \mathrm{CO}\right), 1.81-1.77\left(\mathrm{~m}, 27 \mathrm{H}, \mathrm{C}\left(\mathrm{CH}_{3}\right)_{3}\right), 1.41-1.34(\mathrm{~m}$, $\left.18 \mathrm{H}, \mathrm{C}\left(\mathrm{CH}_{3}\right)_{3}\right) .{ }^{13} \mathrm{C}$ NMR $\left(\mathrm{DMF}-d_{7}\right): \delta$ 172.1, 172.0, 171.5, 171.4, 170.3, 168.7, 168.6, 157.2, 157.1, 155.6, $155.4,155.2,154.4,154.1,153.7,153.6,152.6,152.3$, $142.3,139.9,139.7,137.6,137.2,135.1,134.6,131.8$, $130.1,129.4,128.6,128.5,123.5,122.6,122.4,122.0$, 120.1, 119.7, 119.1, 119.0, 117.7 (Ar-C), 78.8 $\left(\mathrm{OC}\left(\mathrm{CH}_{3}\right)_{3}\right), \quad 72.2, \quad 71.9 \quad\left(\mathrm{CH}_{2} \mathrm{O}\right), \quad 51.3, \quad 51.2$ $\left(\mathrm{NHCH}\left(\mathrm{CH}_{2}\right) \mathrm{CO}\right), 41.0,40.5,40.4,38.8,36.8\left(\mathrm{CH}_{2}\right)$, 32.7, $32.6 \quad\left(\mathrm{C}\left(\mathrm{CH}_{3}\right)_{3}\right), \quad 28.9 \quad\left(\mathrm{OC}\left(\mathrm{CH}_{3}\right)_{3}\right) . \quad$ MS $\left(\right.$ MALDI-TOF) $m / z \quad 1166.466 \quad[\mathrm{M}-2 \mathrm{Boc}]^{+}, 1189.469$ $[\mathrm{M}-2 \mathrm{Boc}+\mathrm{Na}]^{+}, 1205.444 \quad[\mathrm{M}-2 \mathrm{Boc}+\mathrm{K}]^{+}$, calcd for $\mathrm{C}_{62} \mathrm{H}_{66} \mathrm{~N}_{14} \mathrm{O}_{6} \mathrm{Zn} \quad 1166.4581, \quad \mathrm{C}_{62} \mathrm{H}_{66} \mathrm{NaN}_{14} \mathrm{O}_{6} \mathrm{Zn}$ 1189.4479, $\mathrm{C}_{62} \mathrm{H}_{66} \mathrm{KN}_{14} \mathrm{O}_{6} \mathrm{Zn} 1206.4218$ respectively. The protected $\mathrm{ZnPc}(13.1 \mathrm{mg}, 0.0096 \mathrm{mmol})$ was dissolved in a 1:1 mixture of $\mathrm{CH}_{2} \mathrm{Cl}_{2} / \mathrm{TFA}(8 \mathrm{~mL})$ at $0{ }^{\circ} \mathrm{C}$ for $3 \mathrm{~h}$. The solvent was removed under reduced pressure and the residue treated with $2 \mathrm{~N} \mathrm{NaOH}(10$ $\mathrm{mL}$ ) to give a blue solid (10.1 mg, 90.1\%). ${ }^{1} \mathrm{H}$ NMR (THF- $\left.d_{8}\right)$ : $\delta$ 9.58-9.08 (m, 7H, Ar-H), 8.39-8.07 (m, 4H, Ar-H), 7.82-6.86 (m, 5H, Ar-H), 4.15-3.76 (m, 4H, $\left.\mathrm{CH}_{2} \mathrm{O}\right), 3.57-3.20\left(\mathrm{~m}, 8 \mathrm{H}, \mathrm{CH}_{2} \mathrm{NH}\right), 2.28-2.13(\mathrm{~m}, 2 \mathrm{H}$, $\left.\mathrm{CH}_{2} \mathrm{CO}\right), \quad 1.80-1.72\left(\mathrm{~m}, 27 \mathrm{H}, \mathrm{C}\left(\mathrm{CH}_{3}\right)_{3}\right) .{ }^{13} \mathrm{C} \mathrm{NMR}$ $\left(\right.$ DMF- $\left.d_{7}\right): \delta$ 171.2, 171.0, 169.6, 168.2, 157.7, 155.8, $155.7,155.0,154.4,153.9,153.5,151.6,142 . .4$, $140.1,139.8,139.5,137.7,137.2,133.4,131.9,130.4$, $128.5,128.3,123.9,123.4,122.2,121.9,120.8,120.4$, 119.9, 119.8, 117.1, 116.6 (Ar-C), 71.7, $71.6\left(\mathrm{CH}_{2} \mathrm{NH}\right)$, $50.7\left(\mathrm{NHCH}\left(\mathrm{CH}_{2}\right) \mathrm{CO}\right), 40.7,40.2,36.8,36.7\left(\mathrm{CH}_{2}\right)$,

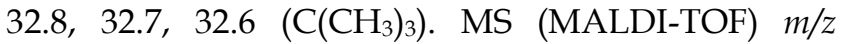
1166.503 [M-2Boc $]^{+}$, calcd for $\mathrm{C}_{62} \mathrm{H}_{66} \mathrm{~N}_{14} \mathrm{O}_{6} \mathrm{Zn}$ 1166.4581. UV-vis (DMF): $\lambda_{\max }(\log \varepsilon) 349$ (4.72), 613 (4.48), $680(5.23) \mathrm{nm}$.

$\mathrm{ZnPc} 10 \mathrm{~b}$. A procedure similar to the one described above for $\mathrm{ZnPc}$ 3a was used: $\mathrm{ZnPc} \mathbf{7 b}$ (18.4 $\mathrm{mg}, 0.017 \mathrm{mmol}), \mathrm{DMF}(0.5 \mathrm{~mL}), \mathrm{Et}_{3} \mathrm{~N}(6.2 \mathrm{mg}, 0.061$ $\mathrm{mmol})$ HOBt $(5.7 \mathrm{mg}, 0.042 \mathrm{mmol})$, $\mathrm{N}$-Boc-ethylenediamine $(6.1 \mathrm{mg}, 0.038 \mathrm{mmol})$ and EDCI $(6.5 \mathrm{mg}, 0.042 \mathrm{mmol})$ After stirring for for 4 days at room temperature and purification the protected $\mathrm{ZnPc}$ was obtained as a blue solid (14.3 $\mathrm{mg}, 61.6 \%)$. ${ }^{1} \mathrm{H}$ NMR (DMF- $\left.d_{7}\right): \delta$ 9.52-9.14 $(\mathrm{m}, 6 \mathrm{H}, \mathrm{Ar}-\mathrm{H})$, 8.80-8.33 (m, 4H, Ar-H), 8.20-8.10 (m, 3H, Ar-H), 7.65-7.61 (m, 2H, Ar-H), 6.79-6.76 (m, 2H, Ar-H) 4.83 (br, $1 \mathrm{H}, \mathrm{NH}), 4.43\left(\mathrm{~d}, 8.24 \mathrm{~Hz}, 2 \mathrm{H}, \mathrm{CH}_{2} \mathrm{O}\right),(\mathrm{d}, 5.76 \mathrm{~Hz}$, $\left.2 \mathrm{H}, \mathrm{CH}_{2} \mathrm{O}\right), 3.39-3.25\left(\mathrm{~m}, 4 \mathrm{H}, \mathrm{CH}_{2} \mathrm{NH}\right), 3.24-3.16(\mathrm{~m}$, $\left.4 \mathrm{H}, \mathrm{CH}_{2} \mathrm{NH}\right), 2.82-2.77\left(\mathrm{~m}, 2 \mathrm{H}, \mathrm{CH}_{2} \mathrm{CO}\right), 1.95-1.84(\mathrm{~m}$, $\left.27 \mathrm{H}, \mathrm{C}\left(\mathrm{CH}_{3}\right)_{3}\right), 1.41\left(\mathrm{~s}, 18 \mathrm{H}, \mathrm{C}\left(\mathrm{CH}_{3}\right)_{3}\right) .{ }^{13} \mathrm{C} \mathrm{NMR}$ $\left(\right.$ DMF- $\left.d_{7}\right): \delta 172.1,171.6,170.4,169.1,169.0,160.6$, $160.5,160.2,160.1,157.3,157.2,154.7,154.4,154.2$, $154.0,153.9,152.9,141.2,139.8,137.5,137.3,136.2$, 134.5, 128.4, 128.23 125.0, 123.2, 122.83, 122.79, 122.0, 121.3, 121.1, 120.7, 119.9, 119.7, 112.7, 111.6 (Ar-C), 78.91, $78.87\left(\mathrm{OC}\left(\mathrm{CH}_{3}\right)_{3}\right), \quad 72.3, \quad 72.0 \quad\left(\mathrm{CH}_{2} \mathrm{O}\right), \quad 51.3$ $\left(\mathrm{NHCH}\left(\mathrm{CH}_{2}\right) \mathrm{CO}\right), 41.1,40.6,40.5,38.8,36.8\left(\mathrm{CH}_{2}\right)$, $32.7\left(\mathrm{C}\left(\mathrm{CH}_{3}\right)_{3}\right), 29.0\left(\mathrm{OC}\left(\mathrm{CH}_{3}\right)_{3}\right)$. MS (MALDI-TOF) $\mathrm{m} / z \quad 1166.471 \quad[\mathrm{M}-2 \mathrm{Boc}]^{+}, 1189.475 \quad[\mathrm{M}-2 \mathrm{Boc}+\mathrm{Na}]^{+}$, 1205.448 [M-2Boc $+\mathrm{K}]^{+}$, calcd for $\mathrm{C}_{62} \mathrm{H}_{66} \mathrm{~N}_{14} \mathrm{O}_{6} \mathrm{Zn}$ 1166.4581, $\quad \mathrm{C}_{62} \mathrm{H}_{66} \mathrm{~N}_{14} \mathrm{NaO}_{6} \mathrm{Zn} \quad$ 1189.4479, $\mathrm{C}_{62} \mathrm{H}_{66} \mathrm{KN}_{14} \mathrm{O}_{6} \mathrm{Zn} 1206.4218$ respectively. The protected $\mathrm{ZnPc}(14.3 \mathrm{mg}, 0.0105 \mathrm{mmol})$ was dissolved in a 1:1 mixture of $\mathrm{CH}_{2} \mathrm{Cl}_{2}$ /TFA $(8 \mathrm{~mL})$ at $0{ }^{\circ} \mathrm{C}$ for $3 \mathrm{~h}$. The solvent was removed under reduced pressure and the residue treated with $2 \mathrm{~N} \mathrm{NaOH}(10 \mathrm{~mL})$ to afford the 
title $\mathrm{ZnPc}(11.1 \mathrm{mg}, 91.2 \%) .{ }^{1} \mathrm{H}$ NMR $\left(\mathrm{THF}-d_{8}\right): \delta$ 9.80-9.36 (m, 8H, Ar-H), 9.01-8.8.97 (m, 1H, Ar-H), 8.43-8.37 (m, 3H, Ar-H), 8.00-7.81 (m, 3H, Ar-H), 7.51 - $7.42(\mathrm{~m}, 2 \mathrm{H}, \mathrm{Ar}-\mathrm{H}), 4.20-3.70\left(\mathrm{~m}, 4 \mathrm{H}, \mathrm{CH}_{2} \mathrm{O}\right)$, 3.47-3.10 (m, 8H, $\left.\mathrm{CH}_{2} \mathrm{NH}\right)$, 2.08-1.93 (m, $\left.2 \mathrm{H}, \mathrm{CH}_{2} \mathrm{CO}\right)$, 1.75-1.65 (m, 27H, $\left.\mathrm{C}\left(\mathrm{CH}_{3}\right)_{3}\right) .{ }^{13} \mathrm{C}$ NMR $\left(\mathrm{DMF}-d_{7}\right): \delta$ $171.8,171.0,170.4,169.8,168.8,161.0,160.4,155.4$, $154.9,154.1,141.6,140.0,137.6,136.4,135.9,134.9$, $134.6,128.4,125.2,123.3,122.7,121.6,121.1,120.7$, 119.8, 112.7, 111.3 (Ar-C), 72.0, $71.5\left(\mathrm{CH}_{2} \mathrm{NH}\right), 50.8$ $\left(\mathrm{NHCH}\left(\mathrm{CH}_{2}\right) \mathrm{CO}\right), 41.0,40.1,36.7\left(\mathrm{CH}_{2}\right), 32.6,32.3$ $\left(\mathrm{C}\left(\mathrm{CH}_{3}\right)_{3}\right) . \quad$ MS (MALDI-TOF) $\mathrm{m} / \mathrm{z} \quad 1166.534$ [M-2Boc $+2 \mathrm{H}]^{+}$, calcd for $\mathrm{C}_{62} \mathrm{H}_{66} \mathrm{~N}_{14} \mathrm{O}_{6} \mathrm{Zn} 1166.4581$. UV-vis (DMF): $\lambda_{\max }(\log \varepsilon) 352$ (4.73), 610 (4.44), 677 (5.19) $\mathrm{nm}$.

$\mathrm{ZnPc} 11 a$. A procedure similar to the one described above for $\mathrm{ZnPc}$ 4a was used: $\mathrm{ZnPc}$ 10a $(20.0$ $\mathrm{mg}, 0.017 \mathrm{mmol})$, DIPA (0.015 mL, $0.107 \mathrm{mmol}), \mathrm{CH}_{3} \mathrm{I}$ $(0.2 \mathrm{~mL})$ and dry THF $(0.5 \mathrm{~mL})$. After work-up and purification, the title $\mathrm{ZnPc}$ was obtained $(15.2 \mathrm{mg}$, $58.9 \%) .{ }^{1} \mathrm{H}$ NMR (DMF- $\left.d_{7}\right): \delta$ 9.56-8.80 $(\mathrm{m}, 10 \mathrm{H}, \mathrm{Ar}-\mathrm{H})$, 8.38-8.24 (m, 4H, Ar-H), 7.96-7.85 (m, 3H, Ar-H), 7.62-7.54 (m, 2H, Ar-H), $7.16(\mathrm{~d}, 8.6 \mathrm{~Hz}, 1 \mathrm{H}, \mathrm{Ar}-\mathrm{H}), 6.90$ $(\mathrm{d}, 8.2 \mathrm{~Hz}, 1 \mathrm{H}, \mathrm{Ar}-\mathrm{H}), 4.22-4.09\left(\mathrm{~m}, 4 \mathrm{H}, \mathrm{OCH}_{2}\right)$, 3.38-3.29 (m, 8H, N-CH $)$, 3.11-3.02 (m, $\left.18 \mathrm{H}, \mathrm{N}-\mathrm{CH}_{3}\right)$, 1.92-1.73 (m, 27H, $\left.\mathrm{C}\left(\mathrm{CH}_{3}\right)_{3}\right) .{ }^{13} \mathrm{C}$ NMR (d-DMF): $\delta$ 172.8, 172.7, 171.7, 170.8, 168.9, 168.8 (C=O), 157.9, $155.9,155.7,155.4,154.9,153.9,153.8,153.6,144.2$, $142.9,140.4,140.1,138.0,137.7,134.7,134.2,128.7$, $128.1,123.4,123.2,122.8,122.7,119.8,119.7,119.5$, 118.4, 117.3, 115.0 (Ar-C), 72.2, 71.9, 70.5, 65.4, 64.4 $\left(\mathrm{N}-\mathrm{CH}_{2}\right), 53.9,53.6\left(\mathrm{~N}-\mathrm{CH}_{3}\right), 32.7,32.6\left(\mathrm{C}_{\left.\left(\mathrm{CH}_{3}\right)_{3}\right) . ~ M S}\right.$ (MALDI-TOF) $m / z$ 1209.761 [M-3CH $\left.\mathrm{CH}_{3}-2 \mathrm{I}\right]^{+}$, calcd for $\mathrm{C}_{65} \mathrm{H}_{73} \mathrm{~N}_{14} \mathrm{O}_{6} \mathrm{Zn}^{+}$1209.513. UV-Vis (DMF): $\lambda_{\max }(\log \varepsilon)$ 348 (4.65), 612 (4.42), 679 (5.19) nm.

$\mathrm{ZnPc} 11 \mathrm{~b}$. A procedure similar to the one described above for ZnPc 4a was used: $\mathrm{ZnPc} \mathbf{1 0 b}(20.0$ $\mathrm{mg}, 0.017 \mathrm{mmol})$, DIPA (0.015 mL, $0.107 \mathrm{mmol}), \mathrm{CH}_{3} \mathrm{I}$ $(0.2 \mathrm{~mL})$ and dry DMF $(0.5 \mathrm{~mL})$. After work-up, the title $\mathrm{ZnPc}$ was obtained as a blue solid $(17.4 \mathrm{mg}$, 67.4\%). ${ }^{1} \mathrm{H}$ NMR (DMF- $\left.d_{7}\right): \delta$ 9.56-9.27 $(\mathrm{m}, 7 \mathrm{H}, \mathrm{Ar}-\mathrm{H})$, 9.04-8.92 (m, 1H, Ar-H), 8.65-8.50 (m, 3H, Ar-H), 8.39-8.31 (m, 3H, Ar-H), 7.92-7.90 (m, 1H, Ar-H), 7.54-7.47 (m, 2H, Ar-H), 4.47-4.31 (m, 4H, $\left.\mathrm{OCH}_{2}\right)$, 381-3.70 (m, 8H, $\left.\mathrm{CH}_{2}\right), 3.38-3.35\left(\mathrm{~m}, 18 \mathrm{H}, \mathrm{N}-\mathrm{CH}_{3}\right)$, 1.79-1.74 (m, 27H, $\left.\mathrm{C}\left(\mathrm{CH}_{3}\right)_{3}\right) .{ }^{13} \mathrm{C}$ NMR (Acetone- $\left.d_{6}\right): \delta$ $172.6,171.8,170.9,169.2,155.5,154.8,154.0,153.5$, $153.0,141.8,140.3,140.2,137.7,136.4,136.0,129.6$, $128.8,128.3,126.2,125.0,123.2,122.8,121.1,120.5$, 119.6, 115.0, 112.8, 111.7 (Ar-C), 72.2, 72.1, 65.6 $\left(\mathrm{N}-\mathrm{CH}_{2}\right), \quad 54.0 \quad\left(\mathrm{~N}-\mathrm{CH}_{3}\right), \quad 32.6 \quad\left(\mathrm{C}_{\left.\left(\mathrm{CH}_{3}\right)_{3}\right) . \quad \text { MS }}\right.$ (MALDI-TOF) $m / z$ 1194.434 [M-4CH $\left.\mathrm{CH}_{3}-2 \mathrm{I}\right]^{+}$, calcd for $\mathrm{C}_{64} \mathrm{H}_{70} \mathrm{~N}_{14} \mathrm{O}_{6} \mathrm{Zn}^{+}$1194.489. UV-Vis (DMF): $\lambda_{\max }(\log \varepsilon)$ 350 (4.55), 610 (4.25), 677 (4.99) nm.
Phthalonitrile $13 a$. A mixture of 3-nitrophthalonitrile 12a (2.0 g, $11.5 \mathrm{mmol})$ and tert-butyl 20-hydroxy-3,6,9,12,15,18-hexaoxaicosan-1oate $(4.99 \mathrm{~g}, 12.6 \mathrm{mmol})$ was dissolved in THF (15 $\mathrm{mL})$. Potassium carbonate, $\mathrm{K}_{2} \mathrm{CO}_{3},(5.26 \mathrm{~g}, 40 \mathrm{mmol})$ was added into the solution in six portions after every $5 \mathrm{~min}$ and the reaction solution was heated to $65^{\circ} \mathrm{C}$ for $6 \mathrm{~h}$ (monitored by mass spectrometry). The solids were filtered off, the solvent evaporated, and the crude oil purified by silica column chromatography using $\mathrm{CH}_{2} \mathrm{Cl}_{2} /$ methanol (199:1 $\rightarrow$ 98:2) for elution. The title compound was obtained as a brown-yellow oil $(4.70 \mathrm{~g}, 78.3 \%) .{ }^{1} \mathrm{H}$ NMR (d-CDCl $\left.3,400 \mathrm{MHz}\right): \delta$ $7.64(\mathrm{~d}, \mathrm{~J}=8.1 \mathrm{~Hz}, 1 \mathrm{H}, \mathrm{Ar}-\mathrm{H}), 7.31$ (d, J = 8.2 Hz, 1H, $\mathrm{Ar}-\mathrm{H}), 4.27\left(\mathrm{t}, \mathrm{J}=4.4,2 \mathrm{H}, \mathrm{OCH}_{2}\right), 3.96\left(\mathrm{~s}, 2 \mathrm{H}, \mathrm{OCH}_{2}\right)$, $3.87\left(\mathrm{t}, 2 \mathrm{H}, \mathrm{J}=4.5, \mathrm{OCH}_{2}\right), 3.70-3.58\left(\mathrm{~m}, 20 \mathrm{H}, \mathrm{OCH}_{2}\right)$, $1.41\left(\mathrm{~s}, 9 \mathrm{H}, \mathrm{C}\left(\mathrm{CH}_{3}\right)_{3}\right) .{ }^{13} \mathrm{C} \mathrm{NMR}\left(\mathrm{CDCl}_{3}\right): \delta 169.65$ $\left(\mathrm{CH}_{2} \mathrm{C}(\mathrm{O}) \mathrm{O} t \mathrm{Bu}\right), 161.41,134.71,125.34,117.55,113.09$, 104.91 (Ar-C), 116.77, 115.41, (CN), $81.49\left(\mathrm{C}\left(\mathrm{CH}_{3}\right)\right.$, 71.11, 70.67, 70.54, 69.72, 69.21, $68.98\left(\mathrm{OCH}_{2}\right), 28.09$ $\left(\mathrm{C}\left(\mathrm{CH}_{3}\right)_{3}\right)$. MS (MALDI-TOF) $\mathrm{m} / \mathrm{z} \quad 545.2232$ $[\mathrm{M}+\mathrm{H}+\mathrm{Na}]^{+}$, calcd for, $\mathrm{C}_{18} \mathrm{H}_{36} \mathrm{NaO}_{9}, 519.2257 ; \mathrm{m} / \mathrm{z}$ 545.2466 $[\mathrm{M}+\mathrm{H}]^{+}$, calcd for, $\mathrm{C}_{26} \mathrm{H}_{37} \mathrm{~N}_{2} \mathrm{NaO}_{9}, 545.2475$.

Phthalonitrile $13 \mathrm{~b}$. The same procedure as described above for 13a was used: 4-nitrophthalonitrile 12b (2.0 g, $11.5 \mathrm{mmol})$ tert-butyl 20-hydroxy-3,6,9,12,15,18-hexaoxaicosan-1-oate (4.99 g, $12.6 \mathrm{mmol})$, THF $(15 \mathrm{~mL})$ and $\mathrm{K}_{2} \mathrm{CO}_{3},(5.26 \mathrm{~g}, 40$ $\mathrm{mmol})$. The crude oil was purified by silica column chromatography using $\mathrm{CH}_{2} \mathrm{Cl}_{2} /$ methanol (98:2) as eluting solvent system, giving a brown oil (4.87 $\mathrm{g}$, 81.2\%). ${ }^{1} \mathrm{H} \mathrm{NMR}\left(\mathrm{d}-\mathrm{CDCl}_{3}, 400 \mathrm{MHz}\right): \delta 7.64$ (d, J = 8.8 $\mathrm{Hz}, 1 \mathrm{H}, \mathrm{Ar}-\mathrm{H}), 7.24$ (s, 1H, Ar-H), 7.18 (d, J = $8.8 \mathrm{~Hz}$, $1 \mathrm{H}, \mathrm{Ar}-\mathrm{H}), 4.15\left(\mathrm{t}, \mathrm{J}=3.5,2 \mathrm{H}, \mathrm{OCH}_{2}\right), 3.91(\mathrm{~s}, 2 \mathrm{H}$, $\left.\mathrm{OCH}_{2}\right), 3.79\left(\mathrm{t}, 2 \mathrm{H}, \mathrm{J}=3.7, \mathrm{OCH}_{2}\right), 3.60-3.50(\mathrm{~m}, 20 \mathrm{H}$, $\left.\mathrm{OCH}_{2}\right), 1.36\left(\mathrm{~s}, 9 \mathrm{H}, \mathrm{C}\left(\mathrm{CH}_{3}\right)_{3}\right) .{ }^{13} \mathrm{C} \mathrm{NMR}\left(\mathrm{CDCl}_{3}\right): \delta$ $169.48\left(\mathrm{CH}_{2} \mathrm{C}(\mathrm{O}) \mathrm{O}^{t} \mathrm{Bu}\right), 161.95,135.13,119.81,119.56$, 117.01, 106.97 (Ar-C), 115.64, 115.20, (CN), 81.30 $\left(\mathrm{C}\left(\mathrm{CH}_{3}\right), 70.71,70.50,70.37,70.29,70.05\left(\mathrm{OCH}_{2}\right), 28.12\right.$ $\left(\mathrm{C}\left(\mathrm{CH}_{3}\right)_{3}\right)$. MS (MALDI-TOF) $\mathrm{m} / z \quad 545.2473$ $[\mathrm{M}+\mathrm{H}+\mathrm{Na}]^{+}$, calcd for, $\mathrm{C}_{26} \mathrm{H}_{37} \mathrm{~N}_{2} \mathrm{NaO}_{9}, 545.2475$.

$\mathrm{ZnPc} 14 \mathrm{a}$. A mixture of 4-tert-butylphthalonitrile (1.32 g, $7.16 \mathrm{mmol})$, phthalonitrile 13a (475.0 mg, 1.42 $\mathrm{mmol}$ ) and zinc(II) acetate (500 $\mathrm{mg}, 2.73 \mathrm{mmol}$ ) was stirred in DMAE (35 mL). The solution was refluxed under the flow of argon and two drops of DBN were added. The reaction solution was refluxed at $145{ }^{\circ} \mathrm{C}$ for $5 \mathrm{~h}$. The solvent was removed under reduced pressure and the residue purified by silica column chromatography using $\mathrm{CH}_{2} \mathrm{Cl}_{2}$ /methanol (97:3) for elution. A second silica column chromatography was performed in chloroform, followed by chloroform/methanol (99:1 $\rightarrow$ 98:2) to afford a blue solid (273.6 mg, 16.9\%). ${ }^{1} \mathrm{H}$ NMR (DMF- $\left.d_{7}\right)$ : $\delta$ 9.63-8.92 (m, 
$6 \mathrm{H}, \mathrm{Ar}-\mathrm{H}), 8.47-8.05(\mathrm{~m}, 3 \mathrm{H}, \mathrm{Ar}-\mathrm{H}), 7.85-7.62(\mathrm{~m}, 3 \mathrm{H}$, Ar-H), 4.95-4.88 (m, 2H, $\left.\mathrm{CH}_{2} \mathrm{O}\right), 4.49-4.39(\mathrm{~m}, 2 \mathrm{H}$, $\left.\mathrm{CH}_{2} \mathrm{O}\right)$, 4.16-4.00 (m, 3H, $\left.\mathrm{CH}_{2} \mathrm{O}\right), 3.88-3.44(\mathrm{~m}, 19 \mathrm{H}$, $\left.\mathrm{CH}_{2} \mathrm{O}\right), 1.88-1.82\left(\mathrm{~m}, 27 \mathrm{H}, \mathrm{C}\left(\mathrm{CH}_{3}\right)_{3}\right), 1.45,1.38,1.36(\mathrm{~s}$, $\left.9 \mathrm{H},-\mathrm{OC}\left(\mathrm{CH}_{3}\right)_{3}\right) .{ }^{13} \mathrm{CNMR}\left(\mathrm{DMF}-d_{7}\right): \delta 170.73,170.66$ $(\mathrm{C}=\mathrm{O}), 158.1,157.8,157.4,157.3,157.2,154.9,154.8$, $154.7,154.5,154.3,154.1,153.8,153.7,141.9,141.8$, $140.1,139.9,139.8,137.9,137.5,137.2,136.7,137.2$, 134.0, 131.6, 131.30, 131.26, 130.5, 128.9, 128.4, 126.9, $126.7,126.4,123.6,123.4,123.3,122.9,120.2,120.1$, $119.8,119.7,118.7,117.0,116.3,114.8,114.7,114.6$, 104.6 (Ar-C), 81.73, $81.68\left(-\mathrm{OC}\left(\mathrm{CH}_{3}\right)_{3}\right), 72.1,71.9,71.7$, 71.5, 71.44, 71.36, 71.3, 71.2, 70.9, 70.4, 70.0, 69.9, 69.62, 69.56, $68.9\left(\mathrm{OCH}_{2}\right), 52.1,45.9,36.8\left(\mathrm{~N}-C H_{2}\right), 32.8,32.7$ $\left(\mathrm{Ar}-\mathrm{C}\left(\mathrm{CH}_{3}\right)_{3}\right), 28.6\left(\mathrm{O}-\mathrm{C}\left(\mathrm{CH}_{3}\right)_{3}\right)$. MS (MALDI-TOF) $\mathrm{m} / \mathrm{z}$ $1139.675[\mathrm{M}+\mathrm{H}]^{+}$, calcd for $\mathrm{C}_{62} \mathrm{H}_{75} \mathrm{~N}_{8} \mathrm{O}_{9} \mathrm{Zn} 1138.495$. The protected $\mathrm{ZnPc}(273.6 \mathrm{mg}, 0.240 \mathrm{mmol})$ was dissolved in a 1:1 mixture of $\mathrm{CH}_{2} \mathrm{Cl}_{2}$ /TFA $(10 \mathrm{~mL})$ and the solution was stirred at $0{ }^{\circ} \mathrm{C}$ for $3 \mathrm{~h}$. After the reaction, the solvent was removed and the resulting residue was treated with $2 \mathrm{~N} \mathrm{NaOH}(15 \mathrm{~mL})$. The product was extracted using 5:1 $\mathrm{CH}_{2} \mathrm{Cl}_{2} /$ methanol $(20 \mathrm{~mL} \times 4)$ and the organic phase was washed with water $(20 \mathrm{~mL}$ $\times 2$ ) and dried over anhydrous sodium sulfate. The solvent was removed under reduced pressure to afford the title $\mathrm{ZnPc}$ as a blue solid $(243.7 \mathrm{mg}$, $93.7 \%)$. ${ }^{1} \mathrm{HNMR}\left(\mathrm{DMF}-d_{7}\right)$ : $\delta$ 9.59-9.11 (m, 6H, Ar-H), 8.40-8.34 (m, 3H, Ar-H), 8.19-7.70 (m, 3H, Ar-H), 5.00-4.94 (m, $\left.2 \mathrm{H}, \mathrm{CH}_{2} \mathrm{O}\right), 4.60-4.43\left(\mathrm{~m}, 2 \mathrm{H}, \mathrm{CH}_{2} \mathrm{O}\right), 4.19-4.06(\mathrm{~m}, 2 \mathrm{H}$, $\left.\mathrm{CH}_{2} \mathrm{O}\right), 3.90-3.04\left(\mathrm{~m}, 16 \mathrm{H}, \mathrm{CH}_{2} \mathrm{O}\right), 1.83-1.78(\mathrm{~m}, 27 \mathrm{H}$, $\left.\mathrm{C}\left(\mathrm{CH}_{3}\right)_{3}\right) .{ }^{13} \mathrm{CNMR}\left(\mathrm{DMF}-d_{7}\right): \delta 170.6(\mathrm{C}=\mathrm{O}), 157.5$, $157.1,156.8,155.9,155.3,155.0,154.5,153.8,153.6$, $142.5,140.5,140.2,140.0,138.3,137.9,137.6,136.2$, $132.5,131.4,130.4,128.9,128.5,128.1,127.2,127.0$, 123.9, 123.6, 123.1, 122.8, 120.7, 120.0, 119.8, 119.7, 119.5, 116.5, 116.1, 113.9 (Ar-C), 72.5, 72.0, 71.7, 71.5, 71.3, 71.2, 71.0, 70.5, 70.2, 69.7, 69.6, 68.9, $68.6\left(\mathrm{OCH}_{2}\right)$, 52.1, 46.2, 36.8, $36.7\left(\mathrm{~N}-\mathrm{CH}_{2}\right), 32.7,32.6\left(\mathrm{Ar}-\mathrm{C}\left(\mathrm{CH}_{3}\right)_{3}\right)$. MS (MALDI-TOF) $\mathrm{m} / \mathrm{z} 1083.444[\mathrm{M}+\mathrm{H}]^{+}$, calcd for $\mathrm{C}_{58} \mathrm{H}_{67} \mathrm{~N}_{8} \mathrm{O}_{9} \mathrm{Zn}$ 1083.432. UV-vis (DMF): $\lambda_{\max }(\log \varepsilon)$ 345 (4.77), 613 (4.57), 681 (5.34) nm.

$\mathrm{ZnPc} 14 \mathrm{~b}$. A mixture of 4-tert-butylphthalonitrile (385 mg, $2.09 \mathrm{mmol})$, phthalonitrile 13b $(273.4 \mathrm{mg}$, $0.69 \mathrm{mmol})$ and zinc(II) acetate $(254.7 \mathrm{mg}, 1.4 \mathrm{mmol})$ were stirred in DMAE $(35 \mathrm{~mL})$. The solution was refluxed under a flow of argon, and two drops of DBN were added into the reaction solution. The reaction was treated as $\mathrm{ZnPc}$ 14a above to afford blue solid (121.6 mg, 15.5\%). ${ }^{1} \mathrm{HNMR}\left(\mathrm{DMF}-d_{7}\right)$ : $\delta$ 9.59-8.92 (m, 7H, Ar-H), 8.47-8.35 (m, 3H, Ar-H), 7.88-7.78 (m, 2H, Ar- $\mathrm{H}), 4.74-4.58\left(\mathrm{~m}, 2 \mathrm{H}, \mathrm{CH}_{2} \mathrm{O}\right), 4.19-4.00(\mathrm{~m}, 4 \mathrm{H}$, $\left.\mathrm{CH}_{2} \mathrm{O}\right), 3.87-3.57\left(\mathrm{~m}, 18 \mathrm{H}, \mathrm{CH}_{2} \mathrm{O}\right), 1.83-1.75(\mathrm{~m}, 27 \mathrm{H}$, $\left.\mathrm{C}\left(\mathrm{CH}_{3}\right)_{3}\right), 1.42-1.38$ (s, 9H, $\left.-\mathrm{OC}\left(\mathrm{CH}_{3}\right)_{3}\right) .{ }^{13} \mathrm{CNMR}$ $\left(\mathrm{DMF}-d_{7}\right): \delta 170.7(\mathrm{C}=\mathrm{O}), 158.4,158.1,155.0,154.9$,
$154.8,154.6,154.4,154.2,154.0,142.8,141.8,140.0$, $137.6,133.5,132.9,132.5,132.2,131.7,131.3,130.4$, $128.9,128.4,124.8,123.9,123.33,123.25,122.9,120.8$, 120.2, 119.9, 119.2, 118.9, 109.4, 107.4, 104.2 (Ar-C), $81.7\left(-\mathrm{OC}\left(\mathrm{CH}_{3}\right)_{3}\right), 71.74,71.69,71.5,71.4,71.33,71.30$, $70.8,70.2,69.8,69.61,69.57,69.0\left(\mathrm{OCH}_{2}\right), 52.1,47.4$, $45.5, \quad 36.8 \quad\left(\mathrm{~N}-\mathrm{CH}_{2}\right), \quad 32.6 \quad\left(\mathrm{Ar}-\mathrm{C}\left(\mathrm{CH}_{3}\right)_{3}\right), \quad 28.5$ $\left(\mathrm{O}-\mathrm{C}\left(\mathrm{CH}_{3}\right)_{3}\right)$. MS (MALDI-TOF) $\mathrm{m} / z 1138.454[\mathrm{M}]^{+}$, 1082.448.454 $\left[\mathrm{M}-\mathrm{C}_{4} \mathrm{H}_{9}\right]^{+}$, calcd for $\mathrm{C}_{62} \mathrm{H}_{74} \mathrm{~N}_{8} \mathrm{O}_{9} \mathrm{Zn}$ 1138.487, $\mathrm{C}_{58} \mathrm{H}_{66} \mathrm{~N}_{8} \mathrm{O}_{9} \mathrm{Zn}$ 1082.424. The blue solid (113.0 mg, $0.119 \mathrm{mmol}$ ) was dissolved in a mixture of $\mathrm{CH}_{2} \mathrm{Cl}_{2}$ /TFA (4 mL/4 mL) and the solution was stirred at $0{ }^{\circ} \mathrm{C}$ for 3 hours. The solvent was removed under reduced pressure and the residue treated with $2 \mathrm{~N} \mathrm{NaOH}(10 \mathrm{~mL})$ to afford a blue solid $(94.7 \mathrm{mg}, 93.7$ $\%)$ was obtained. ${ }^{1} \mathrm{HNMR}\left(\mathrm{DMF}-d_{7}\right): \delta 9.59-9.09(\mathrm{~m}$, $7 \mathrm{H}, \mathrm{Ar}-\mathrm{H}), 8.36-8.24(\mathrm{~m}, 3 \mathrm{H}, \mathrm{Ar}-\mathrm{H})$, 7.89-7.70 (m, $2 \mathrm{H}$, Ar-H), 4.56-4.46 (m, 2H, $\left.\mathrm{CH}_{2} \mathrm{O}\right), 3.90-3.04(\mathrm{~m}, 24 \mathrm{H}$, $\left.\mathrm{CH}_{2} \mathrm{O}\right), \quad 1.83-1.78 \quad\left(\mathrm{~m}, 27 \mathrm{H}, \quad \mathrm{C}\left(\mathrm{CH}_{3}\right)_{3}\right) .{ }^{13} \mathrm{CNMR}$ $\left(\mathrm{DMF}-d_{7}\right): \delta 171.8(\mathrm{C}=\mathrm{O}), 159.6,158.2,157.9,157.1$, $155.2,155.0,154.9,154.6,154.1,154.0,153.8,153.6$, $142.2,141.9,140.2,141.1,140.0,137.8,137.6,134.4$, $133.4,133.0,132.5,131.6,131.4130 .8,130.4,128.9$, $128.4,128.3,128.1,128.0,126.3,124.7,124.6,123.9$, 123.2, 122.8, 120.7, 120.0, 119.9, 119.8, 119.1, 115.0, 107.5, 107.4, 107.2 (Ar-C), 71.7, 71.6, 71.5, 71.4, 71.3, 71.2, 71.0, 70.7, 70.5, 70.1, 69.8, 69.5, $68.9\left(\mathrm{OCH}_{2}\right), 52.1$, 47.4, 46.1, 40.9, 36.8, $36.5\left(\mathrm{~N}-\mathrm{CH}_{2}\right), 32.6\left(\mathrm{Ar}-\mathrm{C}\left(\mathrm{CH}_{3}\right)_{3}\right)$. MS (MALDI-TOF) $\mathrm{m} / \mathrm{z} 1083.428[\mathrm{M}+\mathrm{H}]^{+}$, calcd for $\mathrm{C}_{58} \mathrm{H}_{67} \mathrm{~N}_{8} \mathrm{O}$. $\mathrm{Zn}$ 1083.432. UV-vis (DMF): $\lambda_{\max }(\log \varepsilon)$ 351 (4.65), 609 (4.38), 676 (5.14) nm.

$\mathrm{ZnPc} 15 a$. A procedure similar to the one described above for $\mathrm{ZnPc}$ 3a was used: $\mathrm{ZnPc}$ 14a (20.0 $\mathrm{mg}, 0.018 \mathrm{mmol}), \mathrm{DMF}(0.4 \mathrm{~mL}), \mathrm{Et}_{3} \mathrm{~N}(3.3 \mathrm{mg}, 0.032$ $\mathrm{mmol})$ HOBt $(4.7 \mathrm{mg}, 0.035 \mathrm{mmol})$, 1,4-bis-Boc-triazaheptane $(7.0 \mathrm{mg}, 0.023 \mathrm{mmol})$ and EDCI ( $4.0 \mathrm{mg}, 0.026 \mathrm{mmol})$. After work-up and purification the protected $\mathrm{ZnPc}$ was obtained as a blue solid (16.1 mg, 63.6\%). ${ }^{1} \mathrm{H}$ NMR (DMF- $\left.d_{7}\right)$ : $\delta$ 9.54-9.20 (m, 5H, Ar-H), 9.06-8.84 (m, 1H, Ar-H), 8.47-8.35 (m, $3 \mathrm{H}, \mathrm{Ar}-\mathrm{H}), 7.82-7.76(\mathrm{~m}, 2 \mathrm{H}, \mathrm{Ar}-\mathrm{H}), 6.76-6.70(\mathrm{~m}, 1 \mathrm{H}$, Ar-H), 4.96-4.92 (m, 2H, $\left.\mathrm{COCH}_{2} \mathrm{O}\right), 4.58-4.44(\mathrm{~m}, 2 \mathrm{H}$, $\left.\mathrm{CH}_{2} \mathrm{O}\right), 4.19-4.10\left(\mathrm{~m}, 1 \mathrm{H}, \mathrm{CH}_{2} \mathrm{O}\right), 4.07-3.09(\mathrm{~m}, 1 \mathrm{H}$, $\left.\mathrm{CH}_{2} \mathrm{O}\right)$, 3.88-3.72 (m, 5H, $\left.\mathrm{CH}_{2} \mathrm{O}\right), 3.60-3.43(\mathrm{~m}, 17 \mathrm{H}$, $\left.\mathrm{CH}_{2} \mathrm{O}\right), 3.34-3.28\left(\mathrm{~m}, 6 \mathrm{H}, \mathrm{CH}_{2} \mathrm{NH}\right), 3.20-3.18(\mathrm{~m}, 2 \mathrm{H}$, $\left.\mathrm{CH}_{2} \mathrm{NH}\right), 1.86-1.82\left(\mathrm{~m}, 27 \mathrm{H}, \mathrm{C}\left(\mathrm{CH}_{3}\right)_{3}\right), 1.46-1.39(\mathrm{~m}$, $\left.18 \mathrm{H},-\mathrm{OC}\left(\mathrm{CH}_{3}\right)_{3}\right) .{ }^{13} \mathrm{C}$ NMR $\left(\mathrm{DMF}-d_{7}\right): \delta 170.7,175.1$, 156.4, 154.8, 154.0, 139.8, 137.5, 131.8, 128.5, 123.4, 119.8, 116.4, 114.9, 114.7 (Ar-C), 79.9, $78.7\left(\mathrm{O}-\mathrm{C}\left(\mathrm{CH}_{3}\right)_{3}\right)$, 72.0, 71.71, 71.66, 71.5, 71.4, 71.3, 71.2, 71.0, 70.4, 69.9 $\left(\mathrm{CH}_{2} \mathrm{O}\right), 48.4,48.2,44.340 .1,39.9,38.4,36.8\left(\mathrm{~N}^{-\mathrm{CH}_{2}}\right)$, $32.6\left(\mathrm{Ar}-\mathrm{C}\left(\mathrm{CH}_{3}\right)_{3}\right), \quad 29.0, \quad 28.8 \quad\left(\mathrm{O}-\mathrm{C}\left(\mathrm{CH}_{3}\right)_{3}\right) . \quad$ MS

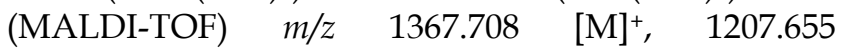
$\left[\mathrm{M}-2^{t} \mathrm{Bu}+\mathrm{K}\right]^{+}$; calcd for $\mathrm{C}_{72} \mathrm{H}_{93} \mathrm{~N}_{11} \mathrm{O}_{12} \mathrm{Zn}$ 1367.630, 
$\mathrm{C}_{62} \mathrm{H}_{78} \mathrm{KN}_{11} \mathrm{O}_{8} \mathrm{Zn}$ 1207.496. The blue solid (16.1 mg, $0.0118 \mathrm{mmol}$ ) was dissolved in a 1:1 mixture of $\mathrm{CH}_{2} \mathrm{Cl}_{2} /$ TFA $(6 \mathrm{~mL})$ and stirred at $0{ }^{\circ} \mathrm{C}$ for $3 \mathrm{~h}$. The solvent was removed under reduced pressure and the residue treated with $2 \mathrm{~N} \mathrm{NaOH}(10 \mathrm{~mL})$ to give a blue solid (12.5 mg, 91.0 \%). ${ }^{1} \mathrm{H}$ NMR (DMF- $\left.d_{7}\right)$ : $\delta$ 9.56-8.95 $(\mathrm{m}, 7 \mathrm{H}, \mathrm{Ar}-\mathrm{H}), 8.52-8.31(\mathrm{~m}, 3 \mathrm{H}, \mathrm{Ar}-\mathrm{H}), 8.13-8.03(\mathrm{~m}$, $1 \mathrm{H}, \mathrm{Ar}-\mathrm{H}), 7.83-7.70(\mathrm{~m}, 1 \mathrm{H}, \mathrm{Ar}-\mathrm{H}), 5.02-4.83(\mathrm{~m}, 2 \mathrm{H}$, $\left.\mathrm{COCH}_{2} \mathrm{O}\right), 4.59-4.35\left(\mathrm{~m}, 2 \mathrm{H}, \mathrm{CH}_{2} \mathrm{O}\right), 4.19-4.00(\mathrm{~m}, 2 \mathrm{H}$, $\left.\mathrm{CH}_{2} \mathrm{O}\right), 3.92-3.00\left(\mathrm{~m}, 22 \mathrm{H}, \mathrm{CH}_{2} \mathrm{O}\right), 1.79(\mathrm{~s}, 27 \mathrm{H}$, $\left.\mathrm{C}\left(\mathrm{CH}_{3}\right)_{3}\right) .{ }^{13} \mathrm{C}$ NMR $\left(\mathrm{DMF}-d_{7}\right): \delta 171.2,170.9,170.3$, $157.3,155.0,154.4,154.1,154.0,142.2,140.3,140.1$, $138.0,137.7,131.6,129.0,128.3,126.9,123.6,123.3$, 119.8, 116.5, 115.0, 114.7 (Ar-C), 71.9, 71.6, 71.4, 71.3, $71.2,71.1,70.8,70.6,70.1,69.6\left(\mathrm{CH}_{2} \mathrm{O}\right), 49.1,48.0,47.5$, $47.0,46.6,46.3,45.9,45.8,44.6,44.3,39.6,38.8,36.8$ $\left(\mathrm{N}-\mathrm{CH}_{2}\right), 32.6\left(\mathrm{Ar}-\mathrm{C}\left(\mathrm{CH}_{3}\right)_{3}\right)$. MS (MALDI-TOF) $\mathrm{m} / \mathrm{z}$ $1167.520[\mathrm{M}]^{+}$, calcd for $\mathrm{C}_{62} \mathrm{H}_{77} \mathrm{~N}_{11} \mathrm{O}_{8} \mathrm{Zn} 1167.525$. UV-vis (DMF): $\lambda_{\max }(\log \varepsilon) 346$ (4.77), 615 (4.55), 683 (5.31) $\mathrm{nm}$.

$\mathrm{ZnPc} 15 \mathrm{~b}$. A procedure similar to the one described above for $\mathrm{ZnPc}$ 3a was used: $\mathrm{ZnPc} \mathbf{1 4 b}$ (20.0 $\mathrm{mg}, 0.018 \mathrm{mmol}), \mathrm{DMF}(0.4 \mathrm{~mL}), \mathrm{Et}_{3} \mathrm{~N}(3.2 \mathrm{mg}, 0.032$ $\mathrm{mmol})$ HOBt $(4.7 \mathrm{mg}, \quad 0.035 \mathrm{mmol})$, 1,4-bis-Boc-triazaheptane $(7.0 \mathrm{mg}, 0.023 \mathrm{mmol})$, and EDCI $(4.0 \mathrm{mg}, 0.026 \mathrm{mmol})$. The protected $\mathrm{ZnPc}$ was obtained as a blue solid (17.1 mg, 65.6\%). ${ }^{1} \mathrm{H}$ NMR $\left(\mathrm{DMF}-d_{7}\right): \delta$ 9.58-9.52 (m, 3H, Ar-H), 9.46-9.22 (m, 4H, Ar-H), 8.96-8.88 (m, 1H, Ar-H), 8.45-8.38 (m, 3H, Ar-H), 7.82-7.76 (m, 2H, Ar-H), 6.76-6.70 (m, 1H, Ar-H), 4.73-4.70 (m, 2H, $\left.\mathrm{COCH}_{2} \mathrm{O}\right), 4.49-4.44(\mathrm{~m}, 2 \mathrm{H}$, $\left.\mathrm{CH}_{2} \mathrm{O}\right)$, 3.89-3.82 (m, $\left.4 \mathrm{H}, \mathrm{CH}_{2} \mathrm{O}\right), 3.77-3.72(\mathrm{~m}, 2 \mathrm{H}$, $\left.\mathrm{CH}_{2} \mathrm{O}\right), 3.69-3.58\left(\mathrm{~m}, 14 \mathrm{H}, \mathrm{CH}_{2} \mathrm{O}\right), 3.35-3.28(\mathrm{~m}, 6 \mathrm{H}$, $\left.\mathrm{CH}_{2} \mathrm{NH}\right), 3.20-3.18\left(\mathrm{~m}, 2 \mathrm{H}, \mathrm{CH}_{2} \mathrm{NH}\right), 1.82-1.80(\mathrm{~m}$, $\left.27 \mathrm{H}, \quad \mathrm{C}\left(\mathrm{CH}_{3}\right)_{3}\right), \quad 1.45-1.36\left(\mathrm{~m}, 18 \mathrm{H},-\mathrm{OC}\left(\mathrm{CH}_{3}\right)_{3}\right)$. ${ }^{13} \mathrm{CNMR}\left(\mathrm{DMF}-d_{7}\right): \delta 170.7,162.2,157.1,156.5,154.9$, $154.8,154.7,154.3,154.2,141.7,139.9,137.5,133.4$, $132.8,132.1,131.4,130.4,128.4,123.4,120.8,119.9$, 119.8, 119.2, 115.0, 113.3, 107.4, 107.2 (Ar-C), 79.9, 78.7 $\left(\mathrm{O}-\mathrm{C}\left(\mathrm{CH}_{3}\right)_{3}\right), 71.74,71.68,71.51,71.48,71.41,71.37$, 71.34, 71.30, 71.1, 70.8, $69.6\left(\mathrm{OCH}_{2}\right), 48.4,48.2,48.0$, 47.6, 47.4, 46.1 40.9, 40.1, 39.9, 38.4, $36.8\left(\mathrm{~N}-C H_{2}\right), 32.6$ $\left(\mathrm{Ar}-\mathrm{C}\left(\mathrm{CH}_{3}\right)_{3}\right), \quad 29.0, \quad 28.8 \quad\left(\mathrm{O}-\mathrm{C}\left(\mathrm{CH}_{3}\right)_{3}\right) . \quad$ MS (MALDI-TOF) $m / z$ 1267.606 [M-tBu] ${ }^{+}$, calcd for $\mathrm{C}_{67} \mathrm{H}_{85} \mathrm{~N}_{11} \mathrm{O}_{10} \mathrm{Zn}$ 1267.577. The blue solid (17.1 mg, $0.013 \mathrm{mmol}$ ) was dissolved in a 1:1 mixture of $\mathrm{CH}_{2} \mathrm{Cl}_{2} /$ TFA $(6 \mathrm{~mL})$ and stirred at $0{ }^{\circ} \mathrm{C}$ for $3 \mathrm{~h}$. The solvent was removed under reduced pressure and the residue treated with $2 \mathrm{~N} \mathrm{NaOH}(10 \mathrm{~mL})$ to obtain a blue solid $(13.5 \mathrm{mg}, 92.8 \%)$. ${ }^{1} \mathrm{H}$ NMR $\left(\mathrm{DMF}-d_{7}\right)$ : $\delta$ 9.60-9.25 (m, 7H, Ar-H), 9.15-8.91 (m, 1H, Ar-H), 8.52-8.31 (m, 3H, Ar-H), 7.89-7.73 (m, 1H, Ar-H), 4.74-4.63 (m, $\left.2 \mathrm{H}, \mathrm{COCH}_{2} \mathrm{O}\right), 4.19-4.05\left(\mathrm{~m}, 3 \mathrm{H}, \mathrm{CH}_{2} \mathrm{O}\right)$, 3.92-3.45 (m, 29H, $\left.\mathrm{CH}_{2} \mathrm{O}\right)$, 3.29-3.10 (m, $\left.6 \mathrm{H}, \mathrm{CH}_{2} \mathrm{NH}\right)$ $1.80\left(\mathrm{~s}, 27 \mathrm{H}, \mathrm{C}\left(\mathrm{CH}_{3}\right)_{3}\right) .{ }^{13} \mathrm{C}$ NMR $\left(\mathrm{DMF}-d_{7}\right): \delta 171.6$, $162.1,160.2$, 159.7, 155.0, 154.6, 154.4, 154.1, 153.9, $141.9,140.1,137.7,133.1,128.2,124.7,123.3,119.8$, 119.1, 107.2 (Ar-C), 71.72, 71.67, 71.6, 71.4, 71.3, 71.2, 71.0, 70.7, $69.6\left(\mathrm{OCH}_{2}\right), 49.0,46.5,38.4,37.4,36.7$ $\left(\mathrm{N}-\mathrm{CH}_{2}\right), 32.6\left(\mathrm{Ar}-\mathrm{C}\left(\mathrm{CH}_{3}\right)_{3}\right)$. MS (MALDI-TOF) $\mathrm{m} / \mathrm{z}$ $1167.531[\mathrm{M}]^{+}$, calcd for $\mathrm{C}_{62} \mathrm{H}_{77} \mathrm{~N}_{11} \mathrm{O}_{8} \mathrm{Zn} 1167.525$. UV-vis (DMF): $\lambda_{\max }(\log \varepsilon) 352$ (4.90), 611 (4.61), 678 (5.35) $\mathrm{nm}$.

$\mathrm{ZnPc} 16 a$. A procedure similar to the one described above for ZnPc 4a was used: $\mathrm{ZnPc}$ 15a (20.0 $\mathrm{mg}, 0.017 \mathrm{mmol})$, DIPA (0.015 mL, $0.107 \mathrm{mmol}), \mathrm{CH}_{3} \mathrm{I}$ $(0.2 \mathrm{~mL})$ and dry DMF $(0.5 \mathrm{~mL})$. The title $\mathrm{ZnPc}$ was obtained (17.4 mg, 67.4\%). ${ }^{1} \mathrm{H}$ NMR (DMF- $\left.d_{7}\right): \delta$ 9.57-9.34 (m, 6H, Ar-H), 9.13-8.99 (m, 1H, Ar-H), 8.38-8.18 (m, 3H, Ar-H), 8.20-8.09 (m, 1H, Ar-H), 7.88-7.72 (m, $1 \mathrm{H}, \mathrm{Ar}-\mathrm{H})$, 5.03-4.94 (m, $\left.2 \mathrm{H}, \mathrm{COCH}_{2}\right)$, 4.65-4.36 $\left(\mathrm{m}, 2 \mathrm{H}, \quad \mathrm{CH}_{2} \mathrm{O}\right), 4.15-3.51 \quad(\mathrm{~m}, 28 \mathrm{H}$, $\left.\mathrm{CH}_{2} \mathrm{O} / \mathrm{N}-\mathrm{CH} 2 / \mathrm{N}_{-} \mathrm{CH}_{3}\right), 3.43\left(\mathrm{~s}, 9 \mathrm{H}, \mathrm{N}-\mathrm{CH}_{3}\right), 1.83-1.79$ $\left(\mathrm{m}, 27 \mathrm{H}, \mathrm{C}\left(\mathrm{CH}_{3}\right)_{3}\right) .{ }^{13} \mathrm{C}$ NMR $\left(\mathrm{DMF}-d_{7}\right): \delta 171.7,170.5$ $(\mathrm{C}=\mathrm{O}), 157.5,157.4,155.1,155.0,154.8,154.5,154.1$, 154.0, 142.3, 142.2, 142.1, 140.4, 140.0, 138.0, 137.7, 131.7, 128.4, 126.9, 123.6, 123.3, 119.9, 119.8, 116.5, 115.0, 114.8 (Ar-C), 72.1, 72.0, 71.8, 71.7, 71.4, 71.2, 71.0, 70.7, 70.5, $70.2\left(\mathrm{CH}_{2} \mathrm{O}\right), 64.5,54.5,53.5,52.5,52.2,51.4$, $48.2\left(\mathrm{~N}^{\left.-\mathrm{CH}_{3}\right)}, 43.3,43.2,36.8\left(\mathrm{~N}^{\left.-\mathrm{CH}_{2}\right)} 32.7,32.6\right.\right.$

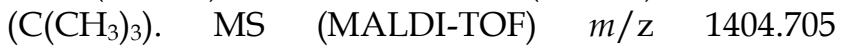
[M-I+2H+K]+; calcd for $\mathrm{C}_{67} \mathrm{H}_{90} \mathrm{IKN}_{11} \mathrm{O}_{8} \mathrm{Zn}^{+} 1404.495$. UV-Vis (DMF): $\lambda_{\max }(\log \varepsilon) 347$ (4.75), 615 (4.51), 682 (5.28) $\mathrm{nm}$.

$\mathrm{ZnPc} 16 \mathrm{~b}$. A similar procedure to the one described above for $\mathrm{ZnPc}$ 4a was used: $\mathrm{ZnPc} \mathbf{1 5 b}(20.0$ $\mathrm{mg}, 0.017 \mathrm{mmol})$, DIPA (0.015 mL, $0.107 \mathrm{mmol}), \mathrm{CH}_{3} \mathrm{I}$ $(0.2 \mathrm{~mL})$ and dry DMF $(0.5 \mathrm{~mL})$. The title $\mathrm{ZnPc}$ was obtained as a blue solid (16.2 $\mathrm{mg}, 62.8 \%) .{ }^{1} \mathrm{H}$ NMR $\left(\mathrm{DMF}-d_{7}\right)$ : $\delta$ 9.57-9.34 (m, 7H, Ar-H), 9.03-8.99 (m, 1H, Ar-H), 8.38-8.18 (m, 4H, Ar-H), 7.84-7.82 (m, 1H, $\mathrm{N}-\mathrm{H}), \quad 4.80-4.70 \quad\left(\mathrm{~m}, 2 \mathrm{H}, \mathrm{COCH}_{2}\right), 4.35$ (br, 2H, $\left.\mathrm{CH}_{2} \mathrm{O}\right), 4.15-3.51 \quad\left(\mathrm{~m}, 28 \mathrm{H}, \quad \mathrm{CH}_{2} \mathrm{O} / \mathrm{N}-\mathrm{CH} 2 / \mathrm{N}-\mathrm{CH}_{3}\right)$, 3.37 (s, 9H, N-CH 3$), 1.85-1.79\left(\mathrm{~m}, 27 \mathrm{H}, \mathrm{C}\left(\mathrm{CH}_{3}\right)_{3}\right) .{ }^{13} \mathrm{C}$ NMR (DMF- $\left.d_{7}\right): \delta 171.7(\mathrm{C}=\mathrm{O}), 162.0,155.0,154.5$, 154.3, 153.9, 151.2, 142.1, 140.2, 137.7, 133.2, 128.3, 128.1, 124.6, 123.2, 119.7, 119.0, 107.5, 107.3, 107.1 (Ar-C), 71.8, 71.7, 71.4, 71.3, 71.2, 71.1, 71.0, 70.7, 69.6 $\left(\mathrm{CH}_{2} \mathrm{O}\right), 64.3,58.6,57.2,55.9,54.3,52.4,47.9\left(\mathrm{~N}-\mathrm{CH}_{3}\right)$,

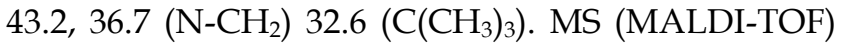
$\mathrm{m} / \mathrm{z} 1493.721[\mathrm{M}]^{+}, 1404.681[\mathrm{M}-\mathrm{I}-\mathrm{H}+\mathrm{K}]^{+}$; calcd for $\mathrm{C}_{67} \mathrm{H}_{89} \mathrm{I}_{2} \mathrm{~N}_{11} \mathrm{O}_{8} \mathrm{Zn}+1493.428, \quad \mathrm{C}_{67} \mathrm{H}_{88} \mathrm{IKN}_{11} \mathrm{O}_{8} \mathrm{Zn}^{+}$ 1404.479. UV-Vis (DMF): $\lambda_{\max }(\log \varepsilon) 351$ (4.81), 610 (4.50), 677 (5.26) $\mathrm{nm}$.

\section{Atomic Force Microscopy (AFM)}

A model 5500 or 5420 scanning probe microscope from Agilent (Chandler, AZ) was used for tap- 
ping-mode atomic force microscopy experiments. Picoview imaging software was used for data acquisition and analysis. Data files were processed using Gwyddion open source software, which is freely available on the internet and supported by the Czech Metrology Institute [37]. Rectangular tapping-mode probes with an average frequency of $164 \mathrm{kHz}$ with a highly reflective aluminum backside coating were purchased from MikroMasch (Estonia) for imaging samples in ambient conditions.

For the AFM sample preparation, Pc samples were dissolved in $10 \mathrm{~mL}$ of DMF to yield solutions of $100 \mu \mathrm{M}$ concentration. An aliquot of $10 \mu \mathrm{L}$ of the prepared solutions was deposited onto freshly cleaved mica(0001) and dried for 4 days before imaging.

\section{Cell studies}

Human carcinoma HEp2 cells were maintained in a 50:50 mixture of DMEM:AMEM (Invitrogen) supplemented with 5\% FBS (Invitrogen), Primocin antibiotic (Invitrogen) and $5 \% \mathrm{CO}_{2}$ at $37{ }^{\circ} \mathrm{C}$. The cells were subcultured twice weekly to maintain subconfluent stocks. The $4^{\text {th }}$ to $15^{\text {th }}$ passage cells were used for all the experiments.

Time-Dependent Cellular Uptake: The HEp2 cells were incubated at 7500 cells per well in a Costar 96-well plate and allowed to grow for $48 \mathrm{~h}$. The stock solutions for each $\mathrm{ZnPc}$ were prepared at $32 \mathrm{mM}$ in DMSO and diluted to give $20 \mu \mathrm{M}$ in medium (a $2 \mathrm{X}$ stock). Further dilution into the 96-well plate achieved a final concentration of $10 \mu \mathrm{M}$ with a maximum DMSO concentration of $1 \%$. Uptake was allowed to continue for $0,1,2,4,8,12$ and $24 \mathrm{~h}$, when it was terminated by removing the loading medium and washing the wells with PBS. Each Pc concentration was determined from standard curves using intrinsic fluorescence, measured with a BMG FLUOstar plate reader equipped with a $355 \mathrm{~nm}$ excitation and a 650 $\mathrm{nm}$ emission filter. Using a CyQuant cell proliferation assay (Invitrogen) as per manufacture's instruction, cells were measured and the uptake expressed in terms of $\mathrm{nM}$ compound concentration per cell.

Dark Cytotoxicity: The HEp2 cells were plated as described above and the compounds diluted into medium to give a final concentration of $400 \mu \mathrm{M}$. By preparing two-fold serial dilutions to $50 \mu \mathrm{M}$, the cells were incubated overnight and the cell toxicity measured using Promega's Cell Titer Blue Viability assay as per manufacturer's instructions. Untreated cells were considered $100 \%$ viable while cells treated with $0.2 \%$ saponin were considered to be $0 \%$ viable. The $\mathrm{IC}_{50}$ values were then determined from dose-response curves obtained using GraphPad Prism software.
Phototoxicity: The cells were plated as described above with $\mathrm{ZnPc}$ concentrations ranging from 6.25-100 $\mu \mathrm{M}$. After overnight loading, new medium containing $50 \mathrm{mM}$ HEPES pH 7.2 was introduced, replacing the former. The cells were then exposed to a NewPort light system equipped with a $175 \mathrm{~W}$ halogen lamp for $20 \mathrm{~min}$, filtered through a water filter to provide approximately $1.5 \mathrm{~J} / \mathrm{cm}^{2}$ light dose. The culture was kept on a $5{ }^{\circ} \mathrm{C}$ Echotherm chilling/heating plate (Torrey Pines Scientific, Inc.) to keep the cells cool. After exposure to light, the plate was incubated overnight and the cell viability measured as described above for the dark cytotoxicity.

Microscopy: The cells were incubated in a glass bottom 6-well plate (MatTek) and allowed to grow for $48 \mathrm{~h}$. They were exposed to $10 \mu \mathrm{M}$ of each compound for $6 \mathrm{~h}$. Organelle tracers (from Invitrogen) were used at the following concentrations: LysoSensor Green 50 nM, MitoTracker Green 250 nM, ER Tracker Blue/white $100 \mathrm{nM}$, and BODIPY FL C5 ceramide 1 $\mu \mathrm{M}$. The tracers were diluted in medium and the cells incubated concurrently with $\mathrm{ZnPc}$ and tracers for 30 min before washing 3 times with PBS. Microscopy images were acquired using a Leica DMRXA microscope with a $40 \times$ NA 0.8 dip objective lens and DAPI, GFP and Texas Red filter cubes (Chroma Technologies).

\section{Results and Discussion}

\section{Syntheses}

The di-cationic ZnPcs 4a, $\mathbf{b}, \mathbf{6} \mathbf{a}, \mathbf{b}, \mathbf{9 a}, \mathbf{b}, \mathbf{1 1} \mathbf{a}, \mathbf{b}$, and $\mathbf{1 6} \mathbf{a}, \mathbf{b}$ were synthesized as shown in Schemes 1 and 2 (Figure A and Figure B), from 3- or 4-nitrophthalonitrile (12a, $\mathbf{b})$. The ZnPcs $\mathbf{1 a}, \mathbf{b}$ and $\mathbf{2} \mathbf{a}, \mathbf{b}$ were prepared according to procedures previously reported [35,36]. In brief, the nitrophthalonitrile reacted with $p$-N-Boc-aminophenol in DMF at $80{ }^{\circ} \mathrm{C}$ under basic conditions to give the corresponding $p$-N-Boc-aminophenoxy)phthalonitriles, which were heated at $140{ }^{\circ} \mathrm{C}$ in dimethylaminoethanol (DMAE) and in the presence of zinc(II) acetate, 3 equiv. 4-tert-butylphthalonitrile and a catalytic amount of 1,5-diazabicyclo(4.3.0)non-5-ene (DBN), giving the Boc-protected $\alpha$ - or $\beta$-substituted $\mathrm{A}_{3} \mathrm{~B}$-type ZnPcs in $15-20 \%$ yields [35]. Deprotection of the Boc groups using TFA followed by reaction with diglycolic anhydride gave $\mathrm{ZnPcs} \mathbf{1} \mathbf{a}, \mathbf{b}$, which were conjugated with commercially available tert-butyl-12-amino-4,7,10-trioxadodecanoate, using 1-hydroxybenzotriazole (HOBt), 1-ethyl-3-(3-dimethylaminopropyl)-carbodiimide hydrochloride (EDCI) and triethylamine (TEA) in DMF to produce pegylated ZnPcs $\mathbf{2} \mathbf{a}, \mathbf{b}$ after deprotection with TFA 
[36,38]. Reaction of ZnPcs $\mathbf{1 a}, \mathbf{b}$ and $\mathbf{2} \mathbf{a}, \mathbf{b}$ with 1,4-bis(N-Boc)-triazaheptane under similar coupling conditions, followed by TFA-mediated Boc-deprotection gave ZnPcs $\mathbf{5 a}, \mathbf{b}$ and $\mathbf{3} \mathbf{a}, \mathbf{b}$, respectively, in $72-79 \%$ yields. Quaternization of the amino groups using excess methyl iodide and diisopropylamine (DIPA) in DMF [35] gave the corresponding di-cationic ZnPcs $\mathbf{6} \mathbf{a}, \mathbf{b}$ and $\mathbf{4 a}, \mathbf{b}$ in $53-68 \%$ yields. The branched ZnPcs $7 \mathbf{a}, \mathbf{b}$ were prepared via reaction of $\mathbf{1 a}, \mathbf{b}$ with di-tert-butyl ester protected L-aspartic acid in DMF, using TEA and 2-(1H-azabenzotriazol-1-yl)-1,1,3,3-tetramethyluroniu $\mathrm{m}$ hexafluorophosphate (HATU) and HOBt, followed by deprotection with TFA [39]. The dicarboxylate terminated ZnPcs $\mathbf{7 a}, \mathbf{b}$ were coupled to $N$-Boc-2,2'-(ethylenedioxy)diethylamine or $\mathrm{N}$-Boc-ethylenediamine using TEA, HOBt and EDCI, giving $\mathrm{ZnPcs} \mathbf{8} \mathbf{a}, \mathbf{b}$ and $\mathbf{1 0} \mathbf{a}, \mathbf{b}$ respectively, which were quaternized as described above, affording the di-cationic ZnPcs 9a,b and 11a,b in 59-68\% yields

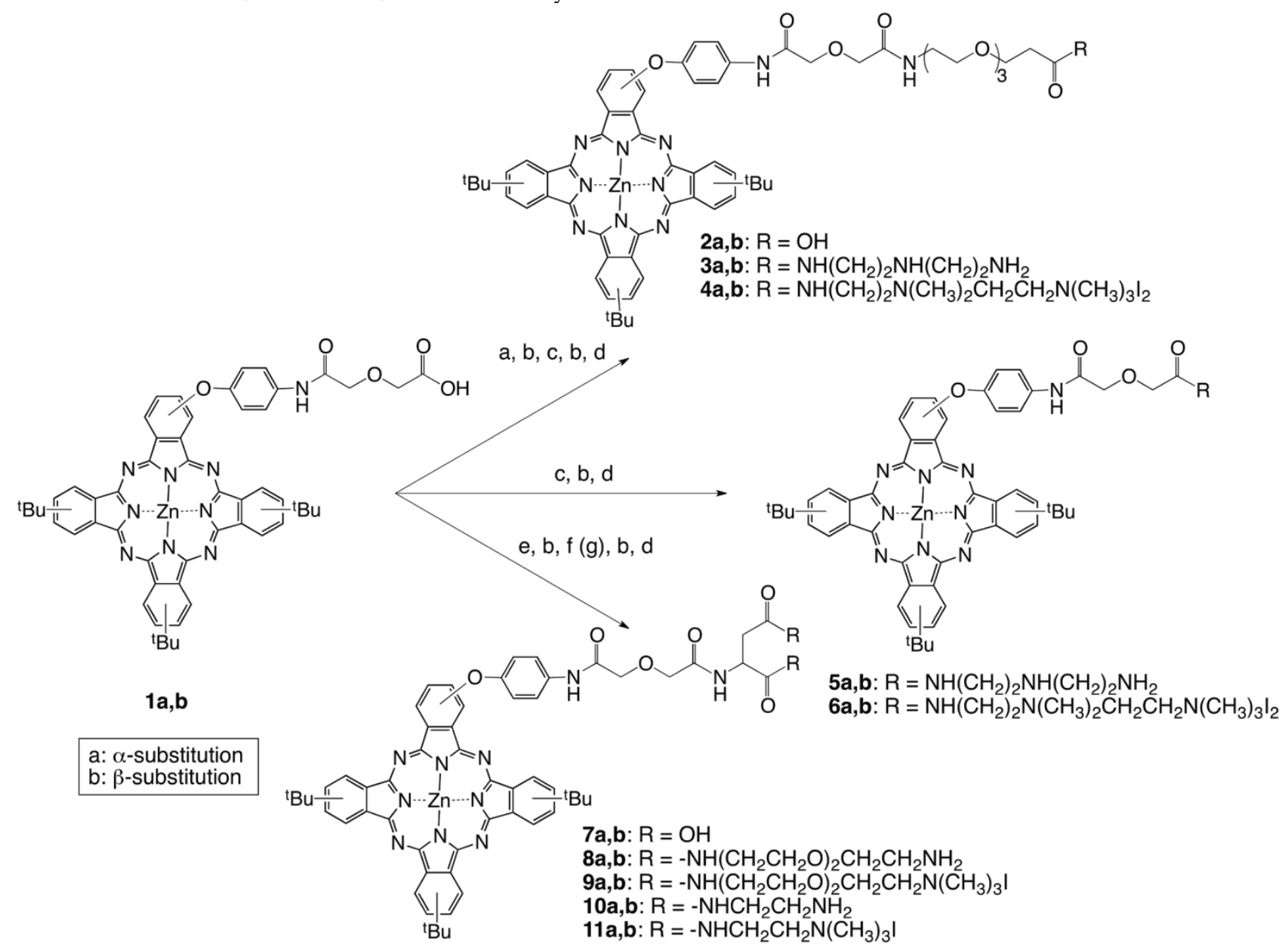

(Scheme 1/Figure A).

Phthalonitriles $\mathbf{1 3} \mathbf{a}, \mathbf{b}$ were obtained from reaction of tert-butyl 20-hydroxy-3,6,9,12,15,18hexaoxaicosan-1-oate, prepared in $38 \%$ yield following a published procedure [40], with 3- or 4-nitrophthalonitrile in THF at $65^{\circ} \mathrm{C}$, in the presence of $\mathrm{K}_{2} \mathrm{CO}_{3}$ [35] (Scheme 2/Figure B). Cyclotetramerization of phthalonitriles $\mathbf{1 3} \mathbf{a}, \mathbf{b}$ with excess 4-tert-butylphthalonitrile in the presence of zinc(II) acetate and a catalytic amount of DBN in DMAE gave the corresponding $\mathrm{A}_{3} \mathrm{~B}$-type $\mathrm{ZnPcs} \mathbf{1 4 a}$, $\mathbf{b}$ in about $12 \%$ yield, after deprotection of the tert-butyl group using TFA at room temperature. Conjugation of the pegylated ZnPcs 14a,b with 1,4-bis(N-Boc)-triazaheptane using TEA, HOBt and EDCI, followed by cleavage of the Boc group gave ZnPcs 15a,b in 58-61\% yields. Quaternization as described above gave the corresponding di-cationic ZnPcs $16 a, b$ in $63-67 \%$ yields.

Figure A. (Scheme I) Synthesis of dicationic ZnPcs 4, 6, 9 and II. Reaction conditions: (a) tert-butyl-I2-amino-4,7,10-trioxadodecanoate, TEA, HOBt, EDCl, DMF (77-82\%); (b) TFA, $\mathrm{CH}_{2} \mathrm{Cl}_{2} .0{ }^{\circ} \mathrm{C}, 3 \mathrm{~h}$ (82-92\%); (c) I,4-bis(N-Boc)-triazaheptane, TEA, HOBt, EDCI, DMF (77-89\%); (d) $\mathrm{CH}_{3}$ l, DIPA, DMF (59-68\%); (e) L-aspartic acid di(tert-butyl) ester, TEA, HATU, DMF (87-89\%); (f) N-Boc-2,2'-(ethylenedioxy)diethylamine, TEA, HOBt, EDCI, DMF (5I-52\%); (g) N-Boc-ethylenediamine, TEA, HOBt, EDCI, DMF (58-62\%). 


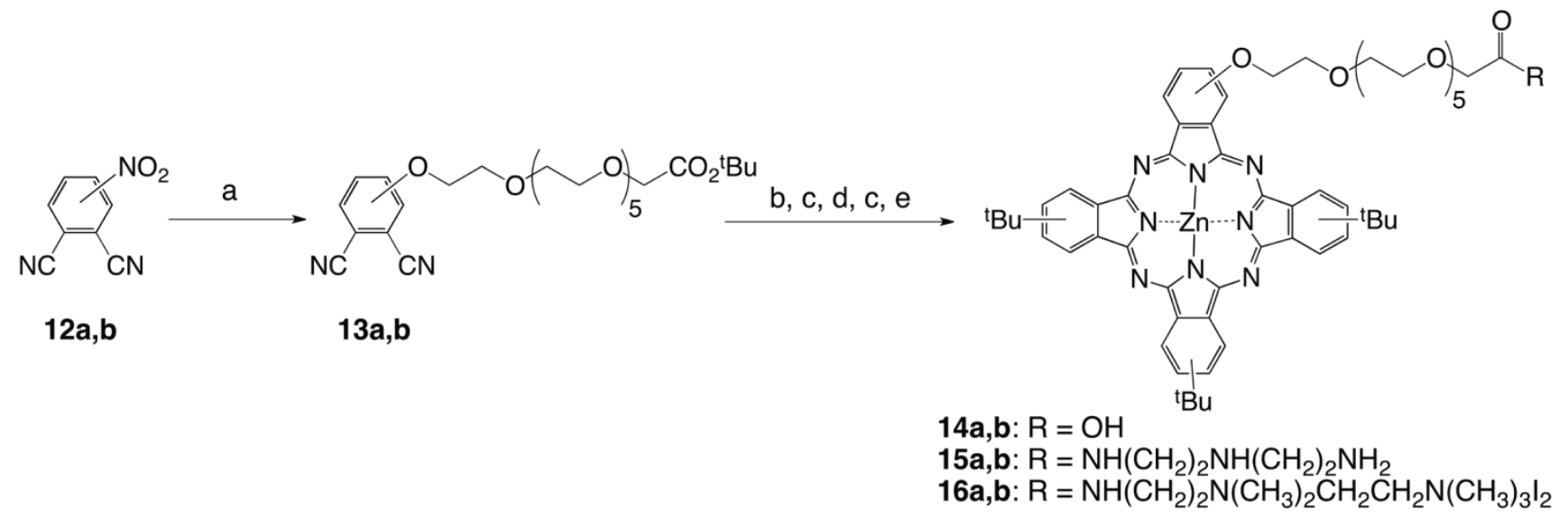

Figure B. (Scheme 2) Synthesis of pegylated ZnPc 16. Reaction conditions: (a) tert-butyl-20-hydroxy-3,6,9,I2, I5, I8-hexaoxaicosan-I-oate, $\mathrm{K}_{2} \mathrm{CO}_{3}$, THF, $65 \circ \mathrm{C}, 6 \mathrm{~h}$ (78\%); (b) 4-tert-butylphthalonitrile, Zn(OAc)2,

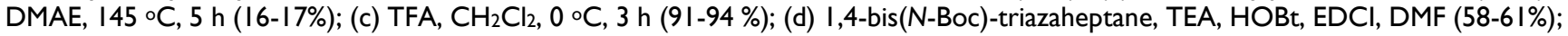
(e) $\mathrm{CH}_{3}$ l, DIPA, DMF, r.t., 2 d (59-67\%).
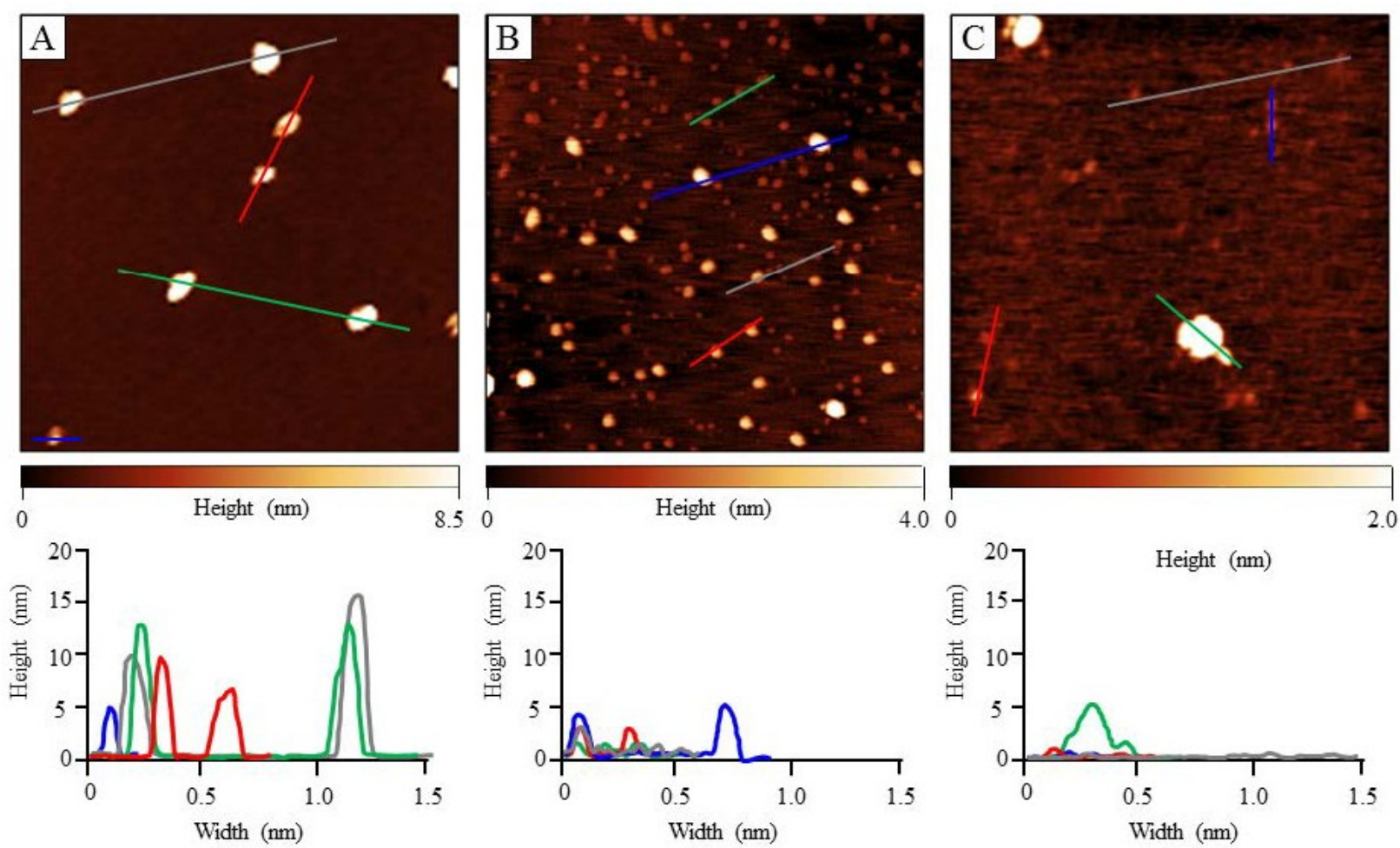

Figure I. Side-by-side comparison of sample aggregation on surfaces of mica(000I). Topography images of Pcs (A) 6a, (B) 2b, and (C) 16a, with corresponding cursor profiles. The frame sizes are $2 \times 2 \mu \mathrm{m}^{2}$, acquired in ambient air using tapping-mode AFM.

All di-cationic ZnPcs 4a,b, 6a, b, 9a, b, 11a,b, and $16 \mathbf{a}, \mathbf{b}$ are soluble in polar organic solvents, such as DMF, THF and methanol, but none of the cationic Pcs was water soluble; they remained aggregated in water, even upon sonication. To compare how the samples self-assemble into aggregate structures, AFM studies were accomplished using tapping-mode for samples prepared on mica surfaces. Topography views are shown in Figure 1 for samples of Pcs $\mathbf{6 a}, \mathbf{2} \mathbf{b}$, and 16a. Considerable differences are apparent for the heights and surface coverage of the samples. The largest aggregates were revealed for the non-pegylated Pc $6 \mathbf{a}$, with an average height of $9.6 \pm$ $0.5 \mathrm{~nm}$ (mean \pm standard error, $n=93$ ). Most of the 
clusters $(70 \%)$ ranged from 8 to $14 \mathrm{~nm}$ in height. The smallest clusters were observed for Pc 16a containing a longer PEG chain than $\mathbf{2 b}$, measuring $1.0 \pm 0.15 \mathrm{~nm}$ $(n=52)$. The average size of surface deposits for Pc $\mathbf{2} \mathbf{b}$ measured $1.1 \pm 0.1 \mathrm{~nm}$, with most of the clusters measuring 0.6 to $1.2 \mathrm{~nm}$ in height $(77 \%, n=227)$. The sizes were measured using height information obtained from individual cursor profiles within the images. The lateral dimensions of surface features depend closely on the AFM probe geometry and are not as reliable for estimating sizes. Comparing the samples using a t-test, the mean values for $\mathbf{1 6 a}$ and $\mathbf{2 b}$ indicate that the surface structures are essentially the same height. However, the size of the aggregates of Pc $\mathbf{6 a}$ is significantly larger than those of either Pcs $\mathbf{2 b}$ or 16a. The sizes of aggregates follow the trend: Pc $\mathbf{6 a}>>$ Pc $\mathbf{2 b}>$ Pc 16a.

Nevertheless, all Pcs remained in aqueous solution upon dilution from concentrated Pc stocks in DMF or DMSO into PBS (final DMF or DMSO concentration of $1 \%$ ) at $10 \mu \mathrm{M}$ concentrations, which were used for the cellular uptake and microscopy experi- ments (vide infra). Since the cationic ZnPcs undergo $N$-demethylation upon storage for over one week at room temperature, as we have previously observed [35], all cationic ZnPcs were characterized and investigated within 2-3 days of their purification.

The spectroscopic properties of the di-cationic ZnPcs 4a,b, 6a,b, 9a,b, 11a,b, 16a,b and their amine precursors in DMF are summarized in Table 1 and shown in Figure 2. No aggregation of the Pcs was apparent up to $10 \mu \mathrm{M}$ concentrations in DMF [42]. All $\mathrm{ZnPcs}$ showed strong $\mathrm{Q}$ absorptions and emissions in the near-IR between $679-686 \mathrm{~nm}$ in DMF, with small Stokes' shifts between $2-4 \mathrm{~nm}$, as is characteristic of this type of macrocycle [35,41-43]. All the ZnPcs show a Soret absorption between $330-360 \mathrm{~nm}$, a strong $\mathrm{Q}$ band between $677-683 \mathrm{~nm}$ and a vibrational band at around $620 \mathrm{~nm}$, that strictly follow the Lambert-Beer law. The ZnPcs had fluorescence quantum yields in the range $0.09-0.23$ in DMF, as expected for this type of compound $[35,41-43]$.

Table I. Spectroscopic Properties of ZnPcs in DMF at room temperature.

\begin{tabular}{|c|c|c|c|c|c|}
\hline $\mathrm{ZnPc}$ & Absorption $\lambda_{\max }(\mathrm{nm})$ & Emission $^{\mathrm{a}} \lambda_{\max }(\mathrm{nm})$ & Stokes' Shift (nm) & $\log \varepsilon\left(\mathrm{M}^{-1} \mathrm{~cm}^{-1}\right)$ & $\phi F^{b}$ \\
\hline $3 a$ & 680 & 684 & 4 & 5.52 & 0.23 \\
\hline $3 b$ & 677 & 680 & 3 & 5.28 & 0.15 \\
\hline $4 a$ & 679 & 683 & 4 & 5.32 & 0.15 \\
\hline $4 \mathrm{~b}$ & 677 & 680 & 3 & 5.30 & 0.14 \\
\hline $5 a$ & 680 & 684 & 4 & 5.19 & 0.19 \\
\hline $5 b$ & 677 & 679 & 2 & 5.19 & 0.20 \\
\hline $6 a$ & 679 & 682 & 3 & 5.23 & 0.21 \\
\hline $6 b$ & 676 & 679 & 3 & 5.31 & 0.15 \\
\hline $7 \mathrm{a}$ & 679 & 682 & 3 & 5.17 & 0.13 \\
\hline $7 \mathrm{~b}$ & 677 & 680 & 3 & 5.28 & 0.10 \\
\hline $8 a$ & 680 & 683 & 3 & 5.20 & 0.14 \\
\hline $8 b$ & 677 & 681 & 4 & 5.27 & 0.11 \\
\hline $9 \mathrm{a}$ & 680 & 683 & 3 & 5.01 & 0.14 \\
\hline $9 b$ & 677 & 680 & 3 & 5.01 & 0.11 \\
\hline $10 \mathrm{a}$ & 680 & 683 & 3 & 5.23 & 0.13 \\
\hline $10 \mathrm{~b}$ & 677 & 680 & 3 & 5.19 & 0.12 \\
\hline $11 a$ & 679 & 682 & 3 & 5.19 & 0.09 \\
\hline $11 b$ & 677 & 680 & 3 & 4.99 & 0.11 \\
\hline $14 \mathrm{a}$ & 681 & 684 & 3 & 5.34 & 0.19 \\
\hline $14 \mathrm{~b}$ & 676 & 680 & 4 & 5.14 & 0.19 \\
\hline $15 a$ & 683 & 686 & 3 & 5.31 & 0.21 \\
\hline $15 b$ & 678 & 681 & 3 & 5.35 & 0.18 \\
\hline $16 a$ & 682 & 685 & 3 & 5.28 & 0.18 \\
\hline $16 \mathrm{~b}$ & 677 & 680 & 3 & 5.26 & 0.17 \\
\hline
\end{tabular}

a Excitation at $640 \mathrm{~nm}$. ${ }^{\mathrm{b}}$ Calculated using ZnPc $\left(\Phi_{\mathrm{f}}=0.17\right)$ as the standard in DMF. 
a)

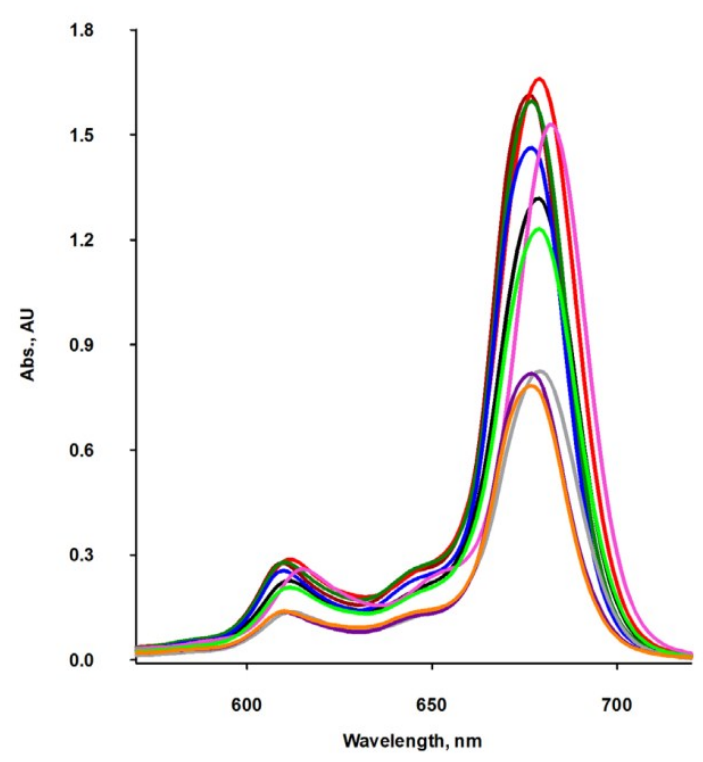

b)

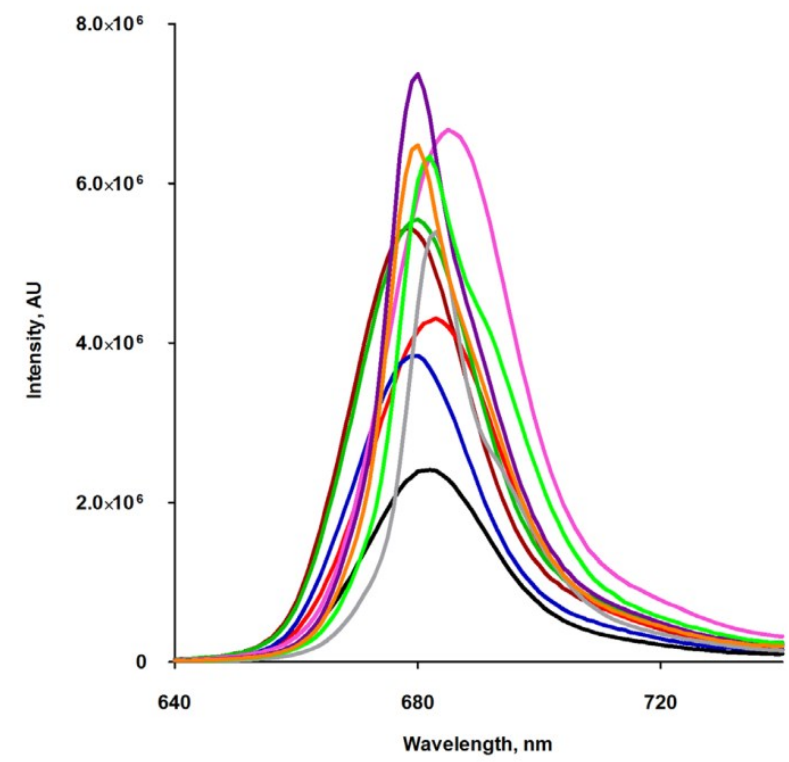

Figure 2. (a) Absorption and (b) fluorescence spectra for Pc 4a (red), 4b (green), 6a (black), 6b (brown), 9a (grey), 9b (purple), I la (light green), I Ib (orange), I6b (blue), I 6a (pink), at 8.0 and 0.5-0.8 $\mu$ M concentrations, respectively, in DMF.

\section{Biological Evaluation}

The biological properties of the cationic $\mathrm{ZnPcs}$ including time-dependent cellular uptake, cytotoxicity and intracellular localization, were investigated in human carcinoma HEp2 cells. The cytotoxicity was evaluated using Promega's Cell Titer Blue viability assay, as we have previously reported $[28,35,36,39,44]$ at concentrations up to $400 \mu \mathrm{M}$ for each di-cationic $\mathrm{ZnPc}$ and for the pegylated, neutral $\mathrm{ZnPc} \mathbf{2 b}$ (see Supplementary Material: Figure S9). The time-dependent uptake into HEp2 cells was investigated at a concentration of $10 \mu \mathrm{M}$ of each Pc up to $24 \mathrm{~h}$ (Figure 3). The subcellular sites of localization were observed by fluorescence microscopy, $6 \mathrm{~h}$ after exposure of HEp2 cells to each ZnPc (see Figures 4-6 and Supporting Information, Supplementary Material: Figures S1-S8). Co-localization experiments were conducted using the organelle specific fluorescent tracers: ER Tracker Blue/White (endoplasmic reticulum, ER), MitoTracker Green (mitochondria), BODIPY Ceramide (Golgi) and LysoSensor Green (lysosomes). Table 2 summarizes the results obtained from these studies. Our results show that all the a-substituted $\mathrm{ZnPcs}$ are much more toxic than the corresponding $\beta$-substituted ZnPcs, both in the dark and upon exposure to approx. $1.5 \mathrm{~J} / \mathrm{cm}^{2}$ light dose. We had previously observed that the cytotoxicity of cationic Pcs depends on the substitution at the macrocycle periphery, and that the a-substituted compounds tend to be more toxic than the corresponding $\beta$-substituted Pcs [35]. This might be due to their increased electron density of the ring and distinct conformations, as shown in Supplementary Material: Figure S21; the $\beta$-substituted di-cationic $\mathrm{ZnPcs}$ tend to adopt more extended conformations than the $\alpha$-substituted analogues. All ZnPcs had very low toxicity in the dark $\left(\mathrm{IC}_{50}>180 \mu \mathrm{M}\right)$, in particular the branched dicationic Pcs $\mathbf{9 a}, \mathbf{b}$ and 11a,b which showed remarkable low dark toxicity $\left(\mathrm{IC}_{50}>400 \mu \mathrm{M}\right)$, maybe due to their very low uptake into cells (see Figure 3). Upon irradiation with low light dose $\left(\sim 1.5 \mathrm{~J} / \mathrm{cm}^{2}\right)$ all $\beta$-substituted ZnPcs were non-toxic up to $100 \mu \mathrm{M}$ concentrations, with the exception of $\mathbf{1 1} \mathbf{b}$, which was moderately phototoxic $\left(\mathrm{IC}_{50}=47 \mu \mathrm{M}\right)$. The most phototoxic compounds were the a-substituted ZnPcs 4a, 6a, 9a, 11a and 16a, with determined IC 50 values (calculated from dose-response curves, see Supporting Information) of $10.7,14.8,28.8,12.7$ and $8.7 \mu \mathrm{M}$, respectively. Of this series, Pcs 4a, 11a and 16a are the most promising for PDT applications due to their high ratio $(>25)$ of dark/photo cytotoxicity and high phototoxicity. It is interesting to note that the most phototoxic Pcs (4a and 16a) contain a PEG group, the two positive charges in close proximity (separated only by an ethylene group), and both localize in the cell ER. It is possible that pegylation of Pc macrocycles favors intracellular localization in the ER, as we have previously observed [38], whereas the positive charges 
might favor localization at the plasma membrane and subcellularly in mitochondria and lysosomes [44-47]. On the other hand, the $\beta$-substituted ZcPcs $\mathbf{6 b}$ and $\mathbf{4 b}$ accumulated within HEp2 cells to a much higher extent than all other Pcs. The cellular uptake of the non-pegylated Pc $\mathbf{6 b}$ was the fastest of all ZnPcs, although it slowed down to a plateau $8 \mathrm{~h}$ after exposure, while Pc $\mathbf{4 b}$ continued to accumulate within cells up to the $24 \mathrm{~h}$ period investigated, probably as a result of its PEG group. Furthermore, the di-cationic Pcs bearing the two charges in close proximity on the same chain, showed increased uptake compared with the neutral Pc-PEG $\mathbf{2} \mathbf{b}$, as well as to the cationic Pcs $\mathbf{9 a}, \mathbf{b}$ and $\mathbf{1 1} \mathbf{a}, \mathbf{b}$ bearing the charges on two side branches. All cationic ZnPcs localized in multiple sites within the cell, with exception of $\mathbf{9 b}$ which was mainly found in lysosomes (Table 2). In addition, ZnPcs 4a, 6a, 11a and $\mathbf{1 6 b}$ were observed at the plasma membrane. The most phototoxic compounds 4a, 11a and 16a all localized within the ER, an important organelle that regulates protein synthesis and stress responses, potentially leading to PDT-induced cell apoptosis [48,49]. Our results show that the intracellular localization of the $\mathrm{ZnPcs}$, rather than the extent of their cellular uptake, and their charge distribution mainly determine their photodynamic activity, probably as a result of their different interactions with intracellular components.

Table 2. Cytotoxicity and intracellular sites of localization for ZnPcs in HEp2 cells.

\begin{tabular}{|c|c|c|c|c|}
\hline $\mathrm{ZnPc}$ & $\begin{array}{l}\text { Dark } \\
\text { toxicity } \\
\left(\mathrm{IC}_{50},\right. \\
\mu \mathrm{M})\end{array}$ & $\begin{array}{l}\text { Phototoxicity } \\
\text { (IC } 50, \mu \mathrm{M})\end{array}$ & Ratio & $\begin{array}{l}\text { Major }(++) \text { and minor }(+) \\
\text { sites of localization }\end{array}$ \\
\hline $2 b$ & 397.3 & $>100.0$ & $>4.0$ & $\begin{array}{l}\text { Mitochondria(++), ER(+), } \\
\text { Golgi(+) }\end{array}$ \\
\hline $4 a$ & 351.7 & 10.7 & 32.9 & $\begin{array}{l}\text { ER(++), Golgi } \\
(+), \text { Lysosomes }(+)\end{array}$ \\
\hline $4 b$ & 280.0 & $>100.0$ & $>2.8$ & $\begin{array}{l}\text { Mitochondria(++), ER(+), } \\
\text { Golgi( }(++)\end{array}$ \\
\hline $6 a$ & 179.9 & 14.8 & 12.2 & Golgi(++), Lysosomes $(+)$ \\
\hline $6 b$ & 346.3 & $>100$ & $>3.5$ & $\begin{array}{l}\text { Mitochondria(++), Golgi(+), } \\
\text { Lysosomes }(++)\end{array}$ \\
\hline $9 a$ & $>400.0$ & 28.8 & $>13.9$ & $\begin{array}{l}\text { Lysosomes }(++) \text {, ER(+), Gol- } \\
\text { gi( }(+)\end{array}$ \\
\hline $9 b$ & $>400.0$ & $>100.0$ & $>4.0$ & Lysosomes $(++)$ \\
\hline $11 \mathrm{a}$ & $>400.0$ & 12.7 & $>31.5$ & $\begin{array}{l}\text { Lysosomes }(++) \text {, ER(+), Gol- } \\
\text { gi( }(+)\end{array}$ \\
\hline $11 \mathrm{~b}$ & $>400.0$ & $>100.0$ & $>4.0$ & Mitochondria $(++)$, Golgi $(+)$ \\
\hline $16 \mathrm{a}$ & 220.1 & 8.7 & 25.3 & $\begin{array}{l}\text { Mitochondria }(++), \text { ER }(++), \\
\text { Lysosomes }(+)\end{array}$ \\
\hline $16 b$ & 249.7 & 47.0 & 5.3 & ER(++), Lysosomes $(+)$ \\
\hline
\end{tabular}

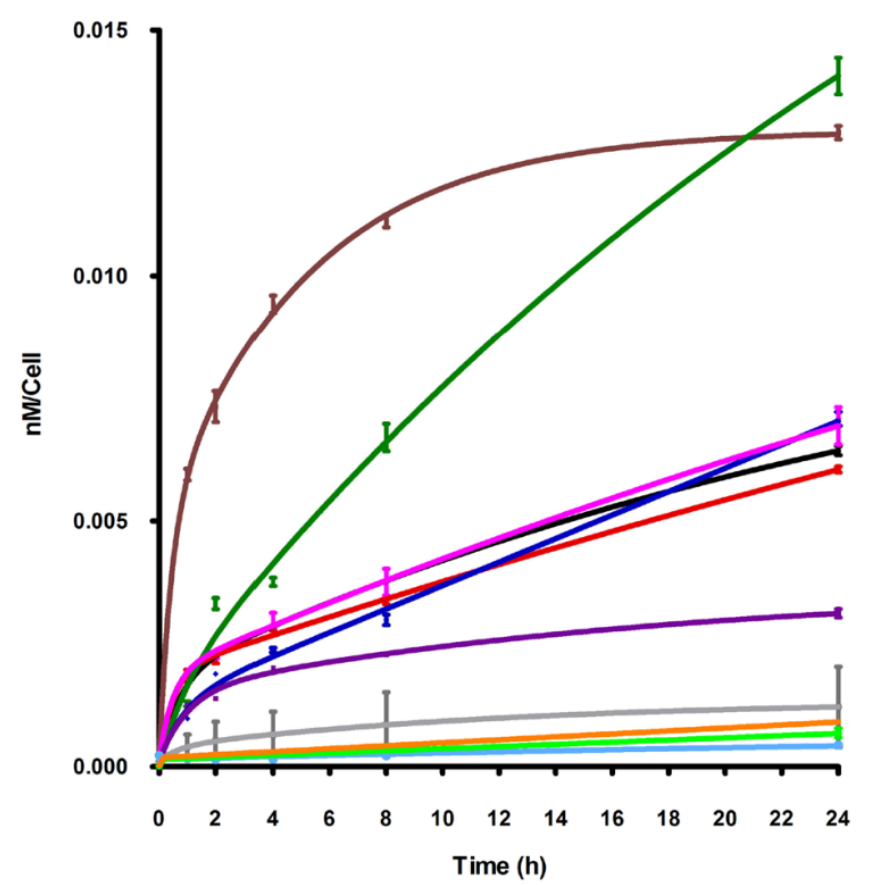

Figure 3. Time-dependent uptake of ZnPcs $\mathbf{2 b}$ (purple), $\mathbf{4 a}$ (red), $\mathbf{4 b}$ (green), $\mathbf{6 a}$ (black), $\mathbf{6 b}$ (brown), $\mathbf{9 a}$ (grey), $\mathbf{9 b}$ (light blue), I la (light green), I I b (orange), I6a (pink), I6b (blue) at $10 \mu \mathrm{M}$ in HEp2 cells. 


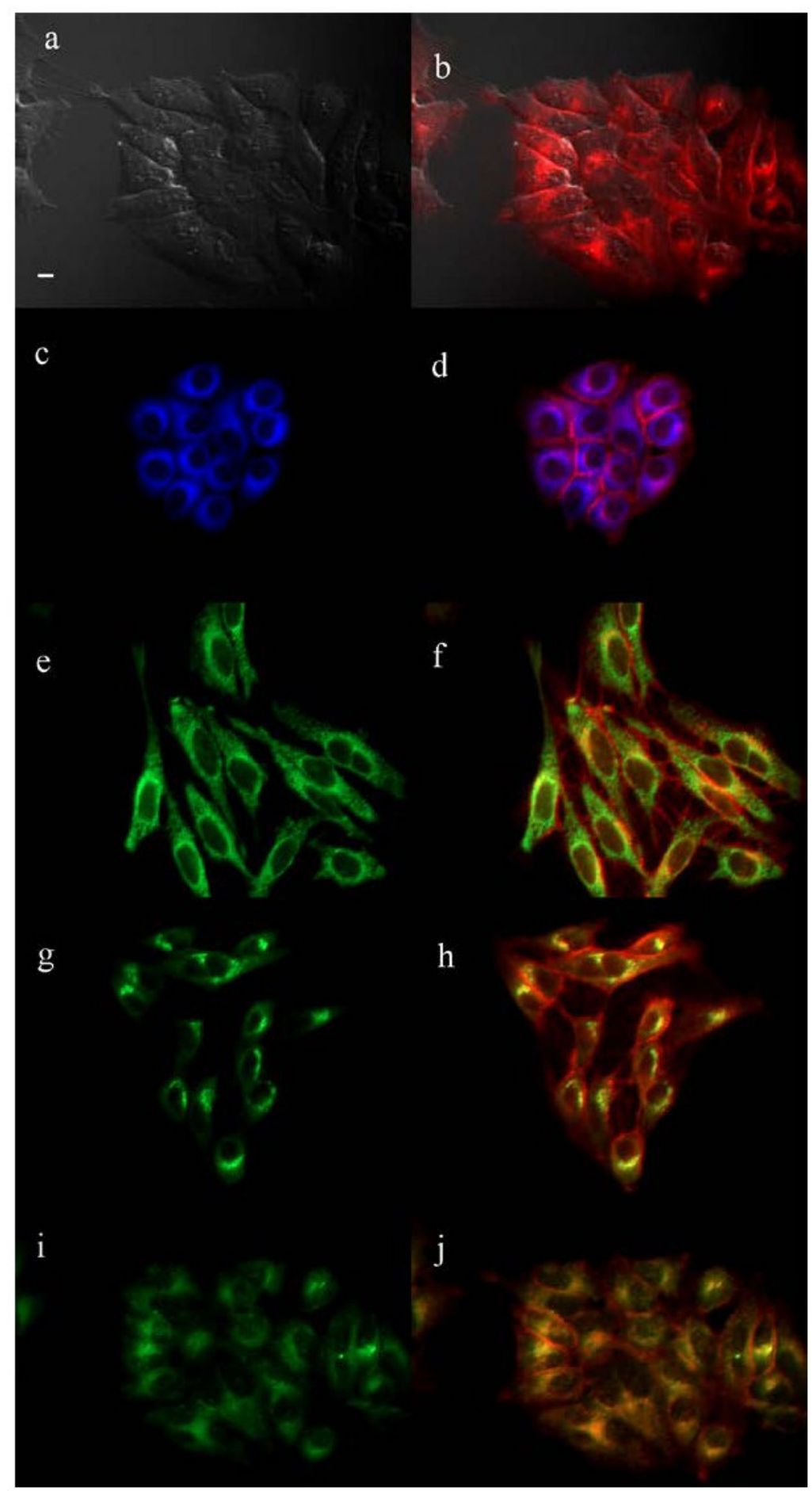

Figure 4. Subcellular localization of $\mathrm{ZnPc} 4 \mathrm{a}$ in HEp2 cells at $10 \mu \mathrm{M}$ for $6 \mathrm{~h}$. (a) Phase contrast, (b) Overlay of $4 \mathrm{a}$ fluorescence and phase contrast, (c) ER Tracker Blue/White fluorescence, (e) MitoTracker green fluorescence, (g) BODIPY Ceramide fluorescence, (i) LysoSensor green fluorescence, and $(d, f, h, j)$ overlays of organelle tracers with $\mathbf{4 a}$ fluorescence. Scale bar: $10 \mu \mathrm{m}$. 


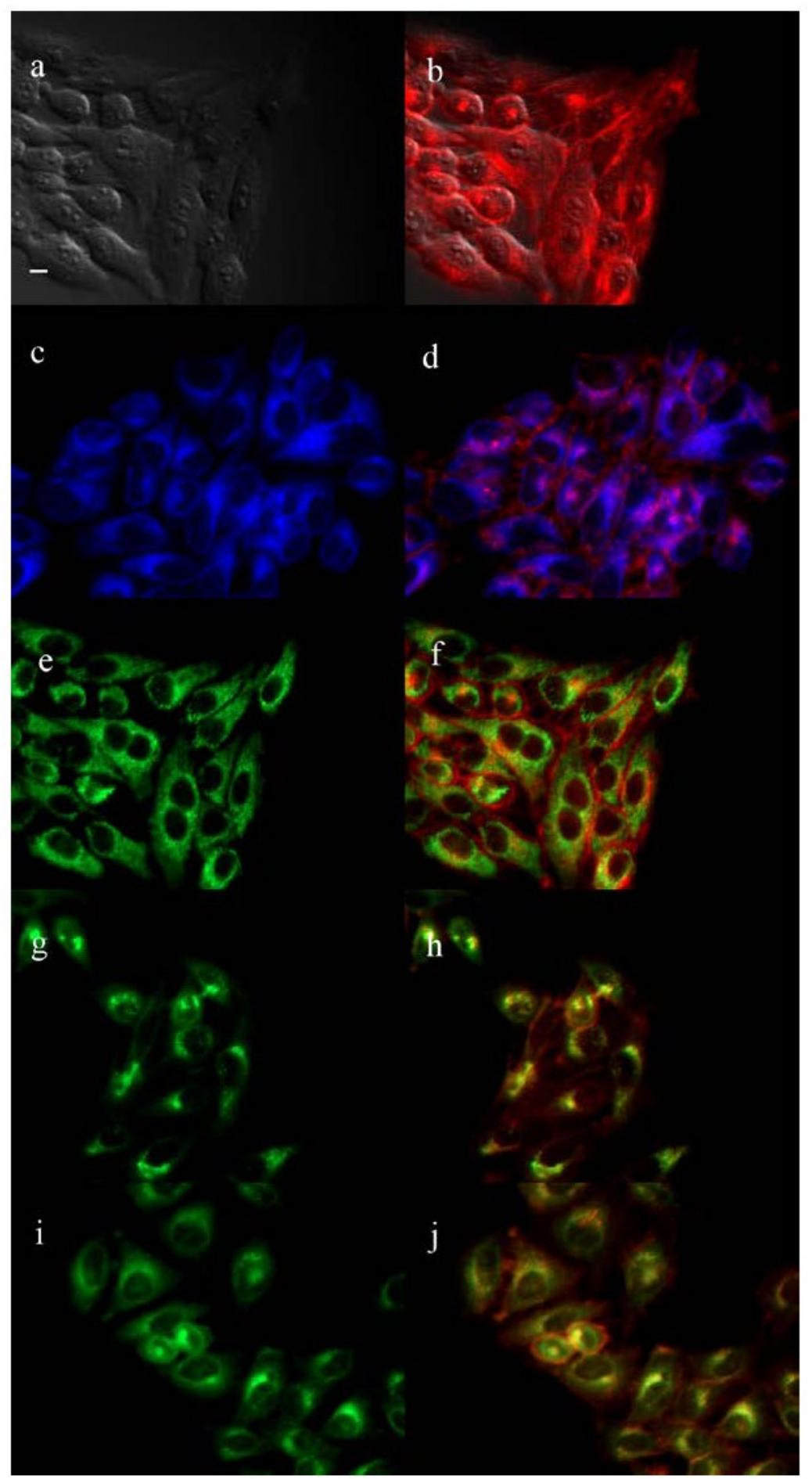

Figure 5. Subcellular localization of ZnPc I Ia in HEp2 cells at I0 $\mathrm{MM}$ for $6 \mathrm{~h}$. (a) Phase contrast, (b) Overlay of I Ia fluorescence and phase contrast, (c) ER Tracker Blue/White fluorescence, (e) MitoTracker green fluorescence, (g) BODIPY Ceramide, fluorescence (i) LysoSensor green fluorescence, and (d, f, h, j) overlays of organelle tracers with I la fluorescence. Scale bar: $10 \mu \mathrm{m}$. 


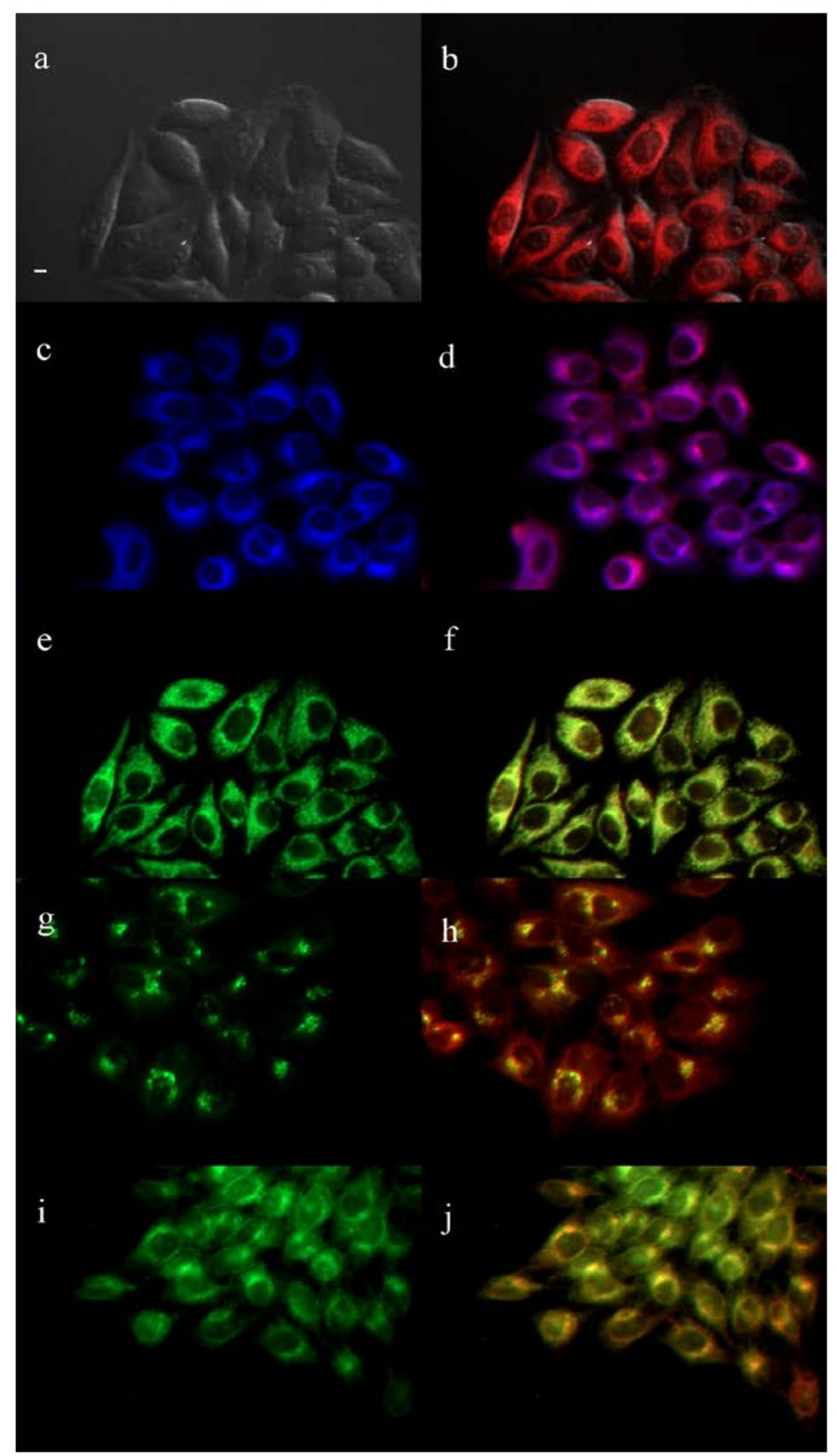

Figure 6. Subcellular localization of ZnPc 16a in HEp2 cells at $10 \mu \mathrm{M}$ for $6 \mathrm{~h}$. (a) Phase contrast, (b) Overlay of I6a fluorescence and phase contrast, (c) ER Tracker Blue/White fluorescence, (e) MitoTracker green fluorescence, (g) BODIPY Ceramide fluorescence, (i) LysoSensor green fluorescence, and (d, f, h, j) overlays of organelle tracers with I6a fluorescence. Scale bar: $10 \mu \mathrm{m}$.

\section{Conclusions}

A series of ten amphiphilic dicationic ZnPcs were synthesized and their cellular properties were investigated in human carcinoma HEp2 cells. All Pcs are $\mathrm{A}_{3} \mathrm{~B}$-type and were prepared by statistical condensation of two different phthalonitriles. All $\alpha$-substituted Pcs were found to be significantly more phototoxic (> 5-fold) than the corresponding $\beta$-substituted Pcs, probably due to their increased 
electron density of the ring and distinct macrocyclic conformation. ZnPc 16a bearing the longer PEG group, showed the highest phototoxicity of this series $\left(\mathrm{IC}_{50}=8.7 \mu \mathrm{M}\right.$ at $\left.1.5 \mathrm{~J} / \mathrm{cm}^{2}\right)$, followed by $4 \mathbf{a}\left(\mathrm{IC}_{50}=10.7\right.$ $\mu \mathrm{M})$; this may be a result of their preferred localization in the cell ER and favorable interaction with important biological targets. Furthermore, our results suggest that a PEG group, as well as the presence of the positive charges in close proximity, tend to increase phototoxicity. On the other hand, the $\beta$-substituted ZcPcs $\mathbf{6 b}$ and $\mathbf{4 b}$ accumulated the most within HEp2 cells, maybe due to their more extended conformations compared with the $\alpha$-substituted ZcPcs. We conclude that the charge localization on the Pc macrocycle ( $\alpha$-substitution and close proximity of charges) and the intracellular distribution of the cationic ZnPcs, rather than the extent of their cellular uptake, mainly determine their photodynamic activity. In the absence of a PEG group, the di-cationic $\mathrm{ZnPcs}$ tend to form large aggregates, as visualized by atomic force microscopy.

\section{Supplementary Material}

Phototoxicity and dark toxicity plots, microscopy images, UV-Vis spectra and ChemBio3D conformations. http://www.thno.org/v02p0850s1.pdf.

\section{Acknowledgments}

This work was supported by the National Institutes of Health, grant number R21 CA139385. JCG acknowledges support from the National Science Foundation (DMR-1006336).

\section{Competing Interests}

The authors have declared that no competing interest exists.

\section{References}

1. Leznoff CC, Lever ABP. Phthalocyanines: Properties and Applications. VCH: Weinheim. 1996:1-4.

2. Ben-Hur E, Chan W-S. In The Porphyrin Handbook: Phthalocyanines in photobiology and their medical applications. Kadish KM, Smith KM, Guilard R. Eds. Academic Press: Boston. 2003; 19: 1-35.

3. Erk P, Hengelsberg H. In The Porphyrin Handbook: Phthalocyanines dyes and pigments. Kadish KM, Smith KM, Guilard R. Eds. Academic Press: Boston. 2003; 19: 106-146.

4. Jori G, Coppellotti O. Inactivation of pathogenic microorganisms by photodynamic techniques: mechanistic aspects and perspective applications. Anti-Infective Agents in Medicinal Chemistry. 2007; 6(2): 119-131.

5. Dougherty TJ, Gomer CJ, Henderson BW, Jori G, Kessel D, Korbelik M, Moan J, Peng Q. Photodynamic therapy. J Natl Cancer Inst. 1998; 90: 889-905.

6. Pandey RK. Recent advances in photodynamic therapy. J. Porphyrins Phthalocyanines. 2000; 4: 368-373.

7. Brown SB, Brown EA, Walker I. The present and future role of photodynamic therapy in cancer treatment. Lancet Oncol. 2004; 5: 497-508.

8. Huang Z. A review of progress in clinical photodynamic therapy. Tech Cancer Res Treatment. 2005; 4: 283-293.

9. Baron ED, Malbasa CL, Santo-Domingo D, Fu P, Miller JD, Hanneman KK, Hsia AH, Oleinick NL, Colussi VC, Cooper KD. Silicon phthalocya- nine (Pc 4) photodynamic therapy is a safe modality for cutaneous neoplasms: results of a Phase 1 clinical trial. Lasers Surg Med. 2010; 42(10): 728-735.

10. Kinsella TJ, Baron ED, Colussi VC, Cooper KD, Hoppel CL, Ingalls ST, Kenney ME, Li X, Oleinick NL, Stevens SR, Remick SC. Preliminary clinical and pharmacologic investigation of photodynamic therapy with the silicon phthalocyanine photosensitizer Pc 4 for primary or metastatic cutaneous cancers. Front Oncol. 2011; 1(14): 1-6.

11. Sokolov VV, Chissov VI, Yakubovskya RI, Aristarkhova EI, Filonenko EV, Belous TA, Vorozhtsov GN, Zharkova NN, Smirnov VV, Zhitkova MB. Photodynamic therapy (PDT) of malignant tumors by photosensitizer Photosens: Results of 45 clinical cases. Proceedings of SPIE (Photochemistry: Photodynamic Therapy and Other Modalities). 1996; 2625: 281-287.

12. Gijsens A, Derycke A, Missiaen L, De Vos D, Huwyler J, Eberle A, de Witte P. Targeting of the photocytotoxic compound AlPcS4 to hela cells by transferrin conjugated peg-liposomes. Int J Cancer. 2002; 101: 78-85.

13. Arnida, Nishiyama N, Kanayama N, Jang W-D, Yamasaki Y, Kataoka K. PEGylated gene nanocarriers based on block catiomers bearing ethylenediamine repeating units directed to remarkable enhancement of photochemical transfection. J Controlled Release. 2006; 115 (2): 208-215.

14. Suzuki T, Oishi M, Nagasaki Y. Photochemical and photobiological studies of zinc phthalocyanine incorporated into PEGylated nanogels for photodynamic therapy. Journal of Photopolymer Science and Technology. 2009; 22(4): 547-550.

15. Durmus M, Ayhan MM, Gürek AG, Ahsen V. Peripherally alpha(a)-substituted novel phthalocyanines. Dyes and Pigments. 2008; 77: 570-577.

16. Bai M, Lo P-C, Ye J, Wu C, Fong W-P, Ng Dennis KP. Facile synthesis of pegylated zinc(II) phthalocyanines via transesterification and their in vitro photodynamic activities. Organic \& Biomolecular Chemistry. 2011; 9(20): 7028-7032.

17. Li H, Fronczek FR, Vicente MGH. Pegylated phthalocyanines: synthesis and spectroscopic properties. Tetrahedron Lett. 2011; 52: 6675-6678.

18. Hamblin MR, Miller JL, Rizvi I, Loew HG, Hasan T. Pegylation of charged polymer-photosensitizer conjugates: effects on photodynamic therapy. Br J Cancer. 2003; 89: 937-943.

19. Rovers JP, Saarnak AE, de Jode M, Sterenborg HJ, Terpstra OT, Grahn MF. Biodistribution and bioactivity of tetra-pegylated meta-tetra(hydroxyphenyl)chlorin compared to native meta-tetra(hydroxyphenyl)chlorin in a rat liver tumor model. Photochem Photobiol. 2000; 71: 211-217.

20. Krueger T, Altermatt HJ, Mettler D, Scholl B, Magnusson L, Ris HB. Experimental photodynamic therapy for malignant pleural mesothelioma with pegylated mTHPC. Lasers Surg Med. 2003; 32: 61-68.

21. Fang J, Sawa T, Akaike T, Greish K, Maeda H. Enhancement of chemotherapeutic response of tumor cells by a heme oxygenase inhibitor, pegylated zinc protoporphyrin. Int J Cancer. 2004; 109: 1-8.

22. Savellano MD, Hasan T. Targeting cells that overexpress the epidermal growth factor receptor with polyethylene glycolated BPD verteporfin photosensitizer immunoconjugates. Photochem Photobiol. 2003; 77: 431-439.

23. Ichikawa K, Hikita T, Maeda N, Takeuchi Y, Namba Y, Oku N. PEGylation of liposome decreases the susceptibility of liposomal drug in cancer photodynamic therapy. Biol Pharm Bull. 2004; 27: 443-444

24. Wöhrle D, Iskander N, Graschew $G$, Sinn $H$, Friedrich EA, Maier-Borst W, Stern J, Schlag P. Synthesis of positively charged phthalocyanines and their activity in the Photodynamic Therapy of Cancer Cells. Photochem Photobiol. 1990; 51: 351-356.

25. Ball DJ, Mayhew S, Wood SR, Griffiths J, Vernon DI, Brown SB. A comparative study of the cellular uptake and photodynamic efficacy of three novel zinc phthalocyanines of differing charge. Photochem Photobiol. 1999; 69: 390-396.

26. Duan W, Lo P-C, Duan L, Fong W-P, Ng Dennis KP. Preparation and in vitro photodynamic activity of amphiphilic zinc(II) phthalocyanines substituted with 2-(dimethylamino)ethylthio moieties and their $\mathrm{N}$-alkylated derivatives. Bioorganic Medicinal Chemistry. 2010; 18: 2672-2677.

27. Dummin H, Cernay T, Zimmermann HW. Selective photosensitization of mitochondria in HeLa cells by cationic $\mathrm{Zn}$ (II) phthalocyanines with lipophilic side-chains. J Photochem Photobiol B: Biol. 1997; 37: 219-229.

28. Li H, Jensen TJ, Fronczek FR, Vicente MGH. Syntheses and Properties of a Series of Cationic Water-Soluble Phthalocyanines. J Med Chem. 2008; 51(3): 502-511.

29. Marino J, Garcia MCV, Dicelio LE, Roguin LP, Awruch J. Photodynamic effects of isosteric water-soluble phthalocyanines on human nasopharynx KB carcinoma cells. Eur J Med Chem. 2010; 45(9): 4129-4139. 
30. Chen Z, Zhou S, Chen J, Deng Y, Luo Z, Chen H, Hamblin MR, Huang M. Pentalysine $\beta$-Carbonylphthalocyanine Zinc: an Effective Tumor-Targeting Photosensitizer for Photodynamic Therapy. Chem Med Chem. 2010; 5(6): 890-898.

31. Durmus M, Ahsen V. Water-soluble cationic gallium(III) and indium(III) phthalocyanines for photodynamic therapy. Journal of Inorganic Biochemistry. 2010; 104(3): 297-309.

32. Minnock A, Vernon DI, Schofield J, Griffiths J, Parish JH, Brown SB. Photoinactivation of bacteria. Use of a cationic water-soluble zinc phthalocyanine to photoinactivate both Gram-negative and Gram-positive bacteria. J Photochem Photobiol B: Biol. 1996; 32:159-164.

33. Mantareva V, Kussovski V, Angelov I, Wohrle D, Dimitrov R, Popova E, Dimitrov S. Non-aggregated Ga(III)-phthalocyanines in the photodynamic inactivation of planktonic and biofilm cultures of pathogenic microorganisms. Photochem Photobiol Sci. 2011; 10: 91-102.

34. Tempesti TC, Alvarez MG, Durantini EN. Synthesis and photodynamic properties of amphiphilic $\mathrm{A}_{3} \mathrm{~B}$-phthalocyanine derivatives bearing $\mathrm{N}$-heterocycles as potential cationic phototherapeutic agents. Dyes and Pigments. 2011; 91: 6-12.

35. Ongarora BG, Hu X, Li H, Fronczek FR, Vicente MGH. Syntheses and properties of trimethylaminophenoxy-substituted Zn(II)-phthalocyanines. Med Chem Commun. 2012; 3: 179-194.

36. Ongarora BG, Fontenot KR, Hu X, Sehgal I, Satyanarayana-Jois SD, Vicente MGH. Phthalocyanine-Peptide Conjugates for Epidermal Growth Factor Receptor Targeting. J Med Chem. 2012; 55: 3725-3738.

37. Nečas DKP. Gwyddion 2.25. Brno, Czech Republic: Czech Metrology Institute. 2009.

38. Sibrian-Vazquez M, Jensen TJ, Vicente MGH. Synthesis and cellular studies of PEG-functionalized meso-tetraphenylporphyrins. J Photochem Photobiol B: Biol. 2007; 86: 9-21.

39. Sehgal I, Sibrian-Vazquez M, Vicente MGH. Photoinduced Cytotoxicity and Biodistribution of Prostate Cancer Cell-Targeted Porphyrins. J Med Chem. 2008; 51: 6014-6020.

40. Warnecke A, Kratz F. Maleimide-oligo(ethylene glycol) Derivatives of Camptothecin as Albumin-Binding Prodrugs: Synthesis and Antitumor Efficacy. Bioconjugate Chemistry. 2003 14: 377-387.

41. Hofman J-W, van Zeeland F, Turker S, Talsma H, Lambrechts SAG, Sakharov DV, Hennink WE, van Nostrum CF. Peripheral and Axial Substitution of Phthalocyanines with Solketal Groups: Synthesis and In Vitro Evaluation for Photodynamic Therapy. J Med Chem. 2007; 50: 1485-1494.

42. Zorlu Y, Dumoulin F, Durmuş M, Ahsen V. Comparative studies of photophysical and photochemical properties of solketal substituted platinum(II) and zinc(II) phthalocyanine sets. Tetrahedron. 2010; 66(17): 3248-3258.

43. Masilela N, Nyokong T. The synthesis and photophysical properties of water soluble tetrasulfonated, octacarboxylated and quaternised 2,(3)-tetra-(2 pyridiloxy) Ga phthalocyanines. Dyes and Pigments. 2010 84(3): 242-248.

44. Jensen TJ, Vicente MGH, Luguya R, Norton J, Fronczek FR, Smith KM. Effect of overall charge and charge distribution on cellular uptake, distribution and phototoxicity of cationic porphyrins in HEp2 cells. J Photochemistry and Photobiology B: Biology. 2010; 100(2): 100-111.

45. Kessel D, Luguya R, Vicente MGH. Localization and photodynamic efficacy of two cationic porphyrins varying in charge distribution. Photochem. Photobiol. 2003; 78: 431-435

46. Sibrian-Vazquez M, Jensen TJ, Fronczek FR, Hammer RP, Vicente MGH. Synthesis and characterization of positively charged porphyrin-peptide conjugates. Bioconjugate Chem. 2005; 16(4): 852-863.

47. Sibrian-Vazquez M, Ortiz J, Nesterova IV, Fernández-Lázaro F, Sastre-Santos A, Soper SA, Vicente MGH. Synthesis and properties of cell-targeted $\mathrm{Zn}(\mathrm{II})$-phthalocyanine-peptide conjugates. Bioconjugate Chem. 2007; 18: 410-420.

48. Rao RV, Hermel E, Castro-Obregon S, del Rio G, Ellerby LM, Ellerby $\mathrm{HM}$, Bredesen DE. Coupling Endoplasmic Reticulum Stress to the Cell Death Program. J. Biol. Chem. 2001; 276(36): 33869-33874.

49. Groenendyk J, Michalak M. Endoplasmic Reticulum Quality Control and Apotosis. Acta Biochim. Pol. 2005; 52: 381-395. 